UNIVERSIDADE DE BRASÍLIA

FACULDADE DE CIÊNCIAS DA SAÚDE

PROGRAMA DE PÓS-GRADUAÇÃO EM ENFERMAGEM

MARIANA ANDRÉ HONORATO FRANZOI

AUDIÇÃO MUSICAL COMO INTERVENÇÃO DE ENFERMAGEM PARA ALÍVIO DA ANSIEDADE NA CRIANÇA EM SITUAÇÃO CIRÚRGICA: ENSAIO CLÍNICO

RANDOMIZADO

BRASÍLIA 
UNIVERSIDADE DE BRASÍLIA

FACULDADE DE CIÊNCIAS DA SAÚDE

PROGRAMA DE PÓS-GRADUAÇÃO EM ENFERMAGEM

MARIANA ANDRÉ HONORATO FRANZOI

\section{AUDIÇÃO MUSICAL COMO INTERVENÇÃO DE ENFERMAGEM PARA ALÍVIO DA ANSIEDADE NA CRIANÇA EM SITUAÇÃO CIRÚRGICA: ENSAIO CLÍNICO RANDOMIZADO}

Dissertação apresentada como requisito parcial para obtenção do Título de Mestre em Enfermagem pelo Programa de Pós-Graduação em Enfermagem da Universidade de Brasília.

Área de Concentração: Políticas, Práticas e Cuidado em Saúde e Enfermagem

Linha de Pesquisa: Processo de Cuidar em Saúde e Enfermagem

Orientadora:

Profa. Dra. Gisele Martins 
Ficha Catalográfica a ser elaborada pela Biblioteca Central da Universidade de Brasília

Franzoi, Mariana André Honorato.

Audição musical como intervenção de enfermagem para alívio da ansiedade na criança em situação cirúrgica: ensaio clínico randomizado / Mariana André Honorato Franzoi. - - 2015.

113 f. : il.; $30 \mathrm{~cm}$.

Dissertação (mestrado) - Universidade de Brasília, Faculdade de Ciências da Saúde, Programa de Pós-Graduação em Enfermagem, 2015. Inclui bibliografia.

Orientação: Profa Dra Gisele Martins.

1. Criança. 2. Procedimentos Cirúrgicos Operatórios. 3. Ansiedade. 4. Música. 5. Enfermagem Pediátrica. 6. Ensaio Clínico Controlado Aleatório. I. Martins, Gisele. II. Título. 


\title{
AUDIÇÃO MUSICAL COMO INTERVENÇÃO DE ENFERMAGEM PARA ALÍVIO DA ANSIEDADE NA CRIANÇA EM SITUAÇÃO CIRÚRGICA: ENSAIO CLÍNICO RANDOMIZADO
}

Dissertação apresentada como requisito parcial para obtenção do Título de Mestre em Enfermagem pelo Programa de Pós-Graduação em Enfermagem da Universidade de Brasília.

Aprovado em:

BANCA EXAMINADORA

Profa. Dra. Gisele Martins

Presidente da Banca

Universidade de Brasília - UnB

\begin{abstract}
Prof. Áderson Luiz Costa Junior
Membro Efetivo, Externo ao Programa

Universidade de Brasília - UnB

Profa. Dra. Eliseth Ribeiro Leão

Membro Efetivo, Externo ao Programa

Instituto de Ensino e Pesquisa Albert Einstein - Albert Einstein
\end{abstract}

Profa. Dra. Laiane Medeiros Ribeiro

Membro Suplente

Universidade de Brasília - UnB 
Dedico este trabalho, antes de tudo, a Deus e também às crianças que vivenciaram a experiência cirúrgica. 


\section{AGRADECIMENTOS}

A Deus, meu motivo de viver, minha alegria e fortaleza. Sem Ele jamais poderia ter chegado até aqui! Obrigada, Deus! "Porque dele, e por ele, e para ele são todas as coisas. A ele, pois, a glória eternamente. Amém” (Rm11.36).

Ao Vini, meu companheiro, amigo, namorado e marido, que esteve comigo durante todo o tempo, incentivando-me e ouvindo incansavelmente minhas ideias, desafios, conquistas e dificuldades relacionadas a essa jornada, além de ter sido paciente nos períodos em que precisei ausentar-me. Obrigada pelo seu amor e compreensão!

Aos meus pais, por ensinaram-me desde cedo a valorizar o estudo, por incentivarem minha ligação com a música (já me deram tantos instrumentos, né?! Flautas, saxofones, teclado, violão, escaleta...) e também por terem suportado minha ausência em muitos momentos.

À minha querida avó Sandra, pelo incentivo e por se preocupar comigo, até mesmo com a pesquisa. Vó, a senhora, perguntou tanta coisa que já está “expert” em minha pesquisa!

Ao meu irmão Thiago, pela amizade.

Aos meus sogros, Geraldino e Fátima, e minha "cunha" enfermeira Viviane, pelo incentivo e palavras de apoio.

À querida Profa. Gisele, que me acompanha desde a graduação e que viveu comigo intensamente cada passo que trilhei. Muito obrigada pela atenção, paciência, disponibilidade, convivência, "torcida", parceria, amizade, apoio, conhecimentos que você compartilhou comigo e outros que aprendemos juntas, enfim, obrigada pela excelente orientação! A você minha eterna gratidão e reconhecimento! Foi tudo tão intenso que vai ser difícil não sentir saudades das longas discussões relacionadas ao tema de pesquisa nas reuniões de orientação, presenciais e/ou à distância, dos tantos e-mails que compartilhamos nesses anos, tantos que o GMAIL sugere adicionar seu nome em todos e-mails que escrevo (risos), das descobertas que tivemos e também das dificuldades que, com certeza, contribuíram para agregar à nossa bagagem de experiência como pesquisadoras! Obrigada mais uma vez! 
À Cristina e à Elisabeth, alunas de Graduação em Enfermagem da UnB e futuras enfermeiras, que participaram como colaboradoras dessa pesquisa, auxiliando-me com muito empenho em vários momentos da coleta de dados. Muito obrigada, meninas! Vocês foram a melhor equipe de pesquisa que eu poderia ter! Espero que essa experiência tenha despertado em vocês o desejo de investigar novos temas em Enfermagem.

Aos meus amigos e enfermeiros, irmãos do coração, Andressa e Benefran, pela amizade que permanece desde a graduação.

À Equipe do CAPSi, meus queridos colegas de trabalho, pelo apoio e por resistir à minha ausência em alguns momentos. Em especial, à Christiane pela compreensão e "torcida", e à Valdelice, Ana Claudia e Maria Cláudia por compartilharem suas experiências como mestrandas e/ou doutorandas.

À Equipe da Clínica Cirúrgica Pediátrica do HMIB, em especial, às técnicas em enfermagem Cida e Alda, e aos enfermeiros Maurício e Isabel, por me acolherem tão bem e estarem sempre dispostos a me auxiliar no que era preciso. Muito obrigada!

Às secretárias do Centro Cirúrgico do HMIB, Claudinha e Kenia, pela receptividade e por compartilharem os mapas cirúrgicos todos os dias. Haja telefonemas e e-mails, hein?!

À Janine, responsável pelo Núcleo de Educação Permanente em Saúde do HMIB, pela atenção e informações que foram tão valorosas para iniciar a pesquisa de campo.

À Angela do Comitê de Ética em Pesquisa da FEPECS, pela disponibilidade e pelas orientações burocráticas relacionadas à submissão do projeto e emendas na Plataforma Brasil.

Às crianças e responsáveis que aceitaram participar da pesquisa. Obrigada por se voluntariarem e viabilizarem esta pesquisa!

À equipe de estatística, Daniel e Lorene, por me auxiliarem na fase da análise de dados, momento tão importante e delicado! Foi um grande prazer trabalhar com vocês! 
À Gisele e à Carolina, da Fiocruz, por viabilizarem a reserva da sala de videoconferência da instituição, local da defesa da dissertação.

À Laine e ao Carlos, pela disponibilidade e apoio relacionado aos preparativos da sala de videoconferência do Albert Einstein.

À Profa e Maestrina Adriana Braga, por ouvir atentamente a relação de músicas que selecionei para compor o repertório da pesquisa e avaliar o tempo musical de cada uma delas.

Ao Prof Áderson Luíz, à Profa Eliseth Leão e à Profa Laiane Medeiros, por aceitarem prontamente o convite para participarem da minha banca de mestrado e contribuírem na avaliação deste trabalho! Foi uma grande honra tê-los nesse momento! Obrigada!

Aos professores do PPGEnf, por contribuírem de forma tão singular na construção de novos conhecimentos.

À Universidade de Brasília, por me proporcionar já 8 anos de exímio ensino e, especificamente, pela oportunidade de cursar o Mestrado em Enfermagem.

Por fim, a todos que não foram citados, mas que contribuíram dando-me apoio e auxiliandome na construção deste trabalho: muito obrigada! 
"A música é o tipo de arte mais perfeita: nunca revela seu último segredo"

(Oscar Wilde) 


\section{RESUMO}

FRANZOI, M. A. H. Audição musical como intervenção de enfermagem para alívio da ansiedade na criança em situação cirúrgica: ensaio clínico randomizado. 2015. p. 113. Dissertação (Mestrado) - Programa de Pós-Graduação em Enfermagem, Faculdade de Ciências da Saúde, Universidade de Brasília, Brasília, 2015.

Introdução: A hospitalização em pediatria é um evento marcante na vida de crianças e de suas famílias e, geralmente, tende a ser um evento traumático e estressante, ainda mais se estiver associada à realização de procedimentos cirúrgicos. A ansiedade é uma das principais reações da criança relacionada à cirurgia. Dentre as estratégias de cuidado, a intervenção musical tem sido cada vez mais utilizada na assistência de enfermagem como terapia complementar para promover relaxamento, conforto emocional e espiritual, distração, alívio da dor e da ansiedade em pacientes hospitalizados. Objetivo: investigar o efeito da audição musical nos níveis de ansiedade pré-operatória de crianças submetidas a cirurgias eletivas em uma clínica cirúrgica pediátrica. Como objetivo secundário, foi analisado o estado emocional auto-referido pelos acompanhantes em relação ao processo cirúrgico da criança. Método: Tratou-se de um estudo piloto do tipo ensaio clínico controlado e randomizado realizado, no período de setembro de 2014 a abril de 2015, no Hospital Materno Infantil de Brasília, hospital público de referência para o atendimento de crianças acometidas por afecções cirúrgicas. Os participantes foram alocados aleatoriamente para o grupo experimental, submetido à audição de músicas por 15 minutos, ou grupo controle, que não ouviu música, apenas recebeu o cuidado padrão da clínica. As variáveis de desfechos avaliadas consistiram na frequência cardíaca, pressão arterial sistólica e diastólica, frequência respiratória, saturação de oxigênio e manifestação comportamental de ansiedade. Os sinais vitais foram mensurados a partir de aparelhos eletrônicos específicos e a ansiedade por meio da Escala de Ansiedade Pré-Operatória de Yale (EAPY-m), ambos mensurados na chegada da criança à clínica e 15 minutos após a primeira mensuração. A pesquisa foi aprovada pelo Comitê de Ética em Pesquisa e registrada na plataforma do Registro Brasileiro de Ensaios Clínicos. Resultados: 52 crianças, de 3 a 12 anos de idade, submetidas a cirurgias eletivas foram aleatoriamente alocadas para o grupo audição $(n=26)$ e grupo controle $(n=26)$. Em ambos os grupos, houve predomínio de crianças do sexo masculino, submetidas principalmente a cirurgias do trato geniturinário. Em relação ao nível de ansiedade pré-operatória, não houve diferença estatisticamente significativa entre os dois grupos, porém verificou-se que o grupo experimental apresentou redução estatisticamente significativa dos escores de ansiedade ( $\mathrm{p}=0,0441$ ), indicando que 15 minutos de audição foi um tempo efetivo para a intervenção musical. Verificou-se, ainda, uma diminuição estatisticamente significativa da frequência respiratória entre pré-escolares do grupo experimental em comparação aos do grupo controle na segunda mensuração $(\mathrm{p}=0,0453)$. A partir da entrevista realizada com os acompanhantes das crianças, constatou-se que a maioria referiu sentir medo, nervosismo, ansiedade e preocupação em relação ao processo cirúrgico, o que aponta para a necessidade de considerar a família no contexto do cuidado cirúrgico pediátrico, principalmente em relação a orientações sobre a anestesia. Conclusão: A audição musical por um tempo mínimo de 15 minutos apresenta-se como uma potencial e efetiva intervenção de enfermagem para o alívio da ansiedade pré-operatória em crianças em situação cirúrgica.

Descritores: Criança; Procedimentos Cirúrgicos Operatórios; Ansiedade; Música; Enfermagem Pediátrica; Ensaio Clínico Controlado Aleatório. 


\begin{abstract}
Franzoi, M.A.H. Music Listening as a nursing intervention to relieve anxiety in children undergoing surgery: a randomized controlled trial. 2015. p. 113. Thesis (Master's Degree in Nursing Sciences) - Graduate Program in Nursing, Faculty of Health Sciences, University of Brasilia, Brasilia, 2015.
\end{abstract}

Introduction: Pediatric hospitalization tends to be a traumatic and stressful event in children's lives and their families, especially if it is associated with surgical procedures. Anxiety is one of the main child's reactions related to the surgery. Among some care strategies, the musical intervention has been increasingly used in the nursing care as a complementary therapy to promote relaxation, emotional and spiritual comfort, distraction, pain and anxiety relief in hospitalized patients. Objective: To investigate the effect of music listening on the levels of preoperative anxiety in children undergoing elective surgery in a pediatric surgical inpatient unit. As a secondary objective, a parental self-report considering that their children were undergoing surgery procedures was obtained and analyzed with regard to their emotional profile. Method: It was a pilot randomized controlled trial, carried out from September 2014 to April 2015, at the Hospital Materno-Infantil in Brasilia, a public tertiary hospital and especialized in the care of children affected by surgical conditions. Participants were randomly allocated to one of two groups: the experimental group which was under music listening for 15 minutes or control group which did not listen to music, but only received the standard care provided at the surgical clinic. The main outcomes variables were: heart rate, systolic and diastolic blood pressure, respiratory rate, oxygen saturation and behavioral manifestations of anxiety. Vital signs were measured by means and anxiety level was obtained by the Preoperative Anxiety Scale Yale (YPAS-m), both measured at the child's clinic arrival and 15 minutes after the first measure. The study was approved by the Research Ethics Committee and registered in the Brazilian Registry of Clinical Trials platform. Results: Out of 52 children undergoing elective surgery, at 3 years old up to 12 years old, were randomly allocated to the music listening group $(n=26)$ and control group $(n=26)$. Both groups have a predominance of male children and the type of genitourinary surgery. Regarding the level of preoperative anxiety, there was no statistically significant difference between the two groups, but it was found that the music listening group showed a statistically significant reduction in their anxiety scores $(\mathrm{p}=0.0441)$, suggesting that 15 minutes of listening was an effective time to the music intervention. There was also a statistically significant decrease in respiratory rate among preschool children in the experimental group compared to the control group, specifically in the second measure $(\mathrm{p}=0.0453)$. Taking into account the parental interviews, it was found that the vast majority of them reported feeling of fear, anxiety and concern about the surgical procedure which have highlighted to the importance to include the family in the context of pediatric surgical care, mainly in relation to the information about anesthesia. Conclusion: Music listening for 15 minutes minimally has showed to be a potentially effective nursing intervention for the preoperative anxiety relief in children undergoing surgical procedures.

Descriptors: Child; Surgical Procedures, Operative; Anxiety; Music; Pediatric Nursing; Randomized Controlled Trial. 


\section{RESUMEN}

FRANZOI, M. A. H. Audición musical como una intervención de enfermería para aliviar la ansiedad en niños en situación quirúrgica: ensayo clínico controlado aleatorio. 2015. p. 113. Disertación (Máster en Enfermería) - Programa de Postgrado en Enfermería, Facultad de Ciencias de la Salud, Universidad de Brasilia, Brasilia, 2015.

Introducción: La hospitalización en pediatría tiende a ser un evento estresante en la vida de los niños y sus familias, especialmente si asociada con procedimientos quirúrgicos. Entre algunas de las estrategias, la intervención musical ha sido cada vez más utilizada en la atención de enfermería como una terapia complementaria para promover relajación, comodidad emocional y espiritual, alivio de la ansiedad y del dolor en los pacientes hospitalizados. Objetivo: investigar el efecto de la audición musical en los niveles de ansiedad preoperatoria de los niños sometidos a cirugía electiva de una clínica de cirugía pediátrica. El objetivo secundario, a su vez, ha sido analizar el estado emocional autoinformado por los acompañantes en relación al proceso quirúrgico del niño Método: Estudio piloto del tipo ensayo clínico aleatorio realizado desde septiembre 2014 hasta abril 2015, en el Hospital Materno Infantil de Brasília, hospital de referencia pública para el cuidado de niños afectados por las condiciones quirúrgicas. Los participantes han sido divididos al azar en el grupo experimental, que fué sometido a la audición de la música durante 15 minutos y el grupo de control, que no escuchó a la música, sólo recibió la atención estándar de la clínica. Se evaluaron la frecuencia cardiaca, presión arterial sistólica y diastólica, frecuencia respiratoria, saturación de oxígeno y manifestaciones comportamentales de ansiedad. Se midieron los signos vitales por medio de dispositivos electrónicos específicos y la ansiedad a través de la Escala de Ansiedad Preoperatoria de Yale (EAPY-m), ambos medidos a la llegada del niño a la clínica y 15 minutos después de la primera medición. El estudio fue aprobado por el Comité Ético de Investigación e inscrito en el Registro Brasileño de Ensayos Clínicos. Resultados: 52 niños sometidos a cirugía electiva, de 3 a 12 años de edad, fueron asignados aleatoriamente para el grupo experimental $(\mathrm{n}=26)$ y el grupo de control $(n=26)$. En ambos grupos, hubo un predominio de los ninõs varones, sometidos principalmente a la cirugía genitourinaria. En relación con el nivel de ansiedad preoperatoria, no hubo diferencia estadísticamente significativa entre los dos grupos, pero se verificó que el grupo experimental presentó una reducción estadísticamente significativa en las puntuaciones de ansiedad ( $\mathrm{p}=0,0441$ ), lo que indica que 15 minutos fue un tiempo efectivo para la intervención musical. También hubo una disminución estadísticamente significativa en la frecuencia respiratoria entre niños preescolares del grupo experimental en comparación a los del grupo de control en la segunda medición $(\mathrm{p}=0,0453)$. A partir de la entrevista realizada con los acompañantes de los niños, se constató que la gran mayoría reportó sentir miedo, nerviosismo, ansiedad y preocupación, lo que apunta a la necesidad de considerar la familia también en el contexto de la asistencia quirúrgica en pediatría, especialmente en relación a la orientación sobre la anestesia. Conclusión: La audición musical por una duración mínima de 15 minutos se presenta como una intervención de enfermería potencialmente eficaz para el alivio de la ansiedad preoperatoria en niños en situación quirúrgica.

Descriptores: Niño; Procedimientos Quirúrgicos Operativos; Ansiedad; Música; Enfermería Pediátrica; Ensayo Clínico Controlado Aleatorio. 


\section{LISTA DE FIGURAS}

Figura 1 - Estratégia PICOT. Brasília, DF, 2015

Figura 2 - Equipamentos reprodutores de música utilizados na pesquisa. Brasília, DF,

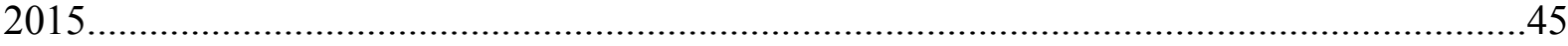

Figura 3 - Equipamentos para mensurar SSVV. Brasília, DF, 2015 ...................................47

Figura 4 - Fluxograma da coleta de dados. Brasília, DF, 2015 .........................................52

Figura 5 - Organograma da coleta de dados. Brasília, DF, 2015 ........................................53

Figura 6 - Diagrama de fluxo dos participantes da pesquisa. Brasília, DF, 2015 ..................58

Figura 7 - Clínica dia do HMIB (a). Brasília, DF, 2015 .......................................................59

Figura 8 - Clínica dia do HMIB (b). Brasília, DF, 2015 .......................................................59 


\section{LISTA DE QUADROS}

Quadro 1 - Diferença entre música e musicoterapia em medicina. Brasília, DF, 2015 .29 


\section{LISTA DE TABELAS}

Tabela 1 - Escores por categorias de cada domínio da EAPY-m, Brasília, DF, 2015.

Tabela 2 - Dados demográficos dos participantes do grupo controle e experimental, Brasília, DF, 2015

Tabela 3 - Estado de ansiedade, por grupo, avaliado no tempo 1 e 2. Brasília, DF, 2015.

Tabela 4 - Média e desvio padrão dos escores da EAPY-m por grupo, faixa etária, primeira cirurgia, tipo de cirurgia e estado emocional dos pais, para cada tempo. Brasília, DF, 2015

Tabela 5 - Média e desvio padrão dos escores da EAPY-m por grupo, para cada tempo. Brasília, DF, 2015.

Tabela 6 - Média dos escores dos domínios da EAPY-m por grupo, para cada tempo. Brasília, DF, 2015

Tabela 7 - Média e desvio padrão dos sinais vitais por grupo, faixa etária e tempo, seguido do p-valor da ANOVA, com medidas repetidas no tempo. Brasília, DF, 2015.

Tabela 8 - Frequência absoluta e percentual de estado emocional dos acompanhantes por grupo. Brasília, DF, 2015.

Tabela 9 - Média e desvio padrão da escala EAPY-m por estado emocional dos acompanhantes, para cada tempo. Brasília, DF, 2015. 


\section{LISTA DE SIGLAS}

ANOVA

CCP

CEP

COREN - SP

CONSORT

DE

DF

DP

EAPY-m

EBE

ECCR

$\mathrm{FC}$

FEPECS

FR

GC

GE

GESCAF

HMIB

IDATE-C

ICTRP

JBI

NIC

OMS

OR

PBE

PD

$\mathrm{PNH}$

PS

$\mathrm{SatO}_{2}$

SSVV

TCLE
Análise de Variância

Clínica cirúrgica pediátrica

Comitê de Ética em Pesquisa

Conselho Regional de Enfermagem do Estado de São Paulo

Consolidated Standards of Reporting Trials

Diagnóstico de Enfermagem

Distrito Federal

Desvio padrão

Escala de Ansiedade Pré-operatória de Yale modificada

Enfermagem Baseada em Evidências

Ensaio Clínico Controlado Randomizado

Frequência Cardíaca

Fundação de Ensino e Pesquisa em Ciências da Saúde

Frequência Respiratória

Grupo controle

Grupo experimental

Grupo de Estudos em Saúde da Criança, Adolescente e Família

Hospital Materno Infantil de Brasília

Inventário de Ansiedade Traço-Estado Infantil (IDATE-C)

Internacional Clinical Trials Registry Plataform

Joanna Briggs Institute

Nursing Intervention Classification

Organização Mundial da Saúde

Odds Ratio

Prática Baseada em Evidências

Pressão Arterial Diastólica

Política Nacional de Humanização

Pressão Arterial Sistólica

Saturação de Oxigênio

Sinais vitais

Termo de Consentimento Livre e Esclarecido 


\section{SUMÁRIO}

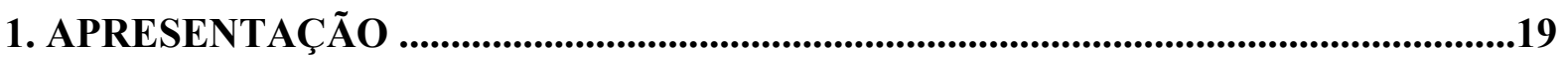

2. INTRODUÇÃ

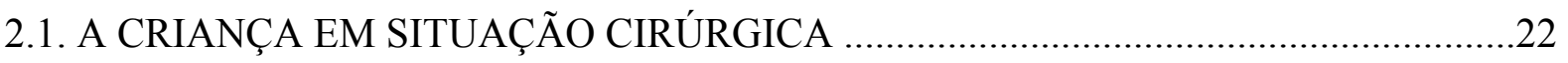

2.2. A INTERVENÇÃO MUSICAL E A ENFERMAGEM: HISTÓRIA E CONCEITOS....27

2.3. EVIDÊNCIAS NA EFETIVIDADE DO USO DA INTERVENÇÃO MUSICAL ...........31

2.4. REFERENCIAL TEÓRICO: A PRÁTICA BASEADA EM EVIDÊNCIAS ...................33

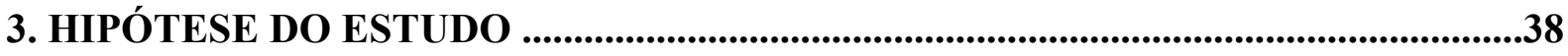

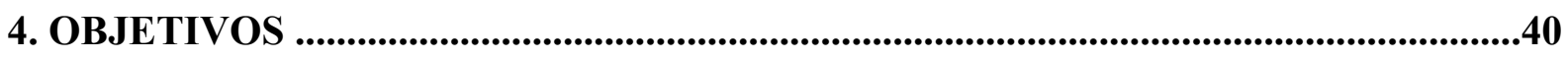

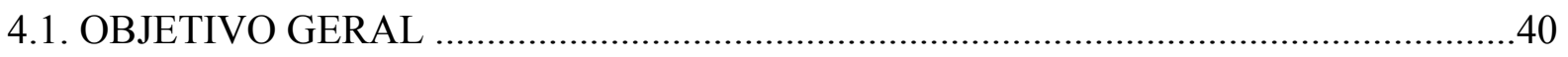

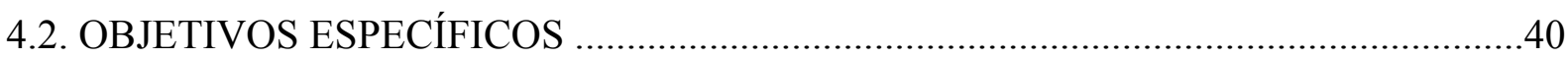

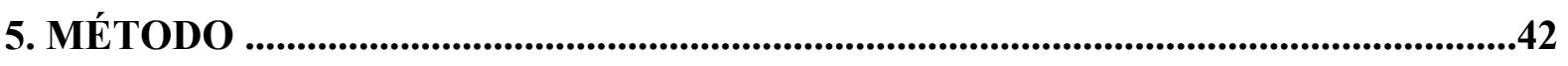

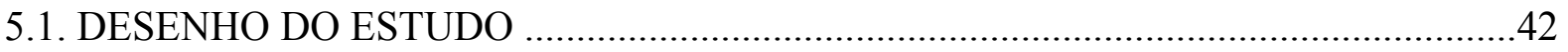

5.2. LOCAL DO ESTUDO E RECRUTAMENTO ….........................................................42

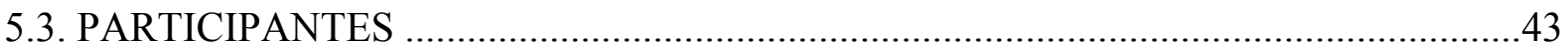

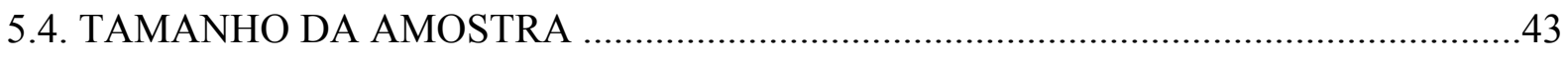

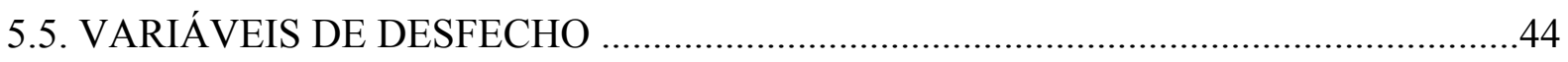

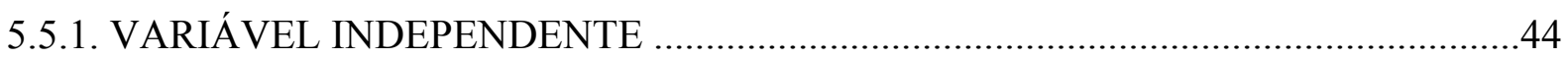

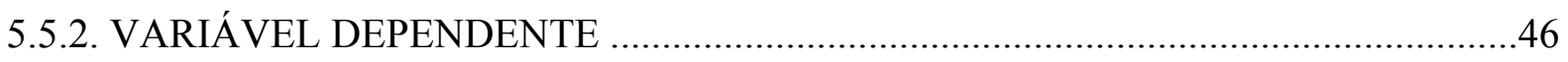

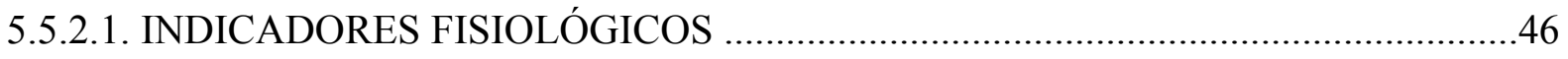

5.5.2.2. MANIFESTAÇÃO COMPORTAMENTAL DE ANSIEDADE …............................47

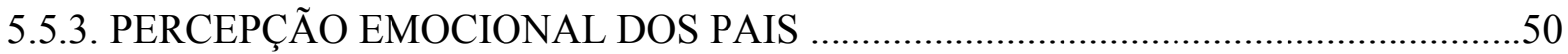

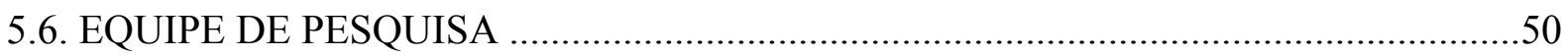

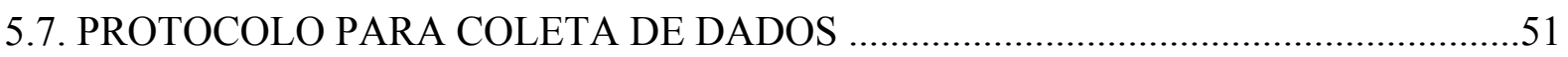

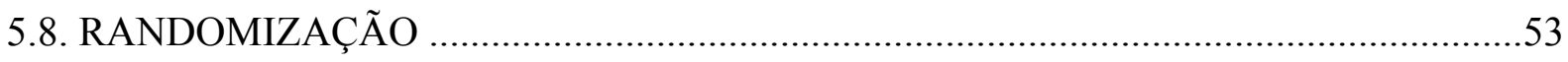

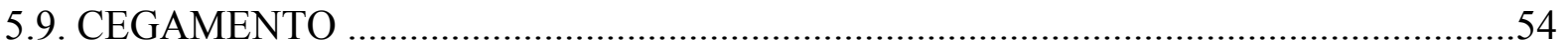

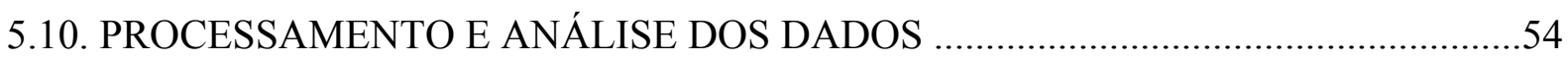

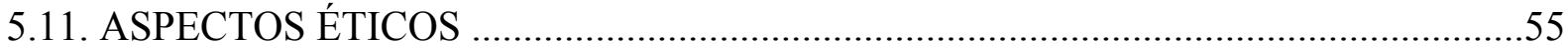

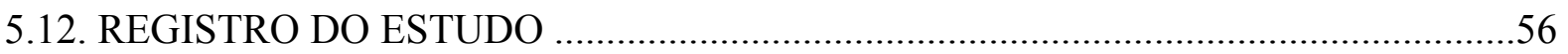

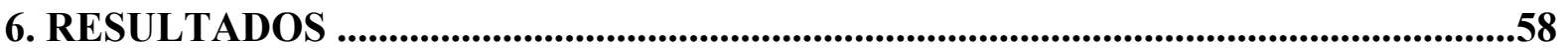

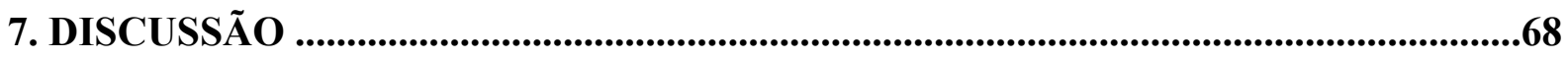

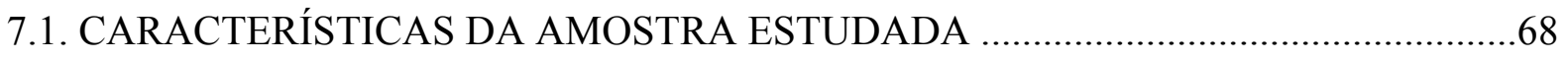


7.2. COMPREENDENDO O EFEITO DA MÚSICA: COMPARAÇÃO DAS VARIÁVEIS DE DESFECHO ENTRE GRUPO EXPERIMENTAL E CONTROLE …………………......72

7.3. ESTADO EMOCIONAL DOS ACOMPANHANTES ………………………….......75

7.4. LIMITAÇÕES DO ESTUDO E IMPLICAÇÕES PARA PESQUISA E PRÁTICA CLÍNICA DE ENFERMAGEM ...................................................................................

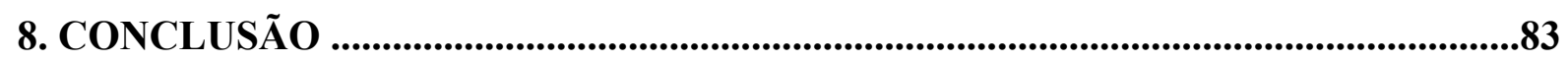

9. REFERÊNCIAS ............................................................................................84

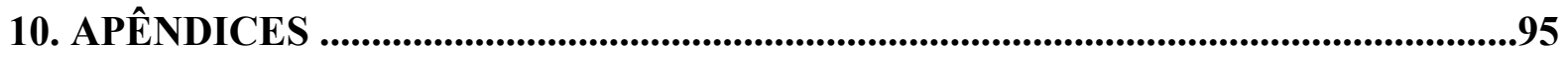

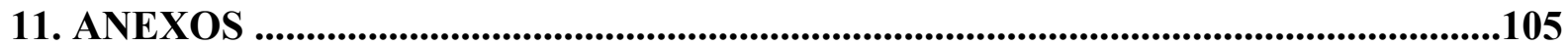




\section{Apresentação}

O desejo e o interesse em realizar esta pesquisa ocorreu durante a graduação em Enfermagem na Universidade de Brasília. Tudo começou no sétimo semestre, no qual cursei as disciplinas de Enfermagem Pediátrica e de Urgências Pediátricas. Na ocasião, tive a oportunidade de conhecer muitos conceitos em pediatria e também de praticá-los durante o período de estágio no Hospital Universitário de Brasília.

$\mathrm{Na}$ última atividade do estágio, os alunos foram desafiados a propor atividades lúdicas adaptadas às necessidades desenvolvimentais das crianças internadas na Pediatria ClínicoCirúrgica com o objetivo de propiciar um ambiente acolhedor e que incluísse o brincar no cenário hospitalar, ao menos, naquele dia.

Minha participação consistiu em oferecer, juntamente com outros colegas, música ao vivo às crianças internadas. Naquela oportunidade, toquei saxofone e cantei com alguns colegas músicas de interesse das crianças e adolescentes que lá estavam, e presenciei crianças distraindo-se e esquecendo-se da dor, outras até mesmo dormindo ao som das cantigas, depois de tantas horas acordadas devido intensas dores e estresse. Daquele dia em diante, as pesquisas e as leituras que eu realizava sobre o uso da música como recurso terapêutico dirigido a crianças hospitalizadas só se expandiram.

A experiência no estágio de graduação e as leituras relacionadas ao tema instigaramme tanto que levaram a traçar como meta a elaboração de um projeto de pesquisa para investigar o efeito da música no cenário pediátrico, especificamente, de crianças em situação cirúrgica, condição associada, principalmente, a reações de estresse, medo e ansiedade.

A escolha dessa proposta soma-se o fato de ser também apaixonada pela arte de combinar os sons harmoniosamente e uma aprendiz constante da Música, visto que sou formada no Curso de Saxofone Básico da Escola de Música de Brasília.

Como fruto dessa jornada, em 2013, publiquei meu primeiro artigo científico relacionado a essa temática como produto de minha inserção no Grupo de Estudos em Saúde da Criança, Adolescente e Família (GESCAF) e, em agosto do mesmo ano, ingressei no Programa de Pós-Graduação em Enfermagem da UnB a fim de iniciar meu projeto de investigação sobre o uso da música como recurso terapêutico no contexto pediátrico e contribuir com conhecimentos e evidências científicas para a prática e assistência de enfermagem pediátrica.

Desde então, tenho aperfeiçoado meu conhecimento teórico-clínico sobre o uso da música como intervenção de enfermagem e utilizando-a também em meu processo de 
trabalho, na área de saúde mental infantil. Inclusive, como produto recente da minha especialização lato sensu em Linhas de Cuidado em Enfermagem, área de Atenção Psicossocial, relatei a experiência sobre o uso da música como intervenção de enfermagem dirigida a crianças com transtorno do espectro do autismo em um Centro de Atenção Psicossocial Infanto-Juvenil do Distrito Federal. A audição musical, seja no contexto da saúde mental infantil ou no contexto clínico-hospitalar, cativa-me cada vez mais e instiga-me a investigar e aprofundar meus conhecimentos baseados em evidências.

Assim, a presente dissertação é mais um fruto da combinação entre paixão, curiosidade, cientificidade, música e enfermagem! 


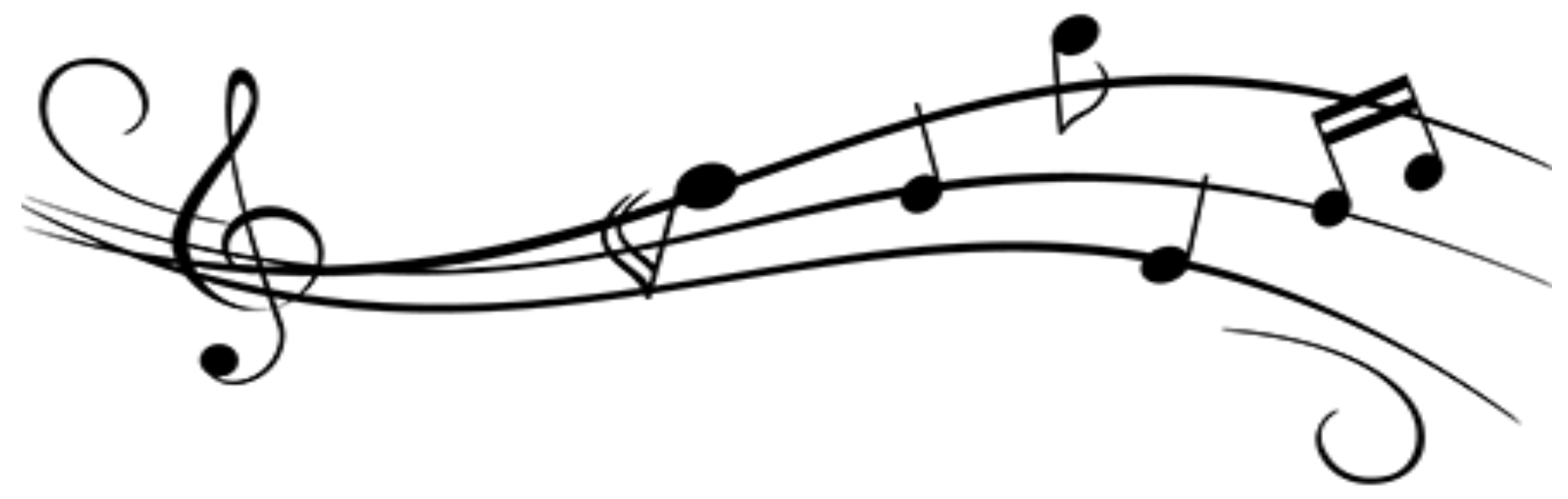

2. INTRODUÇÃO 


\section{Introdução}

A presente dissertação seguiu as Normas Consolidadas de Relatórios de Ensaios Clínicos, ou seja, diretrizes do CONSORT (Consolidated Standards of Reporting Trials), especificamente, a extensão para estudos randomizados de intervenção/tratamento não farmacológico (BOUTRON et al, 2008).

O CONSORT, enunciado de orientações composto por vinte e cinco itens e um diagrama de representação de fluxo de participantes, tem como objetivo orientar a construção de relatórios padronizados, claros e objetivos acerca de ensaios clínicos no meio científico, favorecendo interpretações críticas e sólidas dos estudos (MARTINS; SOUSA; OLIVEIRA, 2009; BOUTRON et al, 2008).

Os itens abordados no CONSORT contemplam todos os aspectos de uma pesquisa clínica, desde orientações e informações relacionadas à estrutura de título até detalhes sobre a apresentação de resultados e discussão das evidências obtidas no estudo, evitando assim a omissão de possíveis erros sistemáticos que possam comprometer a validade e confiabilidade dos resultados e de sua aplicabilidade dentro do contexto da prática baseada em evidências (MARTINS; SOUSA; OLIVEIRA, 2009).

\subsection{A criança em situação cirúrgica}

A hospitalização em pediatria é um evento marcante na vida das crianças e de suas famílias, e geralmente, tende ser percebido como um evento traumático, pois implica em privações na esfera afetiva, cognitiva e lúdica.

O hospital é um ambiente estranho, repleto de pessoas desconhecidas e de equipamentos médicos, com normas e rotinas rigorosas, que soam muitas vezes para as crianças como proibições em fazer algo que gostam como, por exemplo, vestir sua própria roupa ao invés da roupa da instituição ou mesmo não comer determinado tipo de comida que apreciam. (MURAKAMI; CAMPOS, 2011; QUIRINO; COLLET; NEVES, 2010; BORTOLOTE; BRÊTAS, 2008).

A rotina de vida das crianças hospitalizadas é significativamente alterada pela privação de convívio com familiares e amigos, de frequentar a escola e até mesmo de brincar. Os procedimentos e exames médicos, o desconforto, a dor e o processo de adoecimento em si também são outros fatores estressantes nessa experiência de hospitalização (CAIRES; ESTEVES, ALMEIDA, 2014; COLLET; OLIVEIRA; VIERA, 2010a; SABATÉS, 2008), que pode ser ainda mais marcante se estiver associada à realização de um procedimento 
cirúrgico e/ou se for a primeira experiência de internação da criança (SILVA; GARANHANI, 2011; BROERING; CREPALDI, 2008).

A criança pode reagir ao processo cirúrgico apresentando diferentes comportamentos e sentimentos. Nesse caso, o estresse, o medo e a ansiedade são considerados desfechos clínicos muito comuns relacionados às diferentes etapas de um evento cirúrgico, a saber: o próprio processo de internação pré-operatória, a necessidade de realização de exames clínicos e laboratoriais, o jejum, a separação dos pais, a sedação anestésica, o transporte para a sala de cirurgia, o tempo de permanência na sala de recuperação pós-anestésica, a dor pós-operatória, a recuperação após a cirurgia, a alteração da imagem corporal, dentre outras (GARANHANI; VALLE, 2012; HOCKENBERRY; WILSON, 2011; MAGALHÃES; GUSMAM; GRECCA, 2010).

Estima-se que $40 \%$ a $75 \%$ das crianças submetidas a cirurgias experienciam ansiedade significativa e medo no período pré-operatório (CUMINO et al, 2013), manifestados por alterações psicológicas e fisiológicas, como comportamentos agressivos, regressivos, negativos, de apreensão, aumento da frequência cardíaca, da pressão arterial, da frequência respiratória, do débito cardíaco, da transpiração, do consumo de oxigênio, da tensão muscular, inclusive com dilatação das pupilas (PITTMAN; KRIDLI, 2011; ALVES, 2010; WEBER, 2010; SABATÉS, 2008). Além disso, a ansiedade pré-operatória pode afetar diretamente o período de recuperação pós-cirurgia ao gerar distúrbios do sono e alimentares, enurese, maior consumo de analgésicos, entre outros (AHMED et al, 2011).

De fato, a criança é mais vulnerável à resposta de ansiedade e medo decorrentes do processo cirúrgico, já que apresenta limitação da capacidade cognitiva por ser um indivíduo em fase inicial do curso de vida, e geralmente por possuir limitada experiência e conhecimento relacionados aos cuidados em saúde (FRANZOI; PAULA; MARTINS, 2013; SABATÉS, 2008; LI, 2007).

O estado de ansiedade dos pais é outro fator que também influencia o nível de ansiedade e o repertório de comportamentos da criança no período pré-operatório (ROSÁRIO; ESCH, 2014; AHMED et al, 2011; GUARATINI et al, 2006).

O modo como pais e/ou cuidadores percebem e enfrentam o evento cirúrgico interfere diretamente na vivência da criança frente ao procedimento. Sentimentos de insegurança, medo da morte e desconfiança/dúvidas do que ocorre no centro cirúrgico, são alguns dos sentimentos negativos observados nos responsáveis que acompanham seus filhos (BROERING; CREPALDI, 2011a). 
A ansiedade dos cuidadores pode intensificar ainda mais os níveis de ansiedade das crianças no pré-operatório, gerando principalmente maiores dificuldades de separação entre pais e filhos, bem como contribuir para alterações de comportamento dos pacientes pediátricos no pós-operatório (CUMINO et al, 2013; MAGALHÃES; GUSMAM; GRECCA, 2010).

Além do preparo psicológico dirigido à criança, há que se estender esse preparo aos cuidadores também e orientá-los sobre os procedimentos a serem realizados, aspectos relacionados à medicação anestésica, cuidados pós-operatórios e outras dúvidas que eles possam ter (BROERING; CREPALDI, 2011; MAGALHÃES; GUSMAM; GRECCA, 2010).

Assim, é importante que o profissional de saúde aborde, além das necessidades de cuidados clínicos e biológicos da criança, as necessidades psicológicas, sociais, emocionais e culturais da mesma, aspectos muitas vezes ignorados pela equipe de saúde, que se concentra prioritariamente em restaurar o órgão debilitado por meio de procedimento cirúrgico ao invés de prover um cuidado humanizado e integral (RIBEIRO; GOMES; THOFEHRN, 2014; BROERING; CREPALDI, 2011b).

É considerando esse olhar reducionista do profissional de saúde sobre a doença, baseado muitas vezes na prática automática de queixa-conduta, na qual as dimensões sociais e subjetivas, tão presentes e inerentes ao ato de cuidar de indivíduos, mas que são deixadas de lado, que se propôs a PNH - Política Nacional de Humanização (BRASIL, 2004).

O HumanizaSUS, como também é conhecida a PNH, tem como objetivo humanizar as práticas em saúde e, aqui, entenda-se o termo humanizar não apenas como tornar mais humana a relação com o usuário de saúde, mas ofertar atendimento de qualidade, articulando os avanços tecnológicos na área da saúde com acolhimento, melhorias no ambiente de cuidado e das condições de trabalho dos profissionais de saúde (BRASIL, 2004). Mais ainda, humanizar, na perspectiva da $\mathrm{PNH}$, consiste na co-responsabilidade por trabalhadores, usuários e gestores nos processos de gestão e de cuidado em saúde (BRASIL, 2013).

A ambiência, uma das diretrizes da PNH, consiste na criação de espaços acolhedores, confortáveis e bem estruturados que respeitem a privacidade das pessoas que se encontram nesses lugares e que promovam mudanças no processo de trabalho (BRASIL, 2013).

O conceito de ambiência contempla três dimensões ou eixo norteadores: confortabilidade - espaço físico e arquitetônico em si, que abrange elementos qualificadores como temperatura, odor, ruído, decorações, iluminação e móveis diversos; produtor de subjetividades - concepção de espaço de encontros e constituição de relação terapêutica entre 
profissionais e usuários; e, por fim, o espaço como recurso facilitador do processo de trabalho por meio da otimização dos recursos materiais e humanos, favorecendo um atendimento humanizado, acolhedor e resolutivo (RIBEIRO; GOMES; THOFEHRN, 2014; BRASIL, 2010).

Em revisão de literatura sobre estratégias de humanização da assistência em pediatria a partir da ambiência, Ribeiro, Gomes e Thofehrn (2014) verificaram que os três eixos têm sido adotados na prática clínica para promover a ambiência nas unidades hospitalares pediátricas. Dentre algumas ações estão as atividades lúdicas, as leituras de contos infantis, a utilização da música, o uso da própria arquitetura e a construção do cuidado compartilhado com a família, intervenções tão importantes para proporcionar um cuidado humanizado e atraumático.

Entende-se aqui por cuidado atraumático, uma abordagem assistencial que está em consonância com a $\mathrm{PNH}$, definido como a provisão de cuidados terapêuticos em diferentes contextos, por profissionais da saúde, e pelo uso de intervenções que eliminem ou minimizem o sofrimento psicológico e físico percebido pelas crianças e suas famílias. A assistência atraumática tem como objetivo evitar ou minimizar os efeitos do estresse psicológico e físico da criança, ou seja, não causar mais danos ou traumas à situação de hospitalização vivida. Para atingir esse objetivo, o cuidado atraumático está fundamentado em três princípios fundamentais: (a) evitar ou minimizar a separação da criança da família; (b) promover uma sensação de controle; (c) e evitar ou minimizar lesões e dores (HOCKENBERRY; WILSON, 2011; HUFF et al, 2009).

A cirurgia por si só é um evento traumático, que causa traumas físicos e que também pode provocar danos psicológicos. Portanto, o desafio em oferecer um cuidado atraumático em pacientes em situação cirúrgica está em intervir principalmente na dimensão psicológica para minimizar ou evitar o estresse psicológico.

Dentre as estratégias mais utilizadas no contexto da prática pediátrica cirúrgica para promover um cuidado atraumático e humanizado, que favoreçam experiências positivas de enfrentamento da criança e sua família, estão o uso do brinquedo terapêutico, a promoção de atividades lúdicas, a presença/participação dos pais no momento da indução anestésica e as atividades instrucionais de preparo pré-operatório dirigidas tanto aos pais como às crianças (SANTOS, 2014; MERINELO; JARDIM, 2013; AHMED et al, 2011; ALVES, 2010)

Apesar dessas estratégias já utilizadas, o desafio maior consiste em identificar intervenções efetivas na perspectiva do cuidado atraumático e que sejam sensíveis às necessidades desenvolvimentais de crianças, ou seja, favoráveis à continuidade do processo 
de desenvolvimento infantil dentro do ambiente hospitalar, meio ambiente que, como tantos outros, interfere/afeta diretamente o processo de desenvolvimento e crescimento da criança (ALMEIDA; CASTRO, 2010; BORTOLETE; BRÊTAS, 2008; JUSTUS et al, 2006).

Assim, para que as intervenções em pediatria sejam sensíveis às necessidades desenvolvimentais, é importante que considerem os indicadores do desenvolvimento cognitivo, social e/ou de linguagem universais e específicos de cada criança.

Os pré-escolares, por exemplo, podem apresentar um pensamento mágico sobre o mundo - o raciocínio está baseado na imaginação e no que se observa (o que vê, ouve e experimenta), não levando em conta a lógica, ou seja, não conseguem relacionar funcionalmente as razões reais à cirurgia em si (PIAGET, 2014; HOCKENBERRY; WILSON, 2011).

A compreensão é limitada diante de explicações verbais, pois a criança pré-escolar ainda não é capaz de abstraí-las e sintetizá-las para além dos seus sentimentos e de suas experiências, o que faz com que o significado e a explicação para eventos desconhecidos, como a cirurgia, sejam bem mais fantasiosos, bizarros e assustadores do que a realidade de fato (HOCKENBERRY; WILSON, 2011).

Além disso, vale ressaltar que durante a fase pré-escolar, a linguagem e o vocabulário da criança desenvolvem-se significativamente até tornar-se o principal veículo de comunicação e interação social com o mundo ao redor. As crianças em fase pré-escolar inicial, que possuem entre 3 e 4 anos, utilizam a linguagem cada vez mais, porém sem compreender necessariamente o significado real das palavras, explicando muitas vezes diversos conceitos conforme a descrição que ouviram de outras pessoas adultas e restringindo-os à situação em que os aprendeu (HOCKENBERRY; WILSON, 2011).

De modo geral, fazem muitas perguntas também, dão nomes a objetos, animais e indivíduos familiares, falam incessantemente e independentemente de ter alguém as escutando e gostam de brinquedos musicais que falam e imitam novas palavras. Além disso, as crianças por volta dos 30 meses gostam muito de rimas e de cantar, e crianças de 4 anos de idade já conhecem e cantam canções simples (HOCKENBERRY; WILSON, 2011).

Dessa forma, é necessário explorar e compreender o pensamento da criança préescolar através de abordagens não-verbais, uma vez que essas crianças possuem compreensão limitada para explicações verbais. Nesse contexto, entende-se que a música é um recurso sensível à etapa desenvolvimental dos pré-escolares, seja quanto à linguagem e/ou cognição, a ser utilizado como uma intervenção para aliviar a ansiedade, que muitas vezes é acentuada 
pela exposição de explicações verbais inadequadas para esse grupo que as interpreta literalmente e de forma mágica.

Já as crianças em idade escolar tendem a apresentar um raciocínio indutivo, iniciando também o desenvolvimento cognitivo lógico e coerente, que as torna capazes de entender melhor o motivo da cirurgia e os riscos envolvidos, bem como explicá-los logicamente (PIAGET, 2014; HOCKENBERRY; WILSON, 2011). Porém, ter mais entendimento/noção da cirurgia pode acarretar medo e ansiedade relacionados ao procedimento, aos riscos envolvidos e à alteração da imagem/estética.

Quanto ao desenvolvimento de linguagem, os escolares adquirem capacidade de leitura no decorrer dos anos, o que contribui para que possam explorar e expandir seus conhecimentos sobre o mundo. Além dessa habilidade, os escolares estão ávidos para desenvolverem outras habilidades e participarem de tarefas significativas e socialmente úteis, e assim conquistar um senso de independência, responsabilidade e competência. As atividades solitárias e calmas são características dessa fase, e principalmente aquelas que proporcionam o desenvolvimento de habilidades diversas, como aulas de música, pintura, dança, natação, futebol, entre outras (HOCKENBERRY; WILSON, 2011).

Assim, entende-se que a música também é uma ferramenta sensível a escolares, pois nessa fase elas estão abertas a atividades criativas e solitárias, entre elas, a música.

É nesse contexto, considerando as características desenvolvimentais e o cuidado humanizado e atraumático, que se propõe investigar a música como uma tecnologia inovadora a ser utilizada pelo enfermeiro na arte de cuidar em pediatria cirúrgica para promover a ambiência hospitalar - criação de um ambiente acolhedor, confortável e não-ameaçador para a criança.

\subsection{A intervenção musical e a Enfermagem: história e conceitos}

Pode-se dizer que a utilização da música como recurso terapêutico na Enfermagem iniciou-se com Florence Nightingale em 1859, a primeira enfermeira a referenciar a música como um cuidado em saúde no livro "Notas de Enfermagem: o que é e o que não é". Florence fez um breve comentário sobre a música, a partir das suas observações empíricas, afirmando que os instrumentos de sopro, de corda e a voz humana podem ter efeito reconfortante e tranquilizador, enquanto que instrumentos que não produzem som contínuo ou são utilizados com intensidade muito alta, podem prejudicar os pacientes, agitando-os (NIGHTINGALE, 2015; NIGHTINGALE, 2012). 
Décadas mais tarde, na ocasião das duas Guerras Mundiais, o uso da música ganhou maior destaque por meio da atuação das enfermeiras e musicistas norte-americanas Isa Maud Ilsen e Harriet Ayer Seymour no cuidado aos feridos de guerra.

A enfermeira Isa Maud Ilsen interessou-se em empregar a música para tratar indivíduos com diversas condições clínicas como deficiências física, psicológica e intelectual (DAVIS; HADLEY, 2015; TORCHI; BARBOSA, 2006). Também realizou atividades musicoterapêuticas dirigidas aos soldados feridos da Primeira Guerra Mundial, além de lecionar Musicoterapia, na forma de curso de curta duração, na Universidade de Columbia com o objetivo de preparar músicos para trabalharem em hospitais, e também fundar a Associação Nacional para Música nos Hospitais em 1926 (DAVIS; HADLEY, 2015; LEÃO; BUSSOTTI; AQUINO, 2009).

Harriet Seymour, por sua vez, desenvolveu técnicas de musicoterapia por meio da sua experiência e publicou livros sobre educação musical e musicoterapia (DAVIS; HADLEY, 2015). Além disso, utilizou a música em prisões e hospitais na década de 1930, na cidade de Nova Iorque, abriu uma escola de preparação de musicistas para tocar para doentes e fundou a Fundação Nacional de Musicoterapia em 1941 (DAVIS; HADLEY, 2015; TORCHI; BARBOSA, 2006).

Essas enfermeiras, consideradas as "mães" da Musicoterapia, foram precursoras no ensino, investigação e uso dessa nova área do conhecimento - a Musicoterapia.

A utilização da música como intervenção terapêutica na área da enfermagem e das ciências da saúde de modo geral, por vezes, tem sido denominada de musicoterapia. De fato, essa não é a melhor nomenclatura a ser utilizada, uma vez que hoje existe o profissional musicoterapeuta, que possui formação diferenciada e direcionada para utilizar a música na prevenção, reabilitação e/ou tratamento de um indivíduo ou grupo de indivíduos (SILVA; FERREIRA; CARDOZO, 2012; TAETS; BARCELLOS, 2010).

Apesar de ser reconhecida como uma ocupação pelo Ministério do Trabalho, a profissão de musicoterapeuta ainda não está regulamentada no Brasil. Houve vários projetos de lei propostos para regulamentar seu exercício, porém nenhum deles tornou-se lei. A maioria deles foi arquivada na Câmara dos Deputados, sendo o último aprovado nessa Casa Legislativa e no Senado Federal, porém vetado integralmente pelo Presidente da República em 2008, devido algumas lacunas no projeto, dentre elas, a não identificação do exato campo de atuação privativa do musicoterapeuta e a incompatibilidade com a lei que dispõe sobre a Regulamentação do Exercício da Profissão de Músico (BRASIL, 2008). 
Há autores que diferenciam conceitos de música em medicina e musicoterapia em medicina. Cheryl Dileo (1999), uma musicoterapeuta norte-americana, entende que a música em medicina consiste no uso da música como recurso terapêutico complementar ou adjunto aos tratamentos médicos para diversas situações e/ou condições, sendo as mais comuns o estresse, ansiedade e dor. É utilizada por profissionais da área da saúde em geral, como enfermeiros, médicos, odontólogos, entre outros profissionais não-musicoterapeutas, basicamente na modalidade de experiência receptiva como, por exemplo, a audição musical de um repertório de músicas pré-selecionadas na condição de música ambiente em clínicas ou hospitais ou mesmo antes, durante e após procedimentos terapêuticos (SILVA; FERREIRA; CARDOZO, 2012; TAETS; BARCELLOS, 2010; DILEO, 1999).

A musicoterapia em medicina, por sua vez, consiste no processo terapêutico conduzido por musicoterapeuta habilitado e envolve a construção de uma relação terapêutica que se desenvolve por meio da música (SILVA; FERREIRA; CARDOZO, 2012; TAETS; BARCELLOS, 2010; DILEO, 1999). A aplicação da música, nesse caso, ocorre por meio de diferentes técnicas como audição, improvisação, recriação e composição musical a fim de favorecer o desenvolvimento e/ou restabelecimento de funções do indivíduo para que ele alcance melhor integração intra e/ou interpessoal (SILVA; FERREIRA; CARDOZO, 2012; TAETS; BARCELLOS, 2010; DILEO, 1999).

Quadro 1. Diferença entre música e musicoterapia em medicina. Brasília, DF, 2015.

\begin{tabular}{|c|c|}
\hline Música em Medicina & Musicoterapia em Medicina \\
\hline $\begin{array}{l}\text { Utilizada por profissionais da saúde não } \\
\text { musicoterapeutas. }\end{array}$ & $\begin{array}{l}\text { Utilizada somente por profissionais } \\
\text { musicoterapeutas. }\end{array}$ \\
\hline $\begin{array}{l}\text { Aplicação da música consiste } \\
\text { basicamente em experiências receptivas } \\
\text { como, por exemplo, a técnica de audição } \\
\text { musical. }\end{array}$ & $\begin{array}{l}\text { Aplicação da música ocorre por meio de } \\
\text { técnicas de audição, improvisação, } \\
\text { recriação, composição musical, entre } \\
\text { outras técnicas que requerem } \\
\text { conhecimento específico da área. }\end{array}$ \\
\hline $\begin{array}{l}\text { A relação terapêutica entre profissional e } \\
\text { paciente pode existir, porém não se } \\
\text { estabelece por meio da música. }\end{array}$ & $\begin{array}{l}\text { A relação terapêutica entre profissional e } \\
\text { paciente desenvolve-se necessariamente } \\
\text { por meio da música. }\end{array}$ \\
\hline $\begin{array}{l}\text { Os objetivos estão relacionados na } \\
\text { maioria das vezes a aspectos específicos e } \\
\text { pontuais, como a redução de ansiedade, } \\
\text { dor e estresse. }\end{array}$ & $\begin{array}{l}\text { Os objetivos são complexos, já que o } \\
\text { processo terapêutico mobiliza reações do } \\
\text { âmbito biopsicossocial, compreendendo } \\
\text { assim desde a reabilitação física para }\end{array}$ \\
\hline
\end{tabular}




\begin{tabular}{|l|l|}
\hline melhor desenvolvimento motor e \\
sensorial até o restabelecimento de \\
funções pelo paciente para melhor \\
integração intra e/ou interpessoal - auto \\
expressão, comunicação e interação.
\end{tabular}

Fonte: Traduzido e adaptado de Dileo (1999, p. 6).

Tal distinção de conceitos é válida, porém, ao mesmo tempo muito limitada e imprecisa na proposta de Dileo (1999), uma vez que os profissionais não musicoterapeutas, desde que, devidamente capacitados, utilizam diferentes técnicas para aplicação da intervenção musical, e não somente a técnica da audição. Além disso, os objetivos não estão limitados apenas à redução de ansiedade, estresse ou dor, pois, na área da enfermagem, por exemplo, a intervenção musical é indicada para diferentes Diagnósticos de Enfermagem (DE) relacionados a dimensões física, emocional, mental e espiritual como privação de sono, isolamento social, confusão crônica, angústia espiritual, dentre outros (LEÃO et al, 2011).

A intervenção musical está inserida no sistema de Classificação das Intervenções de Enfermagem - Nursing Intervention Classification (NIC) - e é referida/indexada pelo termo de musicoterapia, sendo definida como o "uso da música para ajudar a alcançar uma mudança específica de comportamento, sentimento ou fisiologia" (DOCHTERMAN; BULECHEK, 2008, p.516).

Segundo a NIC, as atividades a serem realizadas pelos enfermeiros ao utilizar essa intervenção consistem em definir a mudança específica no comportamento e/ou fisiologia desejada (p. ex., relaxamento, estimulação, concentração, redução da dor); determinar o interesse do indivíduo pela música; identificar as preferências musicais do indivíduo; informar o indivíduo sobre o propósito da experiência com a música; escolher seleções musicais representativas das preferências do indivíduo; ajudá-lo a assumir uma posição confortável; limitar estímulos externos (luzes, sons, visitas, telefonemas) durante a experiência auditiva; e preparar mídias/CD's de música e dispor o equipamento para o paciente.

Diante das atividades listadas na $N I C$, percebe-se claramente que não se trata de uma intervenção musicoterápica, mas da utilização da música como um recurso na assistência de enfermagem, ou seja, dentro daquela concepção de música em medicina de Dileo (1999), a qual limita a utilização da música por enfermeiros somente ao uso da técnica de audição.

Leão \& Silva (2007), por sua vez, definem a intervenção musical no contexto da Enfermagem como uma recurso complementar a ser utilizado de maneira criteriosa "[..] no 
cuidado ao ser humano, em todas as fases do ciclo vital, visando à restauração do equilíbrio e do bem-estar possível, além de favorecer a comunicação e, em muitos casos, a ampliação da consciência individual no processo saúde-doença”. Esse conceito é muito mais amplo e tem sido adotado para a Enfermagem brasileira, inclusive por Conselhos de Enfermagem. Em parecer sobre a competência do enfermeiro para a utilização da música no cuidado a pacientes, emitido pelo Conselho Regional de Enfermagem do Estado de São Paulo - COREnSP - adotou-se o conceito proposto Leão \& Silva (2007), desde que os enfermeiros possuam conhecimentos sobre a aplicação criteriosa dessa intervenção e observem as responsabilidades e deveres do Código de Ética dos Profissionais de Enfermagem, a fim de garantir um cuidado de enfermagem de qualidade e seguro (CONSELHO REGIONAL DE ENFERMAGEM DE SÃO PAULO, 2010).

O COREN-SP destaca a importância dos enfermeiros buscarem conhecimento sobre o uso da música no cuidado em saúde, o que é de extrema importância, pois sabe-se que quando aplicada indiscriminadamente, a música pode ter ação iatrogênica, gerando efeitos negativos no organismo como irritação e agitação, ou mesmo despertando lembranças e emoções adversas a depender da associação que o paciente faz da música com algum evento significativo de sua vida (SILVA; FERREIRA; CARDOZO, 2012; BRÉSCIA; 2011; TAETS; BARCELLOS, 2010; DOBBRO, 1998).

Diante dessa breve discussão de conceitos e de algumas incongruências apresentadas, destaca-se que a proposta de investigação a ser realizada nessa pesquisa refere-se exclusivamente ao uso da música como intervenção de enfermagem e não como uma intervenção da disciplina/área de conhecimento da musicoterapia.

\subsection{Evidências na efetividade do uso da intervenção musical}

A intervenção musical é utilizada em diferentes contextos de cuidado enfermagem e com objetivos diversos. Revisões integrativas sobre a temática apontam que a música é utilizada na enfermagem como terapia complementar para promover relaxamento, conforto emocional e espiritual, entretenimento, distração, sensação de bem-estar, alívio da dor e ansiedade em pacientes hospitalizados ou com transtornos mentais graves. Também é usada como recurso facilitador na comunicação e estabelecimento de vínculo entre enfermeiro e cliente, bem como para melhor integração e comunicação da equipe de enfermagem no ambiente de trabalho (NÓBREGA; SOUSA, 2013; TAETS; BARCELLOS, 2010) 
De fato, a aplicação da música em enfermagem é ampla, porém, ao mesmo tempo, muito incipiente, já que os efeitos terapêuticos da música ainda não estão claros. Estudos precisam ser realizados com objetivo de avaliar a efetividade da música como intervenção terapêutica (BUSSOTTI; TRAJANO; VENDRAMIM, 2009).

Atualmente, grande parte da produção científica publicada sobre a temática, especificamente de ensaios clínicos, apresenta baixa qualidade metodológica e amostras pequenas, além de se utilizar de uma grande variedade de instrumentos para avaliação dos desfechos. Franzoi, Paula, Martins (2013), Naylor et al. (2011) e Klassen et al. (2008), em suas revisões sistemáticas da literatura, entendem que os efeitos potenciais benéficos da música ainda não estão claros e compreendidos, devido a limitações metodológicas e à heterogeneidade entre os estudos dessa área quanto a cenários clínicos, intervenções, resultados ou mesmo implicações em torno de como e quando aplicar a música na prática assistencial. Assim, afirmam a necessidade de se realizar pesquisas de melhor qualidade metodológica para elucidar os efeitos das diferentes estratégias de intervenção musical.

Apesar dos efeitos da música ainda serem inconclusivos, muitos estudos têm encontrado resultados estatisticamente significativos em relação a determinados desfechos. Os 11 estudos incluídos na revisão sistemática de Pittman e Kridli (2011) concluíram que os pacientes que foram submetidos à intervenção musical apresentaram redução estatisticamente significativa da ansiedade pré-operatória, porém em relação aos parâmetros vitais, nem todos os estudos encontraram uma variação estatisticamente significativa. Além disso, na revisão de Nilsson (2008), 50\% dos estudos incluídos apresentaram redução significativa da ansiedade, sendo menor a evidência do efeito da música sobre os sinais vitais. A revisão de Gillen, Biley e Allen (2008) também confirma esses achados, apesar de haver mais estudos que apresentaram alterações estatisticamente significativas na redução dos sinais vitais.

Vale também destacar o ensaio clínico randomizado de Hatem, Lira e Mattos (2006), um dos poucos estudos nacionais nessa área, que avaliou o efeito terapêutico da música em crianças em pós-operatório imediato de cirurgia cardíaca. Os pesquisadores encontraram diferença estatisticamente significante entre os grupos de participantes, no que se tange a dor, frequência cardíaca e frequência respiratória.

Franzoi, Paula e Martins (2013), realizaram uma revisão sistemática sobre o uso da intervenção musical aplicada à criança e ao adolescente em situação cirúrgica e verificaram que a intervenção musical foi efetiva na diminuição da ansiedade em três dos oito estudos 
incluídos na revisão. Quatro estudos evidenciaram respectivamente aumento da saturação de oxigênio, maior concordância de comportamento no contexto cirúrgico, menor consumo de morfina no pós-operatório e redução significativa da frequência respiratória, cardíaca e de dor.

$\mathrm{Na}$ maioria dos estudos desta revisão descritos acima, utilizou-se a intervenção musical na modalidade passiva (audição musical) em comparação à modalidade ativa, que são as atividades dirigidas por musicoterapeutas. $\mathrm{O}$ estudo apontou a necessidade de realizar pesquisas com delineamento metodológico adequado, já que a maioria dos ensaios clínicos incluídos obteve pontuação mediana no que diz respeito à qualidade metodológica, principalmente em relação ao instrumento utilizado, que deve ser validado e de relevância clínica, às estratégias de mascaramento e randomização dos participantes, que devem ser adequadas à realidade, e às recomendações e protocolos já existentes acerca do uso da intervenção musical, que devem ser observados/adotados (FRANZOI; PAULA; MARTINS, 2013).

\subsection{Referencial Teórico: A Prática Baseada em Evidências}

Os avanços tecnológicos em saúde influenciam diretamente o processo de cuidar, exigindo, dessa forma, mudanças na prática profissional como novas condutas e formas de pensar. Considerando isso, é importante que o enfermeiro, ao tomar decisões, compreenda o verdadeiro impacto dessas inovações sobre o cuidado, pautando suas decisões em conhecimentos válidos, que possuam evidências científicas, para adotar uma conduta segura, acurada e eficaz na prática clínica (PEDROLO et al., 2009).

O cuidado em enfermagem não deve estar mais pautado na intuição, tradição ou mesmo na experiência clínica não sistemática, mas em princípios científicos, de preferência, fundamentado no paradigma da Prática Baseada em Evidências (PBE), referencial teóricometodológico adotado cada vez mais pelas diferentes áreas/disciplinas das Ciências da Saúde (SPRUCE, 2015; MAKIC et al, 2015).

A PBE aplicada à enfermagem, denominada de Enfermagem Baseada em Evidências (EBE), refere-se ao uso de informações válidas e relevantes, oriundas principalmente de pesquisas confiáveis e de boa qualidade, na tomada de decisão do enfermeiro (KARINO; FELLI, 2012; CULLUM et al., 2010). Em suma, a EBE consiste em integrar as melhores evidências à habilidade clínica do enfermeiro, às preferências e características do paciente e 
ao contexto em que se dá o cuidado, para a escolha das melhores possibilidades terapêuticas de enfermagem (SPRUCE, 2015; PEDROLO et al., 2009).

A implementação da PBE, segundo Melnyk e Fineout-Overholt (2011) e Flemming (2010), consiste em um processo de diferentes estágios/passos, que se inicia a partir de questionamentos e incertezas clínicas traduzidas em questões estruturadas e focadas. A partir dessas questões, realizam-se buscas pelas melhores evidências científicas que respondam a essas perguntas, avaliando criticamente as evidências em relação à sua validade, confiabilidade e aplicabilidade. $\mathrm{O}$ estágio seguinte consiste em selecionar a melhor evidência disponível e utilizá-la em conjunto com a experiência clínica do profissional, as preferências do paciente e os recursos disponíveis no contexto do cuidado. Por fim, avaliam-se e divulgam-se os resultados oriundos da tomada de decisão baseada na evidência.

A elaboração de questões clínicas é o primeiro passo para a PBE. Essas questões devem ser bem estruturadas e específicas, formuladas a partir da estratégia PICOT, acrônimo dos elementos que constituem a questão de pesquisa, a saber: população de pacientes com determinada condição ou problema de saúde (P); intervenção ou situação/fenômeno de interesse (I); comparação de intervenções (C); outcomes ou resultados de interesse; e o tempo estabelecido para que a intervenção atinja o desfecho (T).

As diferentes questões clínicas irão indicar evidências de diferentes tipos de pesquisas. Assim, questões focadas no diagnóstico, tratamento e prognóstico de problemas de saúde são melhor respondidas por pesquisas quantitativas, enquanto que questões sobre o significado ou a experiência da doença exigem evidências de pesquisas de natureza qualitativa (KARINO; FELLI, 2012; ROBERTS; DICENSO, 2010).

$\mathrm{Na}$ PBE, além da busca por evidências adequadas ao tipo de questão, deve-se também selecionar pesquisas de qualidade para a tomada de decisão. Cabe ao enfermeiro conhecer os diferentes níveis de evidências/força das pesquisas. No caso de pesquisas quantitativas, elas são classificadas do maior para o menor nível de evidência em: revisões sistemáticas; ensaios clínicos randomizados; ensaios clínicos controlados não randomizados; estudos de coorte/caso-controle; revisão sistemática de estudos qualitativos ou descritivos; conferências e/ou opiniões de especialistas (LEVIN; CHANG, 2014).

De fato, as questões sobre eficácia de intervenções são as mais comumente levantadas, sendo as revisões sistemáticas e os ensaios clínicos controlados randomizados, os melhores 
níveis de evidência para responder esse tipo de pergunta (KARINO; FELLI, 2012; ROBERTS; DICENSO, 2010).

Em revisão integrativa de estudos brasileiros sobre a PBE em saúde, publicados em periódicos científicos nacionais, Lacerda et al (2011) verificaram que estudos de investigação de intervenção em saúde, principalmente na área de saúde da criança e do adolescente, têm sido expressivos no universo das publicações científicas nacionais. Porém, mais do que expressividade, é necessário que as pesquisas clínicas sejam cada vez mais bem delineadas e com elevado rigor metodológico a fim de produzirem evidências sólidas e confiáveis sobre intervenções aplicadas em pediatria.

Assim, considerando a problemática da criança em situação cirúrgica, as evidências sobre o uso da intervenção musical como estratégia de cuidado em enfermagem e o referencial teórico exposto nessa introdução, com o intuito de produzir evidências bem delineadas e com rigor metodológico na área de saúde da criança, mais especificamente, na enfermagem pediátrica, é que se propôs o desenvolvimento do presente trabalho. Este tem como objetivo avaliar o efeito da música sobre a ansiedade pré-operatória de crianças em situação cirúrgica. Para isso, estruturou-se a seguinte questão norteadora, formulada por meio da estratégia PICOT (Figura 1):

\section{$\mathrm{P}=$ Crianças submetidas a cirurgias eletivas}

$\mathrm{I}=$ Audição musical

$\mathrm{C}=$ Cuidado padrão da CCP de um hospital público

$\mathrm{O}=$ Ansiedade

$\mathrm{T}=15$ minutos (pré-operatório)

Figura 1. Estratégia PICOT. Brasília, DF, 2015.

“A intervenção musical, disponibilizada na modalidade de audição musical por um período de quinze minutos no pré-operatório, é uma estratégia de enfermagem efetiva na redução de 
ansiedade de crianças submetidas a cirurgias eletivas, se comparada ao cuidado-padrão da clínica cirúrgica de um hospital público?" 


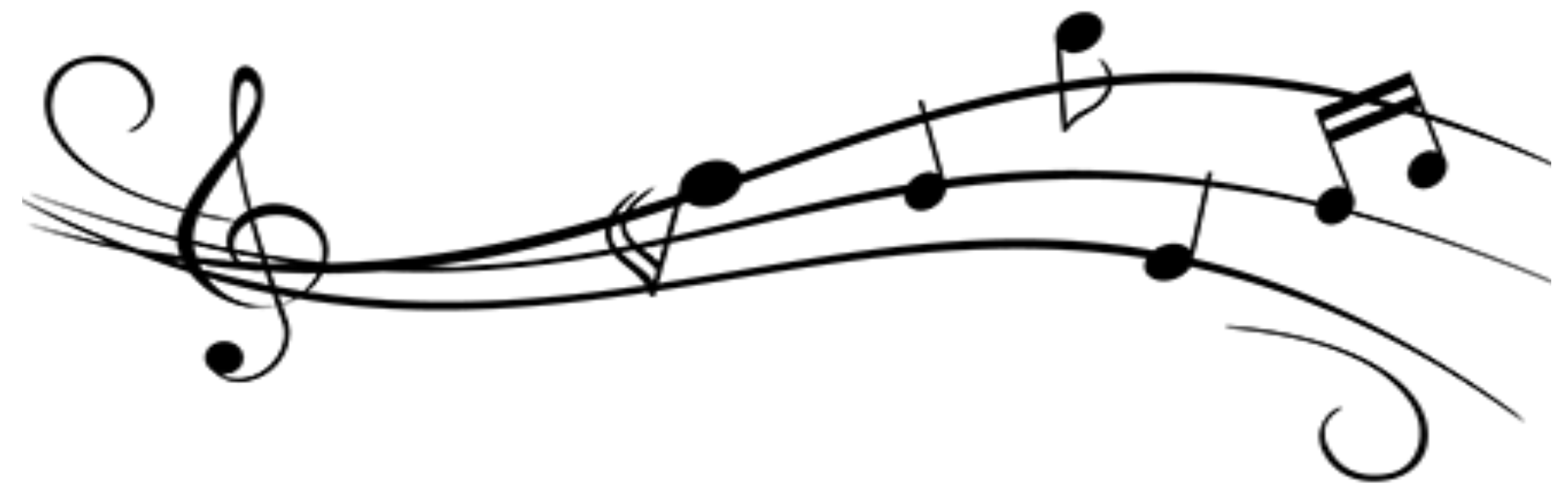




\section{Hipótese do Estudo}

Conforme apresentando na introdução, a intervenção musical tem sido amplamente utilizada no contexto do cuidado em enfermagem e apresentado-se efetiva na redução da ansiedade. Diante disso, a hipótese de estudo é:

- A audição musical, aplicada por um período de 15 minutos, é mais eficaz do que o cuidado padrão de uma clínica pediátrica na redução da ansiedade de crianças pré-escolares e escolares no período pré-operatório. 


\section{Objetivos}

\subsection{Objetivo Geral}

- Avaliar o efeito da audição musical sobre os níveis de ansiedade pré-operatória de crianças submetidas a cirurgias eletivas.

\subsection{Objetivos específicos}

- Descrever as características sóciodemográficas (idade, sexo) e cirúrgicas (tipo de cirurgia, experiências prévias) das crianças e de suas famílias;

- Comparar o nível de ansiedade pré-operatória das crianças que receberam a intervenção musical com aquelas que receberam apenas o cuidado padrão da clínica cirúrgica por meio da aplicação da EAPY-m;

- Comparar os dados vitais - frequência cardíaca, frequência respiratória, pressão arterial sistólica e diastólica, e saturação de oxigênio - das crianças que receberam a intervenção musical com aquelas que receberam apenas o cuidado padrão da clínica cirúrgica;

- Verificar associações entre as características demográficas e cirúrgicas com o nível de ansiedade e SSVV (sinais vitais) das crianças;

- Descrever a percepção das famílias sobre o processo cirúrgico ao qual as crianças seriam submetidas. 


\section{Método}

\subsection{Desenho do estudo}

Esta pesquisa consistiu em um estudo com delineamento do tipo ensaio clínico controlado randomizado (ECCR), estudo de natureza analítica, experimental e prospectiva, indicado para investigar a eficácia de intervenções em saúde, o padrão-ouro de evidências primárias na PBE (ROBERTS; DICENSO, 2010; PEDROLO et al., 2009).

Dessa forma, para testar a hipótese de que a audição musical é mais eficaz do que o cuidado padrão de uma clínica pediátrica na redução da ansiedade pré-operatória de crianças pré-escolares e escolares em situação cirúrgica, estruturou-se um ECCR clássico paralelo, no qual os participantes foram alocados em dois grupos, experimento ou controle, com taxa de alocação de 1:1.

\subsection{Local do Estudo e Recrutamento}

O estudo foi realizado no período de setembro de 2014 a abril de 2015, na Clínica Cirúrgica Pediátrica do Hospital Materno Infantil de Brasília (HMIB), hospital que faz parte da rede de atenção à saúde pública do Distrito Federal. O HMIB está localizado em uma das Regiões Administrativas do Distrito Federal (DF), especificamente a Asa Sul, e é considerado o serviço de referência na assistência a crianças acometidas por afecções cirúrgicas de todo o DF e Entorno.

As cirurgias pediátricas eletivas são realizadas conforme distribuição na escala de trabalho e disponibilidade dos cirurgiões pediátricos e dos anestesistas da Unidade do Centro Cirúrgico do HMIB. Em geral, essas cirurgias ocorrem às segundas e quintas-feiras, nos períodos da manhã e tarde, terça-feira de manhã e, eventualmente, às quartas e sextas-feiras de manhã. Pela manhã, as cirurgias iniciam às 7 horas, e no período da tarde, às 13 horas.

A pesquisadora recebia todos os dias úteis, por e-mail da secretaria do Centro Cirúrgico, o mapa cirúrgico referente ao dia seguinte. Nos mapas constavam as informações dos usuários a serem operados eletivamente, entre as quais: nome, idade, sexo, tipo de cirurgia, médicos responsáveis (cirurgião e anestesista) e se havia indicação para transfusão de hemácias no pré-operatório. $\mathrm{O}$ acesso antecipado ao mapa de cirurgias evitava deslocamentos desnecessários ao HMIB, pois nem sempre ocorriam cirurgias pediátricas em todos os dias da semana.

O recrutamento de potenciais participantes ocorreu nas segundas-feiras e quintasfeiras, pela manhã e à tarde, principais dias da semana em que haviam cirurgias pediátricas, 
geralmente em maior quantidade, mas também foi realizado em outros dias da semana, conforme indicação no mapa cirúrgico do dia.

\subsection{Participantes}

Participaram do estudo crianças pré-escolares e escolares, do sexo masculino e feminino, a serem submetidas a cirurgias pediátricas eletivas no HMIB. Foram estabelecidos os seguintes critérios de inclusão e exclusão para composição da amostra:

\section{Critérios de inclusão}

- criança pré-escolar (3 a 6 anos) ou escolar (6 a 12 anos) de ambos os sexos;

- ser submetida a qualquer cirurgia eletiva;

- concordar em participar da pesquisa, mediante a assinatura/desenho do termo de assentimento;

- responsável concordar que a criança participe da pesquisa, a partir da assinatura do termo de consentimento livre e esclarecido.

\section{Critérios de exclusão}

- ser submetida à cirurgia de urgência;

- criança que tenha recebido medicação pré-anestésica antes do início da intervenção a ser testada (audição musical);

- criança com problemas auditivos referidos pelos responsáveis;

- criança com transtorno mental, que gere déficit significativo de atenção ou concentração, refererido pelos responsáveis;

\subsection{Tamanho da amostra}

Essa pesquisa consistiu em um estudo-piloto, importante para refinar e avaliar a factibilidade do protocolo de pesquisa inicialmente proposto, bem como para gerar estimativas da variância e correlação das variáveis-desfecho da população-alvo, uma vez que os estudos com objetivos semelhantes aos propostos nessa pesquisa ainda são muito incipientes, e os poucos existentes estão voltados à população adulta.

Quando não há dados como desvio-padrão e/ou frequências populacionais das variáveis de interesse em pesquisas semelhantes descritas na literatura, é recomendado realizar um pré-teste com amostra aleatória de 30 a 40 indivíduos para, posteriormente, 
considerar o comportamento desse subgrupo como estimativa populacional para um estudo definitivo (MIOT, 2011; FONTELLES et al 2010).

Dessa forma, com base no Teorema do Limite Central, que garante que a distribuição de médias amostrais oriundas de amostras maiores ou iguais a 30 se aproxima da distribuição normal para qualquer população (DOANE; SEWARD, 2014; NAVIDI, 2012), adotou-se como tamanho da amostra para esse estudo-piloto um "n" maior que 30 crianças, "n" mínimo para permitir uma adequada estimativa de média populacional.

\subsection{Variáveis de desfecho}

\subsubsection{Variável independente}

A audição musical, variável preditora dessa pesquisa, foi aplicada conforme recomendações do Joanna Briggs Institute (JBI) para uso da música na assistência hospitalar, a saber: uso de música orquestrada e não-lírica, com 60 a 80 batimentos por minuto, volume de $60 \mathrm{~dB}$, em tons baixos, executada preferencialmente em instrumentos de cordas e com o mínimo de percussão (JOANNA BRIGGS INSTITUTE, 2011). Ou seja, foram utilizadas músicas com um andamento ${ }^{1}$ mais lento, intensidade ${ }^{2}$ mais suave, com saltos mínimos entre as notas da linha melódica ${ }^{3}$, alterações de dinâmica ${ }^{4}$ previsíveis e graduais, tocadas em instrumentos de cordas, ou seja, músicas consideradas sedativas, que apresentam características potenciais para deprimir respostas fisiológicas (STOUFFER; SHIRK; POLOMANO, 2007).

A escolha das músicas consistiu em um longo processo que compreendeu desde o levantamento até a análise de diferentes músicas instrumentais advindas de $C D$ 's infantis. Após essa etapa, a pesquisadora fez uma lista de prováveis músicas que atendiam às recomendações do JBI (2011), submetendo-as à análise de uma professora-regente de música. Dentre as músicas analisadas pela professora de música, selecionaram-se duas cantigas de roda brasileiras - $\mathrm{O}$ cravo brigou com a rosa e A canoa virou, faixas do $C D$ Cantigas de ninar,

\footnotetext{
${ }^{1} \mathrm{O}$ andamento indica a velocidade em que se executa um trecho musical, medido por meio do metrônomo que traduz a velocidade musical em batidas por minuto (MED, 1996).

${ }^{2}$ De acordo com Med (1996), a intensidade refere-se à amplitude das vibrações sonoras ou ao grau de volume sonoro manifestado em sons fortes ou fracos.

${ }^{3}$ Linha melódica é uma sucessão de sons caracterizada pela variação de alturas - frequências de vibrações sonoras (sons graves e agudos) - e pela variação de ritmo, que se refere ao tempo de emissão das vibrações (MED, 1996).

${ }^{4}$ Conforme Med (1996), a dinâmica musical consiste na variação do grau de intensidade com que o som é emitido ou projeto.
} 
interpretadas por Alexandre Guerra e Michel Freidenson - e duas músicas folclóricas americanas - Over the Rainbow, faixa do CD Bebé: Nanas y canciones infantiles para la relajación del bebé, e Amazing Grace, faixa do CD Taught me love de Trevor Johan Binkley.

Há vários tipos musicais utilizados na assistência hospitalar, desde músicas clássicas, new age, jazz, country, canções de ninar, cantigas de roda a sons da natureza (FRANZOI; PAULA; MARTINS, 2013 JOANNA BRIGGS INSTITUTE, 2011). A pesquisadora fez a opção de escolher cantigas de roda/folclóricas, pois trata-se de um estilo musical utilizado em muitos ensaios clínicos com a população pediátrica (FRANZOI; PAULA; MARTINS, 2013; PITTMAN; KRIDLI, 2011; KLASSEN et al, 2008), e por acreditar que as crianças estejam mais familiarizadas a esse estilo musical do que a músicas clássicas, new age e outros estilos com características sedativas.

As quatro músicas instrumentais selecionadas foram disponibilizadas por meio de três aparelhos MP3 Player Sony NWZ-B172F com fones descartáveis intra-auriculares Bright 0025 e dois headphones multimídia MP3 Acorde SH-S1 que foram utilizados principalmente com crianças que apresentavam pavilhão auricular menor (Figura 2). Como medida de biossegurança para os participantes, os headphones foram desinfectados com álcool a 70\% após cada uso, conforme orientações de precaução padrão em audiologia (MANCINI et al, 2008).

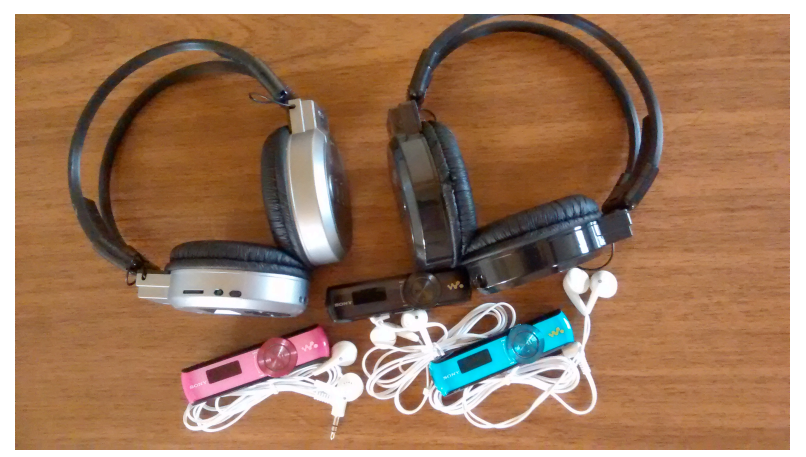

Figura 2. Equipamentos reprodutores de música utilizados na pesquisa. Brasília, DF, 2015.

Estudos realizados com população adulta apontam grande variação na duração da audição musical, de 5 minutos a 4 horas (NILSSON, 2008), com médias entre 15 a 30 minutos (NILSSON, 2008), 5 a 30 minutos (GILLEN; BILEY; ALLEN; 2008) ou mesmo 20 a 30 minutos (BRADT; DILEO; SHIM, 2013). Em revisão sistemática sobre a efetividade da intervenção musical aplicada à criança e ao adolescente em situação cirúrgica (FRANZOI; PAULA; MARTINS, 2013), apenas dois estudos relataram o tempo da intervenção, que foram 30 e 45 minutos. Não há evidências suficientes ainda que determinem o tempo mínimo 
necessário para garantir a efetividade da intervenção musical. Tal fato aponta para a necessidade de pesquisas que esclareçam questões relacionadas à temporalidade de duração adequada para garantir uma intervenção musical efetiva (BRADT; DILEO; SHIM, 2013; FRANZOI; PAULA; MARTINS, 2013). Assim, diante dessa variação e imprecisão descrita na literatura, bem como do cenário em que a pesquisa foi realizada - sala de espera de cirurgias ambulatoriais, a pesquisadora decidiu estabelecer um período de 15 minutos, para duração da intervenção musical.

\subsubsection{Variável dependente}

Fisiologicamente, a resposta do organismo ao estresse envolve a ativação do eixo hipotálamo-hipófise-adrenal e do sistema nervoso simpático, desencadeando a liberação de hormônios e catecolaminas (PITTMAN; KRIDLI, 2011). O aumento dessas substâncias está diretamente relacionado às manifestações objetivas e subjetivas de ansiedade, que compreendem o aumento da frequência cardíaca, da pressão arterial, da frequência respiratória, do débito cardíaco, da transpiração, do consumo de oxigênio, da tensão muscular, a dilatação das pupilas, sentimentos de tensão, agressão, apreensão, entre outros (PITTMAN; KRIDLI, 2011; ARSLAN; ÖZER; ÖZYURT, 2008).

Assim, para mensurar o nível de ansiedade dos participantes, foram utilizados indicadores fisiológicos e comportamental.

\subsubsection{Indicadores fisiológicos}

Em relação ao efeito fisiológico da música, entende-se que essa, através do estímulo auditivo, reduz a atividade do sistema nervoso simpático, o que produz uma resposta hipometabólica, manifestada pela diminuição da atividade adrenérgica e da excitação neuromuscular, bem como na redução da frequência cardíaca, da pressão arterial, da frequência respiratória e do consumo de oxigênio, contribuindo assim para uma resposta de relaxamento do organismo (ARSLAN; ÖZER; ÖZYURT, 2008).

Outra explicação para a ação da música no organismo é de que ela atua como um fator de distração, ao agir sobre o sistema límbico, diminuindo as vias de sinalização de neurotransmissores e ativando a liberação de endorfinas, sendo que a atenção do paciente que antes estava fixada em estímulos negativos passa a ser direcionada a algo agradável e estimulante, o que contribui para diminuir a experiência de sentimentos e emoções desagradáveis (PITTMAN; KRIDLI, 2011). 
Independentemente do modo de ação da música, estudos apontam redução de indicadores vitais como efeito resultante do uso da música no cuidado em saúde (BRADT; DIELO; SHIM, 2013; GILLEN et al, 2008; FERREIRA; REMEDI; LIMA, 2006; HATEM; LIRA; MATTOS, 2006).

Diante disso, nessa pesquisa foram avaliados os seguintes indicadores fisiológicos: frequência cardíaca, frequência respiratória, pressão arterial e saturação de oxigênio. No caso, a pressão arterial e a frequência cardíaca foram mensuradas por meio do monitor de pressão arterial automático Omron HEM-710INT e braçadeira Omron pequena H003DS (braços de 18 a $23 \mathrm{~cm}$ de circunferência), e em alguns casos de crianças mais obesas ou com braço de circunferência maior, utilizou-se a braçadeira Omron HEM-CR24 (braços de 22 a $32 \mathrm{~cm}$ de circunferência). Para medir a saturação de oxigênio, utilizou-se o oxímetro de dedo pediátrico PM100D New Tech. A frequência respiratória, por sua vez, foi medida a partir da observação do número de inspirações realizadas em um minuto pelas crianças, sendo utilizado cronômetro para marcação do tempo (Figura 2).

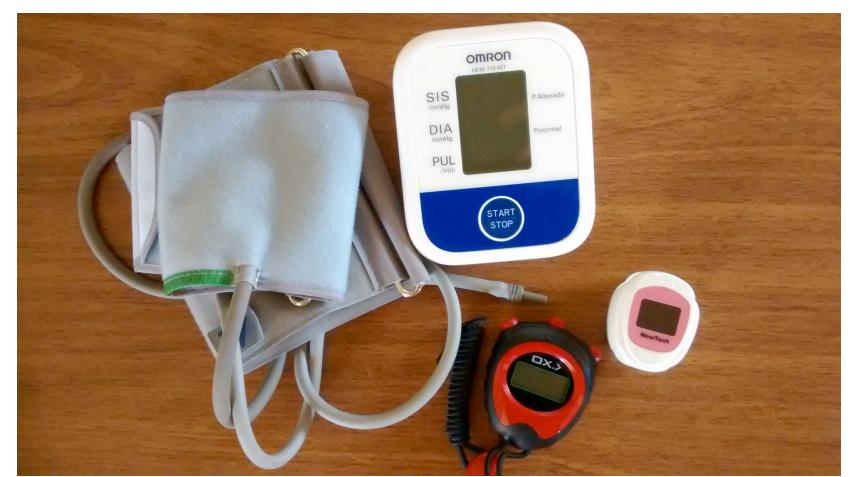

Figura 3. Equipamentos para mensurar SSVV. Brasília, DF, 2015.

\subsubsection{Manifestação comportamental de ansiedade}

A ansiedade pode ser definida como um conjunto de manifestações comportamentais que se apresentam como estado ou traço. A ansiedade traço refere uma característica da personalidade que permanece relativamente estável durante o tempo, enquanto que a ansiedade estado é um condição emocional momentânea, na maioria das vezes, associada à algum evento estressógeno, variando em intensidade à medida que é exposta ou não a este evento (SAMPAIO et al, 2014).

Assim, entende-se que a ansiedade pré-operatória se refere à ansiedade estado, pois consiste numa condição de estado emocional temporária caracterizada por sensações desagradáveis de tensão e apreensão, percebidas conscientemente diante do evento cirúrgico, 
que desencadeiam a ativação do sistema nervoso central, resultando em efeitos tanto fisiológicos quanto psicológicos.

Dentre os instrumentos de mensuração de ansiedade, o Inventário de Ansiedade TraçoEstado Infantil (IDATE-C) é considerado o instrumento padrão-ouro para mensurar a ansiedade na população pediátrica (AHMED et al, 2011; KAIN et al, 1997). Apesar disso, particularmente no Brasil, esse instrumento não deve ser utilizado, pois trata-se de um teste de uso privativo de psicólogos, considerado inadequado pelo Conselho Federal de Psicologia desde 2003 (CFP, 2012; CFP, 2003a; CFP, 2003b).

Diante disso, após realizar levantamentos de instrumentos validados para mensurar a ansiedade em crianças, decidiu-se adotar a Escala de Ansiedade Pré-operatória de Yale modificada (ANEXO A).

A Escala de Ansiedade Pré-operatória de Yale modificada (EAPY-m) é um instrumento que tem sido utilizado amplamente em estudos internacionais (CUZZOCREA et al, 2014; JAHROMI et al, 2012; HOUSSEINPOUR; MEMARZADEH, 2010; GOLAN et al, 2009; KAIN et al, 2004; KAIN et al, 2001) e em alguns estudos nacionais (CUMINO et al, 2013; WEBER, 2010; GUARATINI et al, 2006) para mensurar o nível de ansiedade em crianças cirúrgicas, principalmente no período pré-anestésico imediato e no momento da indução anestésica.

A EAPY foi criada inicialmente para avaliar a ansiedade em crianças de 2 a 6 anos de idade no momento da indução anestésica. Na época, apresentou bom grau de confiabilidade intra e inter-observadores, e se destacou por sua aplicação prática (KAIN et al, 1995).

Em 1997, a EAPY foi modificada com o objetivo de expandir sua aplicabilidade à sala de espera pré-operatória, e não somente ao momento da indução anestésica. Kain et al (1997), validaram a EAPY-m contra o padrão-ouro IDATE-C, obtendo bom grau de validade em comparação ao Inventário, ou seja, a escala Yale apresentou bom desempenho como instrumento de medida em relação ao padrão-ouro, ou melhor, bom grau de acurácia representou realmente o que deveria representar, o fenômeno da ansiedade. A EAPY-m mostrou-se mais vantajosa do que Inventário em alguns aspetos como, por exemplo, em relação ao tempo de aplicação - a EAPY-m leva menos de 1 minuto para ser aplicada se comparada à média de 5 a 10 minutos de tempo do IDATE-C. Além disso, por ser um instrumento de observação e não de auto relato, a EAPY-m pode ser utilizada em crianças pré-escolares, ao contrário do IDATE-C que só pode ser utilizado em crianças maiores de 5 anos. 
A EAPY-m consiste em uma escala observacional composta por vinte e dois itens distribuídos em cinco domínios - atividades, estado de despertar aparente, vocalização, expressividade emocional e interação com a família - que refletem diferentes naturezas de comportamentos que podem ser manifestados pela criança (GUARATINI et al, 2006). Tal instrumento é muito mais sensível às mudanças nos níveis de ansiedade do que aqueles que avaliam a ansiedade de forma global (KAIN et al, 1997).

Sobre a pontuação da EAPY-m, vale ressaltar que a pesquisadora contactou os autores da escala para confirmar os valores de pontuação, uma vez que foram encontradas divergências em muitos artigos. Uns afirmavam que a pontuação varia de 0 a 100 (WRIGHT et al, 2010; KAIN et al, 1995), outro de 21 a 100 pontos (GAO et al, 2014), e outros ainda referiam valores entre 23,33 a 100 pontos (JENKINS et al, 2014; WEBER, 2010). Os autores confirmaram que a EAPY-m varia de 23,33 a 100 pontos, pois para cada domínio é atribuído um escore parcial com base na pontuação observada, que é então dividida pelo número de categorias daquele domínio, conforme representado na tabela 2. Para obter a pontuação final, soma-se o escore de cada domínio aos demais e então se multiplica o resultado por 20 , tal que escores compreendidos no intervalo de 23,33 a 30 pontos indicam estado sem ansiedade, e escores superiores a 30 pontos indicam estado de ansiedade (KAIN et al, 1997; CUMINO et al, 2013; GUARATINI et al, 2006).

Tabela 1. Escores por categorias de cada domínio da EAPY-m, Brasília, DF, 2015.

\begin{tabular}{|c|c|c|c|c|}
\hline Domínios & Atividade & Vocalização & $\begin{array}{l}\text { Expressão } \\
\text { Emocional }\end{array}$ & $\begin{array}{c}\text { Estado de } \\
\text { despertar aparente }\end{array}$ \\
\hline
\end{tabular}

\begin{tabular}{cccccc}
\hline $\begin{array}{c}\mathrm{N}^{\mathrm{o}} \text { de categorias } \\
\text { Escores }\end{array}$ & 4 & 6 & 4 & 4 & 4 \\
\hline Categoria 1 & 0,25 & 0,17 & 0,25 & 0,25 & 0,25 \\
Categoria 2 & 0,5 & 0,33 & 0,5 & 0,5 & 0,5 \\
Categoria 3 & 0,75 & 0,5 & 0,75 & 0,75 & 0,75 \\
Categoria 4 & 1 & 0,67 & 1 & 1 & 1 \\
Categoria 5 & - & 0,83 & - & - & - \\
Categoria 6 & - & 1 & - & - & - \\
\hline
\end{tabular}

Fonte: Adaptado de Cumino et al (2013, p. 476). 
No Brasil, a EAPY-m foi validada, traduzida e utilizada pela primeira vez no estudo de Guaratini et al (2006), no qual se avaliou os níveis de ansiedade de uma amostra composta por 100 crianças, com idade entre 2 e 7 anos, que seriam submetidas a consultas no ambulatório de pediatria ou à avaliação pré-anestésica num hospital da cidade de São Paulo.

Apesar da EAPY-m já ter sido traduzida e validada, seu uso em estudos brasileiros ainda é incipiente. Dentre os poucos estudos, cita-se o de Weber (2010) que utilizou a EAPYm para investigar a influência das atividades lúdicas sobre o nível de ansiedade pré-operatória em crianças de 5 a 12 anos no momento da admissão, no centro cirúrgico ambulatorial de um hospital de Porto Alegre. Além disso, Cumino et al (2013) aplicaram a EAPY-m para avaliar o nível de ansiedade de crianças em dois momentos, na sala de espera pré-operatória e na sala operação, relacionando o estado de ansiedade das crianças ao estado de ansiedade dos pais, que receberam apenas a informação verbal convencional sobre o procedimento anestésico ou além da informação convencional, também receberam um folheto informativo.

\subsubsection{Percepção emocional dos pais}

O modo como pais enfrentam e percebem o evento cirúrgico interfere diretamente na vivência da criança frente ao procedimento, sendo o estado de ansiedade dos pais um fator que pode intensificar ainda mais os níveis de ansiedade das crianças no pré-operatório, gerando principalmente dificuldades de separação entre pais e filhos ou mesmo o desenvolvimento de alterações do comportamento no pós-operatório das crianças (CUMINO et al, 2013; BROERING; CREPALDI, 2011a; MAGALHÃES; GUSMAM; GRECCA, 2010).

Considerando o exposto, a pesquisadora investigou a percepção dos pais em relação ao evento cirúrgico, explorando por meio de uma pergunta norteadora o estado emocional auto-referido por eles, ou seja, se sentiam-se ansiosos ou com medo. Em casos afirmativos, tentava-se identificar o fator que estava relacionado a esse medo ou estado de tensão. Em casos contrários, investigaram-se a quais fatores os pais atribuíam o estado emocional autoreferido de tranquilidade e segurança.

\subsection{Equipe de Pesquisa}

A pesquisadora contou com a participação de duas alunas de iniciação científica do curso de Graduação em Enfermagem da Universidade de Brasília. Num primeiro momento, as alunas foram apresentadas à proposta da pesquisa e submeteram-se a leituras e discussões sobre o tema em estudo e, especificamente, sobre a Escala de Ansiedade Pré-operatória de Yale modificada (EAPY-m), instrumento utilizado na pesquisa. Após esse momento teórico e 
a aprovação do projeto de pesquisa pelo CEP, as alunas receberam treinamento por duas semanas no HMIB.

Inicialmente, elas observaram a pesquisadora na aplicação e preenchimento da EAPY$\mathrm{m}$ e no manuseio dos equipamentos para avaliação dos indicadores fisiológicos. Depois, as próprias alunas aplicaram a EAPY-m e aferiram os sinais vitais nos equipamentos específicos, porém sempre sob orientação da pesquisadora. Durante o treinamento, foram discutidas as divergências e eventuais dúvidas relacionadas a cada item da EAPY-m, porém não foi realizada análise de confiabilidade inter-observadores. Além disso, as alunas foram devidamente orientadas em relação ao preenchimento dos formulários utilizados na pesquisa.

As alunas, auxiliares de pesquisa, foram essenciais para potencializar a coleta de dados, principalmente quando havia muitos potenciais participantes em um mesmo dia, pois quando a pesquisadora estava sozinha, nem sempre conseguia abordar todas as crianças presentes. Vale ressaltar que elas foram acompanhadas todo o tempo pela pesquisadora responsável.

\subsection{Protocolo para coleta de dados}

Em relação aos participantes do grupo experimental, que foi submetido à intervenção musical, a pesquisadora inicialmente obtinha o consentimento dos responsáveis por meio da assinatura do Termo de Consentimento Livre e Esclarecido (TCLE) e o consentimento da criança. A pesquisadora só disponibilizava o Termo de Assentimento Livre e Esclarecido (TALE) para as crianças "assinarem"/desenharem, após concluir toda a coleta dos dados referente a cada uma delas, a fim de isolar qualquer interferência na intervenção em estudo. Após isso, preenchia o formulário de dados demográficos, no qual constavam informações como idade, sexo, tipo de cirurgia, número referente à lista de randomização, data da cirurgia e experiências cirúrgicas prévias (APÊNDICE A). Depois aferia e registrava os dados vitais frequência cardíaca, frequência respiratória, pressão arterial e saturação de oxigênio - em um formulário apropriado (APÊNDICE B), além de avaliar a manifestação comportamental de ansiedade por meio da Escala de Ansiedade Pré-operatória de Yale modificada - EAPY-m (ANEXO A). A seguir, disponibilizava as músicas pré-selecionadas para os participantes ouvirem em um aparelho MP3 Player durante 15 minutos, e após esse período, aferia novamente os sinais vitais e avaliava a ansiedade por meio da EAPY-m.

Quanto ao grupo controle, a pesquisadora, no primeiro momento, obtinha também o consentimento dos responsáveis e criança como descrito anteriormente. Após isso, aferia e registrava os dados vitais já citados e avaliava a ansiedade por meio da EAPY-m, repetindo a 
coleta após 15 minutos decorridos da primeira vez. Ressalta-se que, durante esses 15 minutos, os participantes do grupo controle não recebiam intervenção alguma por parte da pesquisadora, apenas eram observados diante da exposição ao cuidado padrão da Unidade da Clínica Cirúrgica do HMIB.

Após concluir todas essas etapas de coleta, conforme representado abaixo (Figura 1 e 2), a pesquisadora realizava uma breve entrevista semiestruturada com os responsáveis pelas crianças para investigar a percepção deles sobre o processo cirúrgico ao qual a criança estava sendo submetida e os medos/anseios relacionados. Para isso, a pesquisadora utilizou um formulário específico (APÊNDICE C) com algumas perguntas norteadoras relacionadas sobre o que os pais pensavam sobre a cirurgia que o filho faria, se tinham algum medo e quais outros sentimentos estavam presentes e a que aspecto/fase da cirurgia os relacionavam.

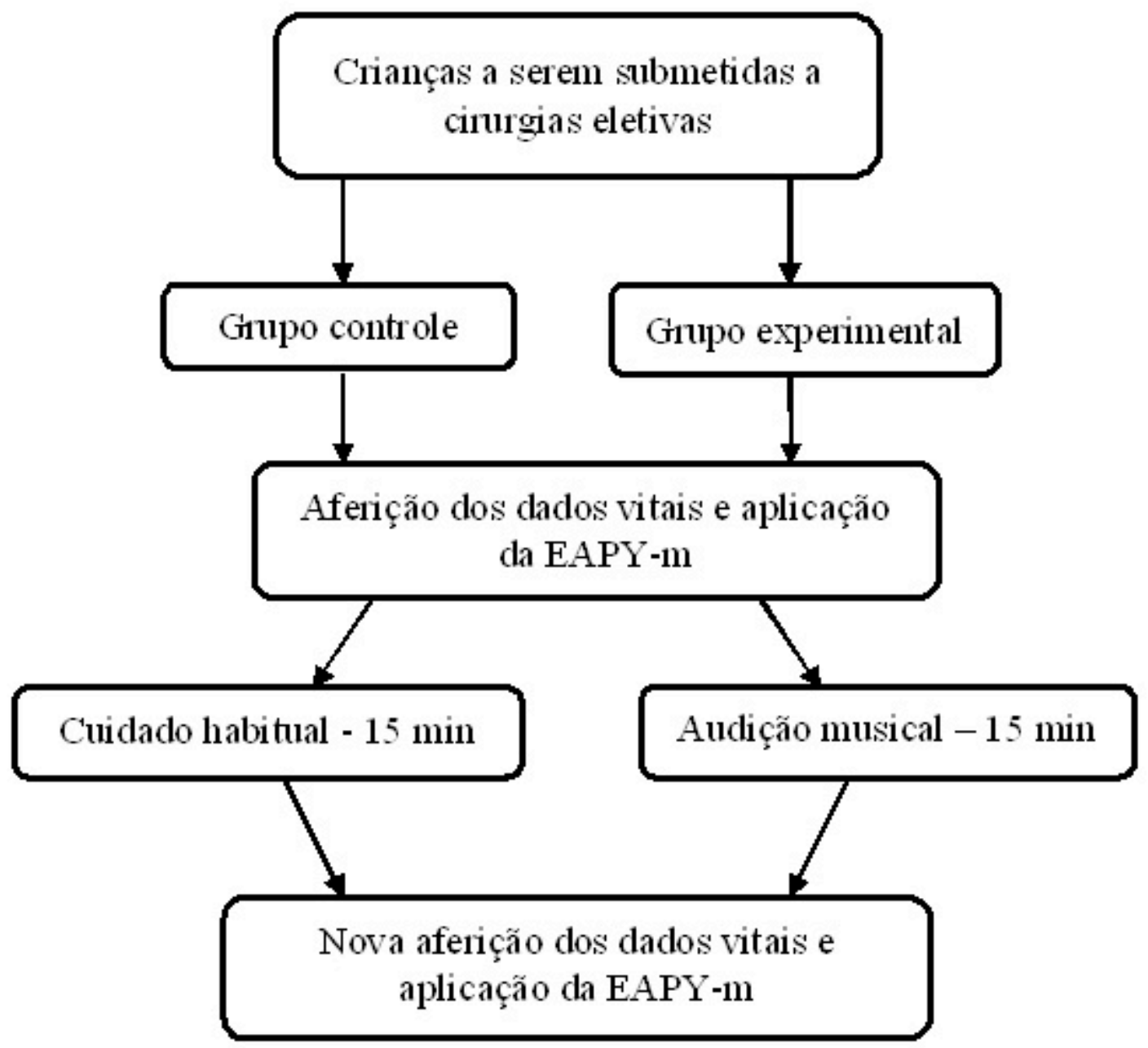

Figura 4. Fluxograma da coleta de dados. Brasília, DF, 2015. 
Tempo 1 (Basal)

Variáveis mensuradas:

$\mathrm{PA}, \mathrm{FC}, \mathrm{FR}, \mathrm{SatO}_{2} \mathrm{e}$

Ansiedade comportamental
Intervenção (15 min):

Audição musical ou cuidado padrão da $\mathrm{CCP}$
Tempo 2 (Pós-intervenção)

Variáveis mensuradas:

$\mathrm{PA}, \mathrm{FC}, \mathrm{FR}, \mathrm{SatO}_{2} \mathrm{e}$

Ansiedade comportamental

Figura 5. Organograma da coleta de dados. Brasília, DF, 2015.

\subsection{Randomização}

As crianças participantes foram randomizadas em dois grupos: experimental ou controle. A randomização deu-se por meio de uma relação de números aleatórios sistematizados, a partir de uma fórmula elaborada no Microsoft Office Excel, por meio de consultoria estatística contratada pela pesquisadora, em que números menores que 0,5 seriam do grupo controle e números maiores que 0,5 , do grupo experimental.

A alocação dos participantes foi realizada conforme ordem de disponibilidade e receptividade dos sujeitos elegíveis. A criança e o responsável que estivessem inicialmente disponíveis (que não estavam sendo examinados e/ou entrevistados pelos médicos e equipe de enfermagem, e que não estavam em ligações telefônicas) e que fossem receptivos ao convite, eram abordados pela pesquisadora e alocados para o grupo controle ou experimento, conforme indicação sequencial da lista. Algumas crianças não eram muito receptivas ao convite no início, porém ao observarem outras que aceitavam participar prontamente, acabavam mudando de ideia e voluntariando-se para a pesquisa.

Quando havia crianças pré-escolares e escolares no mesmo dia, a pesquisadora abordava primeiramente as crianças escolares, dado ao fato das cirurgias no HMIB serem realizadas por ordem crescente de idade, geralmente as crianças escolares eram uma das últimas a serem operadas e a receberem sedativo.

Dessa forma, buscou-se favorecer a obtenção de participantes com maior potencial de serem incluídos na amostra pois, na maioria das vezes, as crianças pré-escolares recebiam sedativos logo após serem avaliadas pelo anestesista ou mesmo já eram encaminhadas ao Centro Cirúrgico, o que inviabilizava a coleta, seja por não atenderem aos critérios de inclusão, no caso delas estarem sob efeito do sedativo, seja pelo fato de serem transportadas 
para outro local, sala de operação, que, por sua vez, configurava um novo momento cirúrgico, o intra-operatório.

Porém, apesar da pesquisadora abordar primeiramente as crianças escolares, não necessariamente elas eram receptivas ao convite para participar da pesquisa, e nem por isso a pesquisadora deixava de abordar/recrutar as crianças pré-escolares, apesar do risco maior de perda amostral.

\subsection{Cegamento}

O cegamento é um fator importante nos ensaios clínicos randomizados controlados para evitar vieses de co-intervenção e de aferição. Dependendo da pesquisa, nem sempre é possível mascarar todos os indivíduos envolvidos no estudo, sejam por motivos técnicos ou de ordem ética. Assim, cabe ao pesquisador buscar alternativas coerentes de "cegamento" relacionadas à intervenção em estudo e ao protocolo de pesquisa proposto (CUMMINGS; GRADY; HULLEY, 2008).

Optou-se por mascarar os participantes em relação à intervenção musical por meio da adaptação da estratégia do estudo de Arslan, Özer, Özyurt (2008). Assim, todas as crianças participantes ouviram música, tanto do grupo controle como do grupo experimental. Porém, no caso das crianças do grupo controle, a pesquisadora disponibilizava aparelhos MP3 Player para estas escutaram música somente após encerrar a coleta de dados.

Além disso, vale ressaltar que a pesquisadora não pode ser cegada, pois ela mesma foi responsável por aplicar a intervenção. Porém, durante a análise estatística, os grupos experimental e controle foram codificados em número "1" e "2" a fim de cegar a equipe estatística, o que caracteriza o estudo como duplo-cego.

\subsection{Processamento e Análise dos dados}

Os dados obtidos foram codificados e digitados com dupla entrada em planilhas do Excel, versão Microsoft Office 2010, para garantir validação do banco de dados por meio da comparação das planilhas e, conseguinte correção de divergências. Após isso, os dados foram exportados para o Software $S A S$, versão 9.0, para a realização de análises estatísticas de cunho descritivo e inferencial.

Os dados sóciodemográficos foram analisados por meio da estatística descritiva (média, desvio-padrão e frequência) e representados em tabelas.

Para as análises estatísticas inferenciais utilizaram-se o teste Qui-Quadrado de independência, o teste de Mann-Whitney e a Análise de Variância (ANOVA) com medidas repetidas, seguida de comparações múltiplas de Tukey, diante da identificação de alguma 
diferença estatisticamente significativa. Ressalta-se que, em todos os testes, considerou-se o nível de significância de 5\%.

Em relação aos dados oriundos da entrevista com os pais, esses foram categorizados e submetidos à análise descritiva (medidas de tendência central e de distribuição de frequência).

Vale destacar que a maioria das análises estatísticas utilizadas para estudos de intervenção consistem em testes paramétricos como Teste t. Apesar disso, considerando que foi utilizado um mesmo instrumento para avaliação pré e pós-intervenção, e seguindo as recomendações dos próprios criadores da EAPY-m (KAIN et al, 1997), decidiu-se pela análise de variância com medidas repetidas no tempo para analisar o poder estatístico dos escores de ansiedade e dados vitais relacionados ao fator tempo, aspecto ignorado em estudos que optam pelos testes paramétricos simples.

\subsection{Aspectos éticos}

Os aspectos éticos previstos na Resolução n 466/2012 do Conselho Nacional de Saúde (BRASIL, 2012), que estabelece as normas e diretrizes de pesquisas que envolvem seres humanos, foram observados e respeitados em todas as etapas dessa pesquisa.

O estudo foi submetido ao Comitê de Ética em Pesquisa (CEP) da Fundação de Ensino e Pesquisa em Ciências da Saúde (FEPECS), após anuência da chefia de Enfermagem da Clínica Cirúrgica Pediátrica e da Direção do HMIB, sendo aprovado em 10/02/2014, sob número de parecer 525.251, CAAE 07045613.3.0000.5553 (ANEXO B).

Ao longo do tempo, houve algumas alterações na proposta de pesquisa inicial em decorrência da realidade do cenário de investigação, o HMIB, e de dificuldades na coleta de dados. A principal modificação foi em relação à população-alvo, que no projeto inicial consistia em crianças do sexo masculino submetidas exclusivamente a cirurgias geniturinárias, e que no projeto atual compreendeu crianças de ambos os sexos, submetidas a qualquer cirurgia ou procedimento cirúrgico eletivo. Ressalta-se que todas as modificações foram realizadas por meio de emendas encaminhadas ao CEP para apreciação, sendo o último parecer consubstanciado, n. 954.343, aprovado em 23/02/2015 (ANEXO C).

A participação das crianças que compuseram a amostra foi solicitada por meio da assinatura do TCLE, em duas vias, do seu representante legal (APÊNDICE D), bem como pela "assinatura" da criança, em duas vias, do TALE elaborado pela pesquisadora, adaptado ao desenvolvimento cognitivo das duas faixas etárias envolvidas (APÊNDICES E e F).

A antiga Resolução n ${ }^{\circ}$ 196/1996 do Conselho Nacional de Saúde (BRASIL, 1996) determinava, nos casos de pesquisas envolvendo crianças, a obrigatoriedade da assinatura do 
TCLE apenas pelo responsável legal, tendo a criança o direito de informação no limite de suas capacidades. Diante disso, muitos profissionais e grupos da área dos direitos humanos questionaram esta normativa que transferia o poder de decisão exclusivamente para a família, não oportunizando um espaço para que crianças e adolescentes manifestassem suas vontades em participar de intervenções que dizem respeito a si próprios (TEIXEIRA; BRAZ, 2010; GAIVA, 2009; SIGAUD et al, 2009).

Atualmente, a nova Resolução já prevê a obrigatoriedade do TALE para anuência de crianças, adolescentes e participantes legalmente incapazes, valorizando dessa forma a vontade e a decisão de cada um deles. Assim, é importante destacar que se fez uso de documento personalizado dirigido exclusivamente às crianças, em linguagem simples e sensível ao estágio desenvolvimental de cada uma delas (APÊNDICE E e F).

Em relação à solicitação de participação dos pais na entrevista para investigar a percepção deles sobre o processo cirúrgico dos filhos, esta foi realizada por meio da assinatura de um TCLE específico, direcionado a eles na condição de sujeitos de pesquisa (APÊNDICE G).

\subsection{Registro do Estudo}

O registro de ensaios clínicos é imprescindível para pesquisadores que realizam esse tipo de estudo. A Organização Mundial de Saúde (OMS) orienta que todos os ensaios clínicos devem ser notificados e registrados antes de serem iniciados (CASTRO, 2009; PECCIN 2007). O registro é importante para garantir a divulgação pública de informações dos estudos, cumprindo, assim, com responsabilidades éticas de transparência para com os participantes envolvidos, além de ser uma ótima estratégia para observar tendências de pesquisa no campo das Ciências da Saúde e evitar duplicação de pesquisas (CASTRO, 2009; PECCIN 2007).

Diante disso, em conformidade às recomendações da OMS, o presente estudo foi registrado na base de dados do Registro Brasileiro de Ensaios Clínicos, vinculada à Internacional Clinical Trials Registry Plataform (ICTRP), com o identificador primário RBR7mcr59 (ANEXO D). 


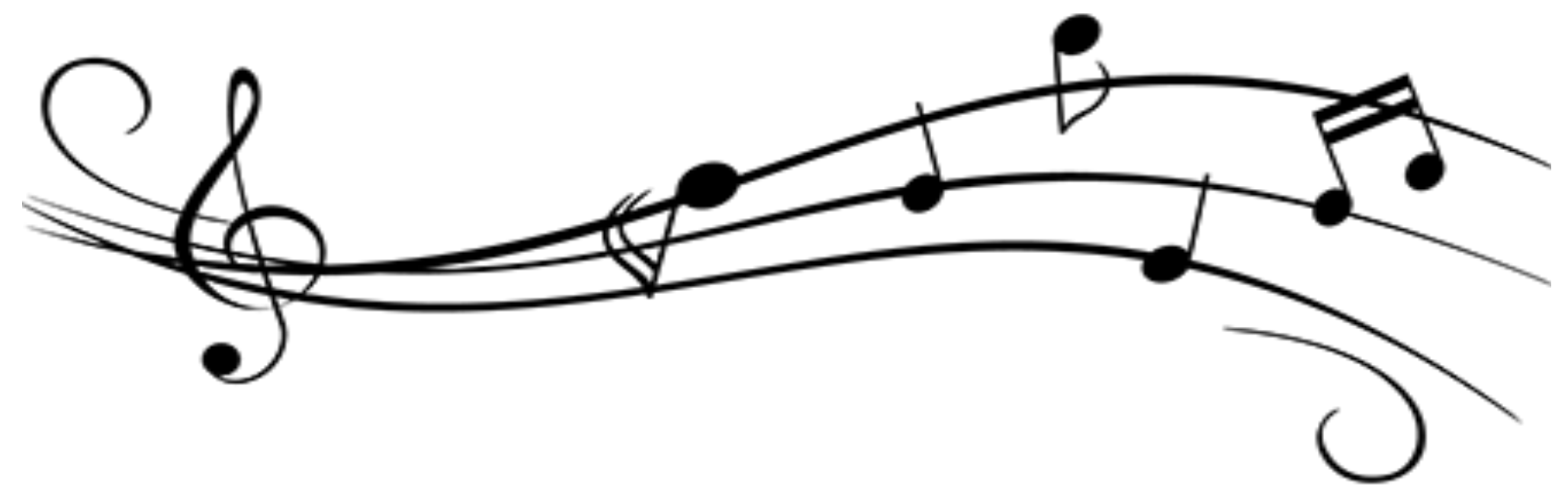

6. RESULTADOS 


\section{Resultados}

Dos 113 potenciais participantes avaliados para elegibilidade, 17 recusaram-se a participar e 96 foram randomizados e alocados para o grupo experimental (GE) ou grupo controle (GC). Desses, apenas 52 crianças compuseram a amostra final, 26 crianças em cada grupo. Os motivos de perda de seguimento foram diversos e estão detalhados na figura 2.

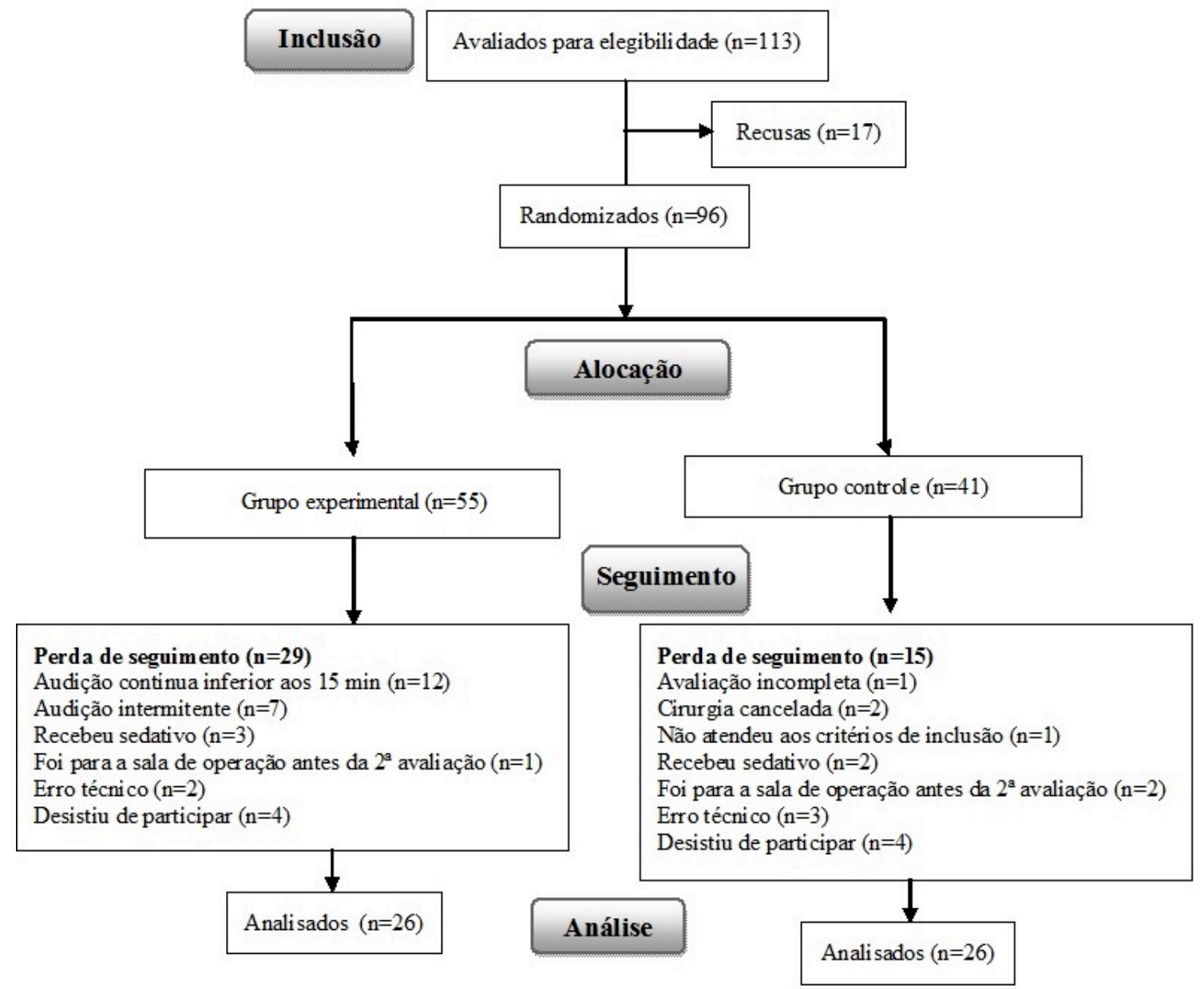

Figura 6. Diagrama de fluxo dos participantes da pesquisa. Brasília, DF, Brasil, 2015.

No GE, que representou $64 \%$ da perda de seguimento da amostra, o principal motivo de perda deu-se por interrupção da audição musical $(n=19)$, seguida da desistência de participação de quatro crianças que preferiram brincar com outras crianças e com os brinquedos disponíveis na sala. Além disso, três crianças receberam sedativo durante a intervenção, uma criança foi convocada para a sala de operação antes da pesquisadora concluir a segunda avaliação dos dados vitais e do comportamento de ansiedade, e duas foram excluídas da amostra devido a erros de preenchimento do formulário.

Quanto ao GC, a maior perda ocorreu devido à desistência dos participantes para brincarem com os brinquedos e jogos da clínica (4), por preenchimento incorreto do 
formulário (3), por receberem sedativo durante a intervenção (2), por serem convocados para a sala de operação antes da pesquisadora concluir a segunda avaliação (2) e também por cancelamento da cirurgia (2). Um participante que foi alocado para esse grupo não preencheu um dos critérios de inclusão, e outro, por estar muito agitado, inviabilizou a avaliação da frequência respiratória pela pesquisadora.

Vale destacar em relação ao GC, que o cuidado padrão não foi constante durante todo o período da coleta de dados. Logo que a pesquisadora iniciou a coleta de dados, esse cuidado consistia em disponibilizar alguns brinquedos, desenhos para colorir ou mesmo acesso à televisão, que raramente era ligada, e que ficavam na sala de espera pré-cirúrgica (Sala-Dia). Essa sala é fruto do financiamento de uma agência japonesa de cooperação internacional que, nesse caso, foi utilizado para reforma e decoração da sala com temas infantis e alguns mobiliários específicos para crianças a fim de promover ambientação hospitalar (Figura 3 e $4)$.

Por sua vez, em outras semanas, os brinquedos e os desenhos para colorir não foram expostos e nem oferecidos às crianças, e a televisão foi retirada da sala. Apesar de, às vezes, terem essas opções disponíveis, muitas crianças optavam em ficar próximas aos seus pais, e havia ainda aquelas que preferiam circular pelo corredor do hospital acompanhada dos responsáveis. E quando não havia opção alguma, restava às crianças buscar maior contato com os pais e/ou brincar.

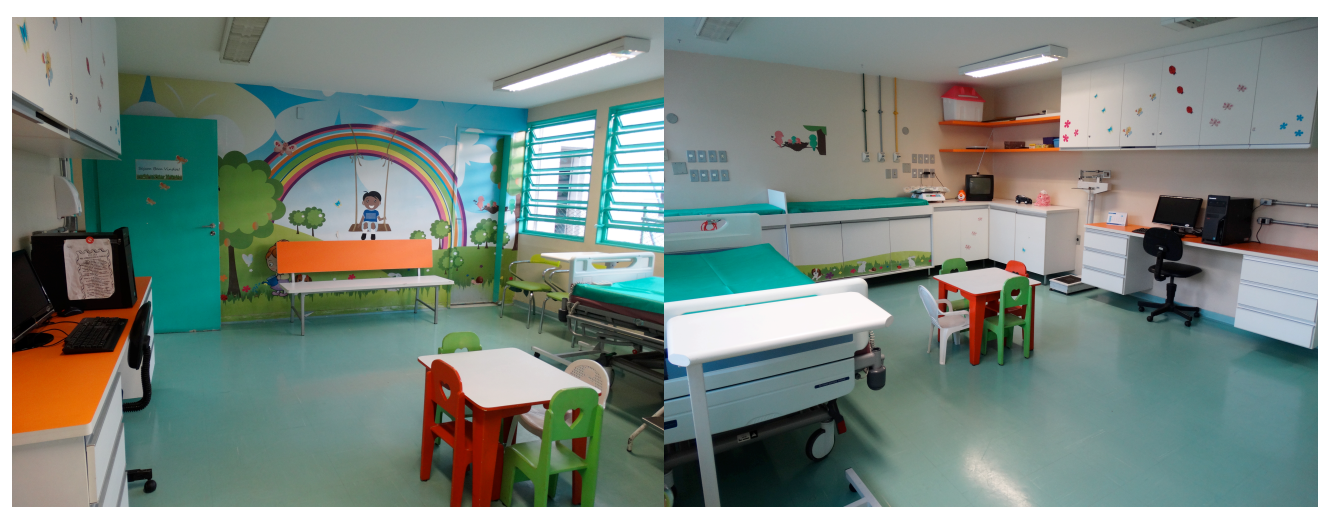

Figura 7 e 8. Sala-Dia do HMIB. Brasília, DF, 2015.

*Fotografias devidamente autorizadas pelo HMIB (Anexo E).

Em relação às características dos participantes, a idade variou de 3 a 12 anos, sendo a média de 6,9 anos. Entre os grupos, a média foi de 6,42 no GC e 7,38 no GE. Sobre o sexo, o masculino foi predominante em ambos os grupos, GC $(84,6 \%)$ e GE $(80,8 \%)$. A maioria das crianças estava sendo submetida pela primeira vez a um procedimento cirúrgico e tinha a mãe como o principal acompanhante. 
Sobre os tipos de cirurgias, houve uma grande variedade, sendo agrupada em três categorias - cabeça e pescoço, região abdominal e geniturinária - com base em literaturas sobre cirurgias pediátricas (BAILEY; JOHNSON, 2009; NARDOZZA; REIS; CAMPOS, 2010; TANNURI, 2010), predominando as cirurgias geniturinárias nos dois grupos, GC $(65,4 \%)$ e GE $(73,1 \%)$.

As cirurgias de cabeça e pescoço compreenderam amigdalectomia, adenoidectomia, incisão e drenagem de abcesso lingual e sublingual, excisão e sutura de linfagioma cervical, exerese de cisto tireoglosso e de cisto branquial. As cirurgias da região abdominal foram herniorrafia/plastia umbilical e videolaparoscopia. E as geniturinárias consistiram em postectomia, orquidopexia, herniorrafia inguinal, correção de hipospádia ou de hidrocele e plástica total do pênis.

Destaca-se que a distribuição de tais características foi homogênea e que não houve diferença estatisticamente significativa entre os grupos (tabela 2).

Tabela 2. Dados demográficos dos participantes do grupo controle e experimental. Brasília, DF, 2015.

\begin{tabular}{|c|c|c|c|c|}
\hline \multirow[b]{2}{*}{ Variáveis } & & \multicolumn{2}{|c|}{ Grupo } & \multirow[b]{2}{*}{$\mathrm{p}$-valor } \\
\hline & & $\begin{array}{l}\text { Controle } \\
(\mathrm{n})=26\end{array}$ & $\begin{array}{l}\text { Experimental } \\
(\mathrm{n})=26\end{array}$ & \\
\hline Idade (anos) & Média +- DP & $6,42+-2,42$ & $7,38+-2,68$ & $0,2197 \dagger$ \\
\hline \multirow{2}{*}{ Sexo n(\%) } & Feminino & $4(15,4 \%)$ & $5(19,2 \%)$ & \multirow{2}{*}{$1,0000 \ddagger$} \\
\hline & Masculino & $22(84,6 \%)$ & $21(80,8 \%)$ & \\
\hline \multirow{3}{*}{$\begin{array}{c}\text { Tipo de cirurgia } \\
\mathrm{n}(\%)\end{array}$} & Cabeça e pescoço & $4(15,4 \%)$ & $2(7,7 \%)$ & \multirow{3}{*}{$0,7621 \neq$} \\
\hline & Região abdominal & $5(19,2 \%)$ & $5(19,2 \%)$ & \\
\hline & Geniturinária & $17(65,4 \%)$ & $19(73,1 \%)$ & \\
\hline \multirow{3}{*}{$\begin{array}{c}\text { Primeira cirurgia } \\
\mathrm{n}(\%)\end{array}$} & Não & $4(15,4 \%)$ & $5(19,2 \%)$ & \multirow{3}{*}{$1,0000 \ddagger$} \\
\hline & Sim & $22(84,6 \%)$ & $21(80,8 \%)$ & \\
\hline & Avó & $0(0 \%)$ & $1(3,8 \%)$ & \\
\hline \multirow{3}{*}{$\begin{array}{c}\text { Acompanhante } \\
\mathrm{n}(\%)\end{array}$} & Mãe & $19(73,1 \%)$ & $22(84,6 \%)$ & \multirow{3}{*}{$0,2791 \neq$} \\
\hline & Mãe e Pai & $5(19,2 \%)$ & $1(3,8 \%)$ & \\
\hline & Pai & $2(7,7 \%)$ & $2(7,7 \%)$ & \\
\hline
\end{tabular}

*DP, desvio padrão; p-valorł', nível de significância do teste de Mann-Whithney; p-valorț, nível de significância do teste Qui-Quadrado para independência.

Quanto à classificação do estado de ansiedade, ou seja, crianças consideradas ansiosas (escores > 30) ou não ansiosas (escores entre 23,33 a 30), não foi detectada associação estatisticamente significativa com os grupos, em nenhum dos tempos, uma vez que o p-valor foi maior que 0,05 em ambos os casos. Observou-se ainda no intervalo de confiança para a Odds Ratio (OR) que, em ambos os tempos, o intervalo contém o valor 1, indicando que essa relação de fato não é estatisticamente significativa, corroborando com o resultado do teste de Qui-Quadrado (tabela 3). 
Tabela 3. Estado de ansiedade, por grupo, avaliado no tempo 1 e 2. Brasília, DF, 2015.

\begin{tabular}{|c|c|c|c|c|c|c|c|c|}
\hline \multirow[t]{2}{*}{ Momentos } & \multicolumn{2}{|c|}{$\begin{array}{c}\text { Grupo } \\
\text { Controle }\end{array}$} & \multicolumn{2}{|c|}{$\begin{array}{c}\text { Grupo } \\
\text { Experimental }\end{array}$} & \multirow[t]{2}{*}{$\begin{array}{l}\text { p- } \\
\text { valor }\end{array}$} & \multirow[t]{2}{*}{$\mathrm{OR} \dagger$} & \multirow[t]{2}{*}{$\begin{array}{c}\text { IC 95\% } \\
\text { OR } \dagger \\
\text { (Inferior) }\end{array}$} & \multirow[t]{2}{*}{$\begin{array}{c}\mathrm{IC} 95 \% \\
\text { OR } \dagger \\
\text { (Superior) }\end{array}$} \\
\hline & ansioso & $\begin{array}{c}\text { não } \\
\text { ansioso }\end{array}$ & ansioso & $\begin{array}{c}\text { não } \\
\text { ansioso }\end{array}$ & & & & \\
\hline Tempo 1 & 16 & 10 & 20 & 6 & 0,2333 & 2,08 & 0,62 & 6,97 \\
\hline Tempo 2 & 12 & 14 & 6 & 20 & 0,0850 & 0,35 & 0,11 & 1,16 \\
\hline
\end{tabular}

Em relação à média de escores da EPAY-m, inter e intra-grupos, não houve alteração no tempo independentemente da faixa etária, do tipo de cirurgia, do estado emocional referido pelos pais e de ser ou não o primeiro procedimento cirúrgico da criança, como pode ser observado na tabela 4 .

Tabela 4. Média e desvio padrão dos escores da EAPY-m por grupo, faixa etária, primeira cirurgia, tipo de cirurgia e estado emocional dos pais, para cada tempo. Brasília, DF, 2015.

\begin{tabular}{|c|c|c|c|c|c|}
\hline \multirow[b]{2}{*}{ Grupo } & \multirow[b]{2}{*}{ Variável } & \multirow[b]{2}{*}{ Categoria } & \multirow[b]{2}{*}{$\mathrm{N}$} & Tempo 1 & Tempo 2 \\
\hline & & & & Média (DP) & Média (DP) \\
\hline \multirow{9}{*}{$\mathrm{GC}$} & \multirow{2}{*}{ Faixa etária } & Pré-escolar & 10 & $33,14(9,21)$ & $31,82(8,89)$ \\
\hline & & Escolar & 16 & $36,76(9,85)$ & $32,7(10,52)$ \\
\hline & \multirow{2}{*}{ Primeira cirurgia } & Não & 4 & $29,20(5,37)$ & $35,0(12,33)$ \\
\hline & & Sim & 22 & $36,49(9,84)$ & $31,90(9,48)$ \\
\hline & \multirow{3}{*}{ Tipo de cirurgia } & Cabeça e pescoço & 4 & $33,75(10,72)$ & $29,2(11,60)$ \\
\hline & & Região abdominal & 5 & $42,32(13,19)$ & $41,96(9,98)$ \\
\hline & & Geniturinária & 17 & $33,71(7,75)$ & $30,31(7,91)$ \\
\hline & \multirow{2}{*}{$\begin{array}{l}\text { Estado emocional } \\
\text { referido pelos pais }\end{array}$} & Tranquilidade & 9 & $31,84(6,32)$ & $29,47(9,56)$ \\
\hline & & Aflição & 17 & $37,24(10,64)$ & $33,92(9,78)$ \\
\hline \multirow{9}{*}{ GE } & \multirow{2}{*}{ Faixa etária } & Pré-escolar & 8 & $43,75(10,95)$ & $29,03(6,78)$ \\
\hline & & Escolar & 18 & $39,44(10,36)$ & $27,92(5,38)$ \\
\hline & \multirow{2}{*}{ Primeira cirurgia } & Não & 5 & $41,68(5,72)$ & $28,40(6,12)$ \\
\hline & & Sim & 21 & $40,55(11,47)$ & $28,23(5,79)$ \\
\hline & \multirow{3}{*}{ Tipo de cirurgia } & Cabeça e pescoço & 2 & $35,00(16,40)$ & $25,90(3,54)$ \\
\hline & & Região abdominal & 5 & $37,32(11,33)$ & $26,40(4,47)$ \\
\hline & & Geniturinária & 19 & $42,28(10,04)$ & $29,00(6,19)$ \\
\hline & \multirow{2}{*}{$\begin{array}{l}\text { Estado emocional } \\
\text { referido pelos pais }\end{array}$} & Tranquilidade & 7 & $37,89(12,77)$ & $24,83(2,44)$ \\
\hline & & Aflição & 19 & $41,83(9,74)$ & $29,53(6,11)$ \\
\hline \multirow{6}{*}{\multicolumn{3}{|c|}{$\begin{array}{l}\dagger p \text {-valor, grupo } \\
\dagger p \text {-valor, interação grupo e tempo } \\
\dagger p \text {-valor, interação faixa etária, grupo e tempo } \\
\dagger p \text {-valor, interação primeira cirurgia, grupo e tempo } \\
\dagger p \text {-valor, interação tipo de cirurgia, grupo e tempo } \\
\text { p-valor estado emocional pais, grupo e tempo }\end{array}$}} & & & 0,9753 \\
\hline & & & & & 0,0441 \\
\hline & & & & & 0,6658 \\
\hline & & & & & 0,7181 \\
\hline & & & & & 0,2539 \\
\hline & & & & & 0,2104 \\
\hline
\end{tabular}

*DP, desvio padrão; †p-valor, ANOVA com medidas repetidas no tempo. 
Porém, foi detectado efeito estatisticamente significativo na EAPY-m da interação do grupo com o tempo $(\mathrm{p}=0,0441)$. Na Tabela 5 pode-se observar que a diminuição nos escores de ansiedade foi muito maior no GE, o qual apresentou uma média de 40,77 no tempo 1 e 28,26 no tempo 2, enquanto no GC a média foi de 35,37 no tempo 1 e 32,38 no tempo 2. Pelas comparações múltiplas de Tukey, observou-se que dentro do GE, a média de escores da EAPY-m foi estatisticamente diferente nos dois tempos ( $\mathrm{p}$-valor=0,0132), ao contrário do $\mathrm{GC}$, que apresentou um p-valor=0,8877.

Tabela 5. Média e desvio padrão dos escores da EAPY-m por grupo, para cada tempo. Brasília, DF, 2015.

\begin{tabular}{ccccc}
\hline Grupo & N & $\begin{array}{c}\text { Tempo 1 } \\
\text { Média (DP) }\end{array}$ & $\begin{array}{c}\text { Tempo 2 } \\
\text { Média (DP) }\end{array}$ & $\begin{array}{c}\text { p-valor } \\
0,0441 \dagger\end{array}$ \\
\hline GC & 26 & $35,37(9,59)$ & $32,38(9,75)$ & $0,8877 \ddagger$ \\
GE & 26 & $40,77(10,52)$ & $28,26(5,73)$ & $0,0132 \ddagger$ \\
\hline
\end{tabular}

*DP, desvio padrão; †p-valor, ANOVA com medidas repetidas no tempo; p-valorł, comparações múltiplas de Tukey.

Sobre os domínios da EAPY-m, verificou-se efeito estatisticamente significativo da interação entre grupo e tempo em relação aos domínios de Atividade, Vocalização, Expressão emocional e Estado de despertar aparente. Pode-se observar na Tabela 6 que a diminuição dos escores foi, em média, maior no GE. De fato, os tempos são estatisticamente diferentes em relação a esses quatro domínios somente no grupo intervenção, uma vez que no GC não foi possível observar essa diferença pelas comparações múltiplas de Tukey.

Ressalta-se que, para o domínio "Interação com os parentes”, foi necessário aplicar a transformação LN na variável dependente para que as suposições sobre os resíduos fossem satisfeitas. 
Tabela 6. Média dos escores dos domínios da EAPY-m por grupo, para cada tempo. Brasília, DF, 2015.

\begin{tabular}{|c|c|c|c|c|c|c|c|}
\hline \multirow{3}{*}{ Domínios } & \multirow{3}{*}{ p-valor* } & \multicolumn{2}{|c|}{$\begin{array}{c}\text { Grupo } \\
\text { Controle } \\
(n=26)\end{array}$} & \multicolumn{4}{|c|}{$\begin{array}{c}\text { Grupo } \\
\text { Experimental } \\
(n=26)\end{array}$} \\
\hline & & Tempo 1 & Tempo 2 & $\begin{array}{l}\text { †p- } \\
\text { valor }\end{array}$ & $\begin{array}{c}\text { Tempo } \\
1\end{array}$ & $\begin{array}{l}\text { Tempo } \\
2\end{array}$ & $\$ \mathrm{p}$-valor \\
\hline & & \multicolumn{2}{|c|}{ Média } & \multicolumn{4}{|c|}{ Média } \\
\hline Atividade & 0,0009 & 0,36 & 0,32 & 0,4135 & 0,44 & 0,28 & $<0,0001$ \\
\hline Vocalização & 0,0254 & 0,27 & 0,24 & 0,6954 & 0,27 & 0,18 & 0,0055 \\
\hline $\begin{array}{l}\text { Expressão } \\
\text { emocional }\end{array}$ & 0,0172 & 0,44 & 0,41 & 0,6158 & 0,5 & 0,36 & 0,005 \\
\hline $\begin{array}{l}\text { Estado de } \\
\text { despertar } \\
\text { aparente }\end{array}$ & 0,0022 & 0,33 & 0,31 & 0,8489 & 0,43 & 0,26 & $<, 00001$ \\
\hline $\begin{array}{l}\text { Interação com } \\
\text { os parentes }\end{array}$ & 0,7427 & 0,38 & 0,34 & $\mathrm{x}$ & 0,39 & 0,34 & $\mathrm{x}$ \\
\hline
\end{tabular}

*p-valor, ANOVA com medidas repetidas no tempo; †p-valor, comparações múltiplas de Tukey referente ao grupo controle; †p-valor, comparações múltiplas de Tukey referente ao grupo intervenção.

Em relação aos dados vitais, verificou-se que houve diferença estatisticamente significativa da interação tripla das variáveis faixa etária, grupo e tempo sobre a frequência cardíaca e respiratória (tabela 7). Vale destacar que para que as suposições sobre os resíduos fossem satisfeitas, em alguns casos foi necessário aplicar uma transformação na variável dependente. As variáveis que precisaram passar por uma transformação foram pressão sistólica, pressão diastólica e saturação de oxigênio, sendo aplicadas as transformações logarítmica para pressão sistólica e diastólica, e a cúbica para saturação de oxigênio.

Diante das comparações múltiplas de Tukey, identificou-se que, no GE, os participantes em idade escolar apresentaram média menor da frequência cardíaca no tempo 2 (segunda avaliação) em comparação aos participantes de idade pré-escolar $(\mathrm{p}=0,0101)$. Quanto ao GC, as crianças pré-escolares tiveram maior média da frequência respiratória em relação às crianças escolares em ambas os tempos $(\mathrm{p}=0,0312 \mathrm{e} \mathrm{p}=0,0344)$. Além disso, as crianças pré-escolares do GE apresentaram menor média da frequência respiratória no tempo 2 se comparada aos pré-escolares do $\mathrm{GC}(\mathrm{p}=0,0453)$. 
Tabela 7. Média e desvio padrão dos sinais vitais por grupo, faixa etária e tempo, seguido do p-valor da ANOVA, com medidas repetidas no tempo. Brasília, DF, 2015.

\begin{tabular}{|c|c|c|c|c|}
\hline \multirow{2}{*}{ Grupo } & \multirow{2}{*}{ Faixa etária } & \multirow{2}{*}{ Sinais Vitais } & Tempo 1 & Tempo 2 \\
\hline & & & \multicolumn{2}{|c|}{ Média (DP)* } \\
\hline \multirow{10}{*}{ Grupo Controle } & \multirow{5}{*}{$\begin{array}{l}\text { Pré-escolar } \\
\quad(n=10)\end{array}$} & $\mathrm{FC}$ & $90,8(16,03)$ & $85,6(13,69)$ \\
\hline & & PS & $98,1(11,11)$ & $110,5(20,60)$ \\
\hline & & $\mathrm{PD}$ & $62,8(14,66)$ & $70,2(26,79)$ \\
\hline & & FR & $22,6(4,65)$ & $22,6(5,13)$ \\
\hline & & $\mathrm{SatO}_{2}$ & $97,8(1,69)$ & $97,2(1,40)$ \\
\hline & \multirow{5}{*}{ Escolar $(n=16)$} & $\mathrm{FC}$ & $83,44(18,42)$ & $85,94(16,89)$ \\
\hline & & PS & $116,75(15,34)$ & $114,69(23,94)$ \\
\hline & & $\mathrm{PD}$ & $65,63(15,69)$ & $64,75(11,26)$ \\
\hline & & FR & $19,19(3,97)$ & $19,25(4,06)$ \\
\hline & & $\mathrm{SatO}_{2}$ & $97,63(2,09)$ & $97,13(1,78)$ \\
\hline \multirow{10}{*}{ Grupo Experimental } & \multirow{5}{*}{$\begin{array}{l}\text { Pré-escolar } \\
\quad(n=8)\end{array}$} & $\mathrm{FC}$ & $94,5(19,88)$ & $96,63(21,18)$ \\
\hline & & PS & $109,75(16,92)$ & $102,25(16,58)$ \\
\hline & & $\mathrm{PD}$ & $70,38(21,19)$ & $64,38(16,41)$ \\
\hline & & FR & $19,5(2,93)$ & $18,88(3,87)$ \\
\hline & & $\mathrm{SatO}_{2}$ & $98,5(1,07)$ & $98(1,07)$ \\
\hline & \multirow{5}{*}{ Escolar $(n=18)$} & $\mathrm{FC}$ & $82,67(10,61)$ & $78,67(14,74)$ \\
\hline & & PS & $112,5(15,03)$ & $109,44(16,48)$ \\
\hline & & $\mathrm{PD}$ & $69,78(17,88)$ & $65,33(18,03)$ \\
\hline & & FR & $20,89(3,69)$ & $20,5(2,75)$ \\
\hline & & $\mathrm{SatO}_{2}$ & $97,83(1,10)$ & $97,72(1,23)$ \\
\hline \multirow{5}{*}{\multicolumn{2}{|c|}{ p-valor** }} & $\mathrm{FC} \dagger$ & \multicolumn{2}{|c|}{0,0304} \\
\hline & & PS: & \multicolumn{2}{|c|}{0,0648} \\
\hline & & $\mathrm{PD} \S$ & \multicolumn{2}{|c|}{0,9913} \\
\hline & & $\mathrm{FR} \|$ & \multicolumn{2}{|c|}{0,0316} \\
\hline & & $\mathrm{SatO}_{2} \mathbb{I}$ & \multicolumn{2}{|c|}{0,8363} \\
\hline
\end{tabular}

*DP, desvio padrão; †FC, frequência respiratória; $¥ \mathrm{PS}$, pressão sistólica; §PD, pressão diastólica; $\| \mathrm{FR}$, frequência respiratória; $\left\lceil\mathrm{SatO}_{2}\right.$, saturação de oxigênio; $* *$ p-valor, ANOVA com medidas repetidas no tempo referente à interação grupo, faixa etária e tempo.

Além disso, foi avaliada a associação do estado emocional referido pelos acompanhantes com os grupos. Para tanto, as respostas foram agrupadas em duas categorias de estado emocional - tranquilidade e aflição. A primeira categoria foi composta por sentimentos de tranquilidade relacionados ao fato das crianças ou dos próprios acompanhantes já terem passado por um procedimento cirúrgico prévio, pelos pais entenderem/perceberem a cirurgia como algo necessário para evitar futuras complicações na saúde dos filhos/criança, e por nutrirem sentimentos positivos de esperança de que tudo correrá bem, por depositarem fé na figura de um Ser superior que está no controle da vida de suas crianças. Além disso, a orientação e preparo pré-operatório recebido e o fato de algumas mães serem profissionais de saúde foi apontado como um aspecto que contribuiu para o estado de tranquilidade. 
A categoria de aflição, por sua vez, compreendeu relato de sentimentos de preocupação, medo, apreensão e nervosismo relacionados principalmente à anestesia como também ao procedimento cirúrgico em si, à recuperação pós-operatória, ao medo da morte e a dúvidas por falta de orientação do médico-cirurgião, pois aguardavam a cirurgia há anos e tinham passado pela última consulta médica há muito tempo.

De fato, o medo relacionado à anestesia foi uma das principais preocupações dos acompanhantes, já que pelos menos 15 dos 36 que referiram sentimentos de aflição, declararam expressamente seus temores relacionados à anestesia. Vale destacar que, durante a coleta de dados, verificou-se que nem todos os médicos anestesistas estiveram disponíveis para orientar as famílias e esclarecer dúvidas, uma vez que realizavam entrevistas rápidas e protocoladas e outros nem compareciam à sala de espera pré-operatória. Ressalta-se, ainda, que seis mães choraram ao responder às perguntas devido ao intenso estado de aflição em que se encontravam.

Diante da análise estatística, verificou-se que grupos não são estatisticamente diferentes em relação ao estado emocional referido pelos pais, uma vez que o p-valor foi maior que 0,05 (tabela 8 ).

Tabela 8. Frequência absoluta e percentual de estado emocional dos acompanhantes por grupo. Brasília, DF, 2015.

\begin{tabular}{|c|c|c|c|c|}
\hline \multirow{3}{*}{ Variável } & \multirow{3}{*}{ Categoria } & \multicolumn{2}{|c|}{ Grupo } & \multirow{3}{*}{ p-valor } \\
\hline & & $\mathrm{GC}$ & GE & \\
\hline & & \multicolumn{2}{|c|}{$\mathrm{N}(\%)$} & \\
\hline \multirow{2}{*}{$\begin{array}{l}\text { Estado emocional dos } \\
\text { acompanhantes }\end{array}$} & Tranquilidade & $9(34,6 \%)$ & $7(27 \%)$ & \multirow{2}{*}{$0.7645^{*}$} \\
\hline & Aflição & $17(65,4 \%)$ & $19(73 \%)$ & \\
\hline
\end{tabular}

*p-valor, teste Qui-Quadrado para independência.

Realizou-se também análise estatística para verificar a possibilidade de associação do estado emocional referido pelos acompanhantes com os escores de ansiedade da EAPY-m por grupo, para cada tempo. Após aplicação do teste de análise de variância (ANOVA), não foi detectada significância estatística da interação do estado emocional dos acompanhantes com escores de ansiedade por grupo e tempo, pois o p-valor resultante foi igual a 0,2104 , valor superior ao nível de significância adotado nesse estudo (tabela 9). 
Tabela 9. Média e desvio padrão da escala EAPY-m por estado emocional dos acompanhantes para cada tempo. Brasília, DF, 2015.

\begin{tabular}{|c|c|c|c|c|c|}
\hline \multirow{2}{*}{ Grupo } & \multirow{2}{*}{ Variável } & \multirow{2}{*}{ Categoria } & \multirow{2}{*}{$\mathrm{N}$} & Tempo 1 & Tempo 2 \\
\hline & & & & Média (DP) & Média (DP) \\
\hline \multirow{2}{*}{$\mathrm{GC}$} & \multirow{4}{*}{$\begin{array}{l}\text { Estado emocional dos } \\
\text { acompanhantes }\end{array}$} & Tranquilidade & 9 & $31,84(6,32)$ & $29,47(9,56)$ \\
\hline & & Aflição & 17 & $37,24(10,64)$ & $33,92(9,78)$ \\
\hline \multirow{2}{*}{ GE } & & Tranquilidade & 7 & $37,89(12,77)$ & $24,83(2,44)$ \\
\hline & & Aflição & 19 & $41,83(9,74)$ & $29,53(6,11)$ \\
\hline
\end{tabular}

Por fim, ressalta-se que alguns pais indagaram se havia música para eles ouvirem e se poderiam participar da intervenção musical também. Ao serem esclarecidos novamente sobre os objetivos da pesquisa, sugeriram a realização de estudos que incluíssem a participação deles na intervenção musical juntamente com os filhos. 


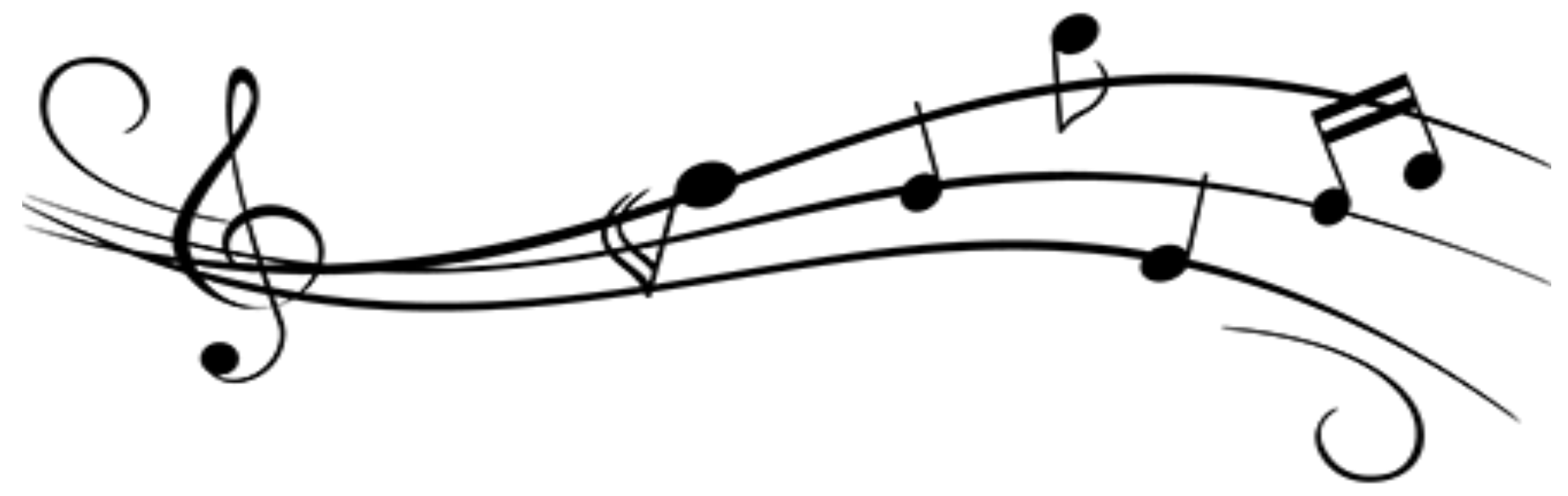




\section{Discussão}

Nesse capítulo, a discussão dos resultados obtidos na pesquisa será apresentada segundo os tópicos abaixo:

a) Características da amostra

b) Compreendendo o efeito da música: comparação das variáveis de desfecho entre grupo experimental e controle

c) Estado emocional dos acompanhantes

d) Limitações do estudo e implicações para pesquisa e prática clínica de enfermagem

\subsection{Características da amostra estudada}

Verificou-se que não houve diferença estatisticamente significativa entre os dois grupos em relação aos dados demográficos (idade, sexo, tipo de cirurgia, acompanhante), o que indica alocação aleatória adequada dos participantes nos grupos.

Houve predominância do sexo masculino e das cirurgias geniturinárias, o que pode ser justificado pelo fato das cirurgias urológicas compreenderem $60 \%$ dos casos da demanda em cirurgias pediátricas (JESUS et al., 2009) e pelas malformações congênitas do sistema geniturinário em crianças serem um dos problemas mais comuns que motivam a consulta com um cirurgião (ROMÃO, 2010). Além disso, dentre as patologias cirúrgicas mais frequentes em pediatria estão a fimose, a parafimose, a hipospádia, a epispádia e a criptorquidia, afecções exclusivas do sexo masculino (COLLET; OLIVEIRA; VIEIRA, 2010b).

Ainda sobre os dados demográficos, a mãe foi o principal acompanhante da criança em ambos os grupos, fato recorrente no universo da pediatria (SAMPAIO et al, 2014; SAMPAIO et al, 2009) e que corrobora com outros autores que realizaram estudos no cenário da cirurgia pediátrica (CUMINO et al, 2013). Estudos apontam que acompanhantes sem vínculo parental contribuem para o estado de ansiedade da criança, mas, em contrapartida, alguns autores também referem que as mães são as mais ansiosas dentre os acompanhantes, o que pode influenciar diretamente o estado emocional da criança (CUMINO et al, 2013; MAGALHÃES, GUSMAM; GRECCA, 2010; MORO; MÓDOLO, 2004). Nessa pesquisa não foi realizada análise em relação à associação do estado de ansiedade das crianças com o gênero dos acompanhantes, já que não identificada significância estatística na associação do estado emocional referido pelos acompanhantes com o estado de ansiedade dos participantes.

As informações sobre perda amostral, muitas vezes, são omitidas em estudos experimentais. Porém, em uma revisão sistemática da Cochrane relacionada à temática da intervenção musical em população adulta (BRADT; DILEO; SHIM, 2013), verificou-se que a 
taxa de desistência nos estudos foi pequena, compreendendo de 0 a $13 \%$ da amostra total, sendo apenas três estudos com taxas maiores de desistência entre $20 \%$ a $33 \%$.

Nessa pesquisa, a taxa de perda foi alta, $54 \%$ da amostra total, que correspondeu ao total de 61 crianças, número superior à amostra válida e analisada. Um dos principais motivos dessa perda foram as recusas e/ou desistências de participar da pesquisa e, particularmente, no grupo experimental, por interrupção da audição musical. Muitas crianças recusaram participar por estarem muito ansiosas e nervosas diante do evento cirúrgico e outras ainda por preferirem brincar com brinquedos que traziam de casa ou que, eventualmente, estivessem disponíveis na sala de espera da clínica, ambiente acolhedor, decorado com temas infantis e alguns brinquedos.

De fato, o brincar é uma estratégia sensível às características desenvolvimentais da criança, ou seja, é a linguagem que a instrumentaliza simbolicamente a se comunicar e a lidar com os problemas e desafios do mundo real (HOCKENBERRY; WILSON, 2011; WEBER, 2010). Ao inserir o lúdico no ambiente hospitalar, busca-se promover um lugar divertido, familiar e não ameaçador para a criança. Portanto, é compreensível a preferência de algumas crianças por brincar em detrimento de ouvir músicas, o que tem sua eficácia também, pois dois estudos que investigaram a ansiedade pré-operatória em crianças que estiveram por alguns minutos numa sala de recreação verificaram que estar em um ambiente com brinquedos é uma ferramenta muito eficaz na redução da ansiedade (WEBER, 2010; HOSSEINPOUR; MEMARZADEH, 2010).

Quanto à interrupção da audição musical, a maioria ouviu as músicas de forma contínua, porém não suportaram os 15 minutos estipulados no protocolo de pesquisa, sendo a média tolerada de 8 minutos. Outras ouviram de forma intermitente, retirando os fones a todo momento para conversar, observar o aparelho MP3 player ou para brincar, principalmente em dias que havia muita oferta de brinquedos na sala de espera. Algumas crianças ainda referiram não gostar das músicas selecionadas e, em alguns casos, crianças recusaram submeter-se à audição por não serem músicas da sua religião.

Revisões sistemáticas sobre a efetividade da música na população pediátrica apontaram uma variedade de gênero musical, compreendendo desde músicas contemporâneas, sons da natureza, clássicas a canções de ninar (FRANZOI; PAULA, MARTINS, 2013; KLASSEN et al, 2008). Diante disso e segundo as recomendações do Joanna Briggs Institute (2011) sobre o tipo de música a ser utilizada no ambiente hospitalar - música orquestrada e não-lírica, com 60 a 80 batimentos por minuto, volume de $60 \mathrm{~dB}$, em tons baixos, executada preferencialmente em instrumentos de cordas e com o mínimo de percussão - decidiu-se 
selecionar cantigas de roda brasileiras não-líricas para esse estudo, músicas que supostamente estão inseridas no contexto cultural da criança brasileira.

Porém, pelo fato das músicas serem instrumentais e com andamento lento, acredita-se que as crianças não estejam habituadas a ouvir essa modalidade de música, o que poderia justificar tantas interrupções da audição musical que ocorreram ao longo da pesquisa. Recusas de participação por crianças devido ao estilo musical foram verificadas em outro estudo que utilizou música clássica no período pós-operatório, porém em menor proporção do que nessa pesquisa (HATEM; LIRA; MATTOS, 2006).

Apesar de estudos apontarem que não há diferença significativa entre participantes que selecionam música e aqueles que não escolhem (JOANNA BRIGGS INSTITUTE, 2011; NILSSON, 2008), estudos recomendam e destacam que as preferências musicais dos participantes devem ser atendidas por entenderem que as músicas escolhidas e conhecidas pelos participantes podem ter maior impacto e correlação com o grau de relaxamento, mas também questionam a priorização da música rotulada como sedativa (GHETTI, 2014; BRADT; DILEO; SHIM, 2013; JIANG et al, 2013; PITTMAN; KRIDLI, 2011; ENGWALL; DUPPILS, 2009; STOUFFER; SHIRK; POLOMANO, 2007; ALLEN et al, 2001).

Exemplo disso é o estudo de Jiang et al (2013) que detectou que o efeito da música sedativa ou estimulante na redução do estresse de pacientes depende da preferência musical, já que não identificaram diferença significativa nos níveis de tensão e ansiedade daqueles participantes que ouviram músicas sedativas e dos que ouviram músicas estimulantes preferidas. Apesar disso, os participantes que ouviram músicas sedativas desconhecidas apresentaram níveis de ansiedade e tensão menores do que aqueles que ouviram músicas estimulantes não preferidas.

Portanto, a discussão não se restringe somente à questão dos participantes selecionarem ou não suas músicas, mas de suas preferências serem atendidas diante de algumas evidências recentes que apontam que a efetividade da música está mais relacionada à preferência do paciente, que pode compreender músicas agitadas ou relaxantes, do que às características próprias das músicas consideradas sedativas. Dobbro (1998), entretanto, questiona se a preferência individual por qualquer música que seja pode produzir efeitos benéficos aos ouvintes, sobressaindo-se às características das músicas consideradas sedativas ou relaxantes.

A escolha de repertório e de critérios de seleção de músicas irão depender da visão adotada sobre como a música produz reações humanas. Na visão referencialista, entende-se que os efeitos são referenciados a aspectos extramusicais como ideias, conceitos, atitudes, 
cultura e emoções do ouvinte. Por outro lado, há a visão absolutista que defende que a gênese das emoções e efeitos produzidos no ouvinte dá-se a partir da própria música, de características estruturais e íntrinsecas à obra musical (WAZLAWICK; CAMARGO; MAHEIRIE, 2007).

No ambiente hospitalar, muitas vezes, em pesquisas e na própria atuação clínica, acaba-se enfatizando mais a estrutura musical em detrimento da preferência musical do paciente, já que é inviável atender à preferência de todos. Além disso, Leão (2009) refere um outro motivo que corrobora para essa ênfase ao afirmar que nem sempre o que o paciente prefere musicalmente é aquilo que realmente ele precisa ou que é mais indicado terapeuticamente para determinado desfecho.

Retomando a discussão sobre a perda de seguimento ao longo da pesquisa, as demais perdas estiveram relacionadas a questões da rotina do serviço que não foram possíveis de alinhar com a pesquisa, como encaminhamento de crianças para o centro cirúrgico antes de concluir a segunda avaliação, administração de sedativos pelos anestesistas durante a realização do experimento e cancelamento de cirurgias, motivos de perda de seguimento encontrados também na maioria dos estudos em uma revisão sistemática da Cochrane (BRADT; DILEO; SHIM, 2013)

A condução de estudos experimentais, especificamente de ensaios clínicos controlados e randomizados, é complexa em cenários da prática clínica, pois trata-se de um ambiente dinâmico onde não há como "controlar" a rotina, os costumes, os profissionais de saúde e a gestão local. Atualmente, tem-se discutido a proposta de modelos híbridos para estudos clínicos de investigação de eficácia de intervenções, que tem como foco avaliar a efetividade de intervenções clínicas e a implementação dessas no contexto da realidade da prática clínica, um grande desafio no universo das pesquisas clínicas (BERNET; WILLENS; BAUER, 2013).

Tradicionalmente, o desenvolvimento e aplicação do conhecimento nesse contexto das pesquisas clínicas se dá de forma unidirecional, passo a passo, e inevitavelmente isolando diversas questões envolvidas nesse processo. De modo geral, realiza-se um ensaio clínico randomizado para determinar se uma intervenção em estudo sob condições controladas tem eficácia em uma determinada população. Num segundo momento, investiga-se a abrangência dessa intervenção em uma população mais ampla, em condições menos controladas, a fim de verificar se o efeito da intervenção se mantém quando aplicada em condições não ideais. E por fim, a última etapa consiste em investigar métodos de implementação para identificar o método mais viável para introduzir a intervenção na prática clínica. É uma abordagem sistemática, que requer muito tempo para produzir conhecimento e torná-lo útil e aplicável à 
realidade da prática clínica, além de viabilizar a compreensão da interação entre a intervenção e a estratégia de implementação da mesma (BERNET; WILLENS; BAUER, 2013).

Os modelos híbridos são propostos como uma opção diferente e mais complexa que o padrão tradicional. Existem três tipos ou abordagens de modelos híbridos: (a) ensaios híbridos tipo 1, que têm como objetivo primário determinar a efetividade de uma intervenção clínica e como objetivo secundário, compreender melhor o contexto para implementação da intervenção em estudo a partir da observação de potencias barreiras e facilitadores para a implementação/execução clínica generalizada; (b) ensaios híbridos tipo 2, que apresentam objetivos co-primários, ou seja, de avaliar simultaneamente a efetividade de intervenções em saúde e a viabilidade e utilidade de implementação dessas intervenção na prática; (c) ensaios híbridos tipo 3, têm como objetivo primário determinar a utilidade de uma intervenção ou estratégia de implementação, e como objetivo secundário, avaliar os resultados clínicos associados à implementação (CURRAN et al, 2012).

Dessa forma, é possível observar que as três abordagens apresentam dois objetivos avaliar a efetividade e implementação de intervenções, porém com ênfases diferentes. O tipo 1 apresenta ênfase maior em testar os efeitos da intervenção, no tipo 3, por sua vez, enfatizase mais a avaliação das estratégias de implementação, e no tipo 2 equipara-se a ênfase nos efeitos da intervenção e aos métodos de implementação dessa (BERNET; WILLENS; BAUER, 2013).

A tipologia híbrida consiste em um processo em evolução ainda, mas, com certeza, é uma abordagem alternativa ao padrão tradicional e que visa identificar as interações importantes entre intervenção e implementação, gerando informações para embasar decisões sobre a implementação ideal e o impacto generalizado da aplicação da intervenção de saúde, e assim acelerar a introdução de inovações valiosas nos serviços de saúde (BERNET; WILLENS; BAUER, 2013).

Nessa perspectiva da abordagem híbrida, o estudo-piloto, que teve como objetivo primordial investigar a efetividade da audição musical, poderia ser realizado como um modelo de ensaio do tipo 1 ou até mesmo do tipo 2 .

\subsection{Compreendendo o efeito da música: comparação das variáveis de desfecho} entre grupo experimental e controle

Quanto a análise das crianças com e sem ansiedade de ambos os grupos nos dois momentos de avaliação, apesar de não ter sido significativa, observa-se que, no tempo 2, o pvalor é igual a 0,0850 , valor próximo ao limite de significância de 5\%, limitado pelo tamanho 
da amostra. Além disso, apesar do intervalo de confiança para Odds Ratio (OR) conter o número 1, a sua amplitude não é grande, o que sustenta/gera indícios de que, no tempo 2, pertencer ao grupo experimental diminui as chances da criança manifestar ansiedade, uma vez que a OR calculada foi de 0,35 .

Com relação à média de escores da EAPY-m houve diferença significante no grupo submetido à audição musical nos dois tempos $(p=0,0132)$, o que, por sua vez, não foi observado no grupo controle. A redução dos escores da EAPY-m do tempo 1 para o tempo 2 sugere que tal alteração esteja relacionada à audição musical, já que foi a única intervenção realizada nesse intervalo de tempo.

Em estudo realizado na China, que investigou o efeito da música sobre a ansiedade e dor de crianças com paralisia cerebral submetidas à acupuntura, houve significância também na interação grupo-tempo. No caso, houve significância inter e intra-grupos, com destaque para o grupo submetido à intervenção musical que apresentou média de escores menores do que o grupo controle. Porém há que se ter cautela para considerar esses resultados, uma vez que havia viés de confundimento, pois as crianças estavam realizando acupuntura simultaneamente à intervenção musical (YU; LIU; MA, 2009).

Além disso, em um estudo que utilizou a EAPY-m para investigar o efeito de estímulos sensoriais (baixa luminosidade combinada com a audição de música clássica) no momento intra-operatório em crianças submetidas a cirurgias (KAIN et al, 2001), verificou-se significância na interação grupo-tempo, tal que o grupo que recebeu a intervenção de estímulos sensoriais apresentou menores escores em comparação ao grupo sem intervenção alguma. Da mesma forma, há certas restrições para comparar tal estudo com a pesquisa apresentada, pois há combinação simultânea de intervenções, além do momento cirúrgico ser diferente.

A significância encontrada nos escores de ansiedade relacionados à interação do grupo experimental com o tempo aponta que 15 minutos é um tempo efetivo de audição musical para reduzir a ansiedade em crianças no pré-operatório, dado novo nesse campo de pesquisa, já que há uma carência de estudos que apontam um tempo mínimo efetivo para a intervenção musical (FRANZOI; PAULA; MARTINS, 2013; BRADT; DILEO; SHIM, 2013; JOANNA BRIGGS INSTITUTE, 2011; PITTMAN; KRIDLI, 2011). Por outro lado, há que se destacar que houve uma grande perda de seguimento no grupo experimental pelo fato de muitas crianças não tolerarem a duração estipulada (15 minutos) para a intervenção.

Destacam-se os domínios de Atividade, Vocalização, Expressão emocional e Estado de despertar aparente, que apresentaram redução significativa da média de escores no grupo 
que ouviu músicas nos dois tempos. Não há muitos estudos que analisaram cada domínio e/ou categoria da EAPY-m diante de uma intervenção. Um estudo realizado no Irã, que avaliou o efeito da permanência de crianças em sala lúdica sobre o nível de ansiedade pré-operatória, encontrou diferença significativa entre os grupos em todos os domínios, sendo que o grupo que permaneceu na sala lúdica apresentou menor pontuação nos cinco domínios em comparação ao grupo que permaneceu na sala de espera (HOSSEINPOUR; MEMARZADEH, 2010).

Sobre os sinais vitais, a redução da frequência cardíaca de crianças escolares do grupo experimental, no tempo 2, em comparação aos participantes de idade pré-escolar pode ser atribuída a aspectos bio-fisiológicos, visto que é esperado que escolares apresentem menor frequência cardíaca que crianças em idade pré-escolar. Além disso, no tempo 2, a média de todos os sinais vitais reduziu em ambas as faixas etárias do GE, com exceção da frequência cardíaca dos pré-escolares que aumentou de 94,5 bpm para 96,63 bpm, o que não pode ser atribuído a uma possível influência da intervenção musical de aumentar a frequência cardíaca de crianças pré-escolares e de reduzir apenas a de crianças escolares, pois se assim o fosse, os demais sinais vitais deveriam refletir esse padrão segundo faixa etária.

Quanto à significância em relação à frequência respiratória, há indício de que a diminuição dessa no tempo 2 entre pré-escolares do grupo submetido à audição musical e préescolares do grupo controle $(\mathrm{p}=0,0453)$ esteja relacionada apenas à intervenção musical, fator diferencial entre os dois grupos.

No grupo controle, a constatação da frequência respiratória dos pré-escolares ser significativamente superior a das crianças escolares em ambos os tempos $(p=0,0312$ e $\mathrm{p}=0,0344$ ) pode indicar apenas uma evidência fisiológica, pois assim como em relação à frequência cardíaca, é esperado que os pré-escolares apresentem maior número de incursões respiratórias que as crianças em idade escolar. Todavia, não se pode desconsiderar também a influência, ou melhor, o efeito do cuidado padrão na sala de espera da clínica como um fator de confundimento em relação ao resultado identificado.

Houve dificuldades em comparar os achados referentes aos sinais vitais com outros estudos, pois não foi localizado estudo que tenha analisado a relação grupo, faixa etária e tempo em relação a esses dados. Pelo contrário, dentre os estudos realizados com população pediátrica e que encontraram significância em relação à frequência cardíaca, respiratória e/ou pressão arterial, a análise compreendeu participantes de 0 anos a 18 anos (HATEM; LIRA; MATTOS, 2006) ou 2 a 12 anos (YU; LIU; MA, 2010), que não foram categorizados por 
faixa etária, o que torna tais resultados inconclusivos, pois cada faixa etária apresenta uma média diferente para os parâmetros fisiológicos.

De toda forma, apesar desse estudo corroborar com a grande maioria dos estudos que não encontraram muitas evidências do efeito da música sobre os parâmetros vitais (BRADT; DILEO; SHIM, 2013; FRANZOI; PITTMAN; KRIDLI, 2011; JOANNA BRIGGS INSTITUTE, 2011), há de se ressaltar a análise estatística diferencial proposta, que considerou as diferentes médias de cada dado vital por faixa etária, apontando significância em relação à diminuição da frequência respiratória entre crianças em idade pré-escolar que ouviram músicas se comparado àquelas que não ouviram.

\subsection{Estado emocional dos acompanhantes}

O acompanhante pediátrico é uma figura importante para a criança em situação cirúrgica, pois implica em apoio emocional e afeto para ela, o que contribui para facilitar o processo de adaptação ao ambiente hospitalar e minimizar os medos e ansiedades da criança no pré-operatório (SAMPAIO et al, 2014; SAMPAIO et al 2009).

O acompanhante geralmente é uma pessoa de vínculo significativo com a criança, na maioria das vezes um membro da família, que se dispõe a cuidar e confortá-la no ambiente hospitalar. Entretanto, apesar dos acompanhantes ocuparem a posição de apoio para a criança em meio ao desconhecido e à ameaça que gera medos e ansiedade, eles também possuem seus próprios receios, medos, preocupações e outros sentimentos relacionados ao evento cirúrgico de suas crianças, o que nem sempre é considerado no plano de cuidados da equipe de saúde (SAMPAIO et al, 2009).

Dessa forma, é importante que o cuidado esteja focado na criança e na família, até porque o estado emocional dos acompanhantes pode influenciar diretamente o estado de ansiedade pré-operatória da criança (CUMINO et al, 2013; MAGALHÃES; GUSMAM; GRECCA, 2010).

Apesar de não ter sido o objetivo principal desse estudo, foi realizada uma breve investigação sobre o estado emocional referido pelos acompanhantes a fim de relacioná-lo ao estado de ansiedade das crianças. Como se tratou de um objetivo secundário, não foi aplicado qualquer instrumento validado de auto relato para mensuração de ansiedade ou medo dos acompanhantes; apenas realizou-se perguntas semiestruturadas.

Os sentimentos relatados foram categorizados em estado de tranquilidade ou aflição. O estado de tranquilidade, menos de $35 \%$ do estado referido pelos acompanhantes nos grupos, foi composto por sentimentos de segurança, esperança e calma associados a experiências de 
cirurgias prévias, orientações dadas pelos profissionais e à fé em Deus. O sentimento de esperança e fé também foi verificado em outro estudo em que os acompanhantes demonstraram tranquilidade em seu discurso relacionado ao apego à figura de um ser superior (SAMPAIO et al, 2009). De fato, muitos estudos apontam que acreditar em um ser superior e sobrenatural auxilia as pessoas a enfrentarem positivamente suas incertezas e sensação de impotência diante de situações estressantes com a doença, hospitalização e a cirurgia (GOMES et al, 2011; BOUSSO; SERAFIM; MISKO, 2010).

Quanto ao estado de aflição, estado referido por $65,4 \%$ no grupo controle e $73 \%$ no grupo experimental, compreendeu sentimentos de preocupação, medo, apreensão e nervosismo relacionados à anestesia, cirurgia, recuperação pós-operatória, cuidados com a ferida operatória, falta de orientação/informação e medo da morte. Esses sentimentos relatados corroboram com os resultados de um estudo que investigou sentimentos dos acompanhantes de crianças em situação cirúrgica (SAMPAIO et al, 2009) e com outro estudo que investigou o estado emocional de pacientes adultos submetidos a cirurgias cardíacas (VARGAS; MAIA; DANTAS, 2006). Além disso, o intenso estado de aflição manifestado por seis mães que choraram durante a entrevista também foi verificado no estudo de Sampaio et al (2009).

O medo relacionado à falta de orientação médica sobre a anestesia e/ou procedimento cirúrgico esteve presente em muitas falas dos acompanhantes, que referiram sentimentos de aflição. De fato, a informação e orientação sobre o processo cirúrgico, dirigida aos acompanhantes pediátricos é muito importante, pois eles também estão emocionalmente fragilizados e possuem seus temores diante do que lhes é desconhecido. Kain et al (2007), por exemplo, demonstraram que os pais que participaram de um programa educacional sobre o processo cirúrgico e anestésico apresentaram menores níveis de ansiedade no período préoperatório. Outro estudo, que avaliou o nível de ansiedade dos acompanhantes de crianças em cirurgia ambulatorial, verificou que os pais que receberam orientações sobre o procedimento cirúrgico em consulta de enfermagem apresentaram menor nível de ansiedade comparado aos que não receberam informações (SAMPAIO et al, 2014).

Alguns pais ainda referiram sentimentos contraditórios ao afirmarem que estavam tranquilos, mas que se sentiam ao mesmo tempo apreensivos, preocupados ou um pouco ansiosos com a cirurgia. Tal fato corrobora com outro estudo que investigou os sentimentos de pacientes adultos no pré-operatório, identificando que alguns pacientes referiam sentimento de medo/aflição, mas ao mesmo tempo o negavam em seu discurso (VARGAS; MAIA; DANTAS, 2006). Além disso, três acompanhantes apenas referiram expressamente 
terem medo que a criança morresse; outros utilizaram-se de eufemismo para se expressaram ao dizerem que tinham medo do filho não acordar ou de não voltar da anestesia.

O medo da morte nem sempre é verbalizado claramente pelos familiares. Dois estudos verificaram que nem todos os familiares conseguem dizer expressamente a palavra morte em relação ao sentimentos e temores que vivenciam diante da situação de parentes internados, utilizando-se muitas vezes de expressões sutis ou até mesmo negando o medo da morte com temor de que ao falarem tal fato fosse concretizado (URIZZI; CORREAA, 2007; LAMY; GOMES; CARVALHO, 1997).

Falar da morte ou mesmo do risco de morte, ainda mais de uma criança não é algo fácil, pois na cultura ocidental há a concepção de que a morte ocorre na impessoalidade e é previsível/aceita apenas na velhice. É impessoal, pois sempre ocorre com o outro, alguém desconhecido ou às vezes até relativamente próximo de uma determinada pessoa, porém quase não é considerada como um acontecimento possível de ocorrer a essa pessoa ou com seu filho (URIZZI; CORRÊA, 2007). Além disso, a morte de uma criança é muito difícil de ser aceita, pois implica na interrupção de um ciclo biológico de vida que esbarra, por sua vez, com o imaginário cultural idealizado de que cada criança tem um futuro pela frente para crescer e desenvolver-se, diferentemente de um idoso, que já vivenciou todos os ciclos da vida - nascimento, crescimento, desenvolvimento, envelhecimento, sendo a morte já esperada e aceita como uma conclusão do ciclo da vida (KUSTER; BISOGNO, 2010).

Por fim, as indagações de alguns pais se poderiam ouvir músicas também ratifica ainda mais a importância de propor intervenções de enfermagem que visem reduzir os anseios e medos dos acompanhantes pediátricos, não somente por meio de intervenções instrucionais, mas também das complementares e integrativas como a música. Algumas pesquisas têm sido desenvolvidas nessa área, exemplo disso é o estudo de Almeida (2010) que investigou o efeito do canto gregoriano sobre o estado de ansiedade de mães de crianças hospitalizadas. Porém, há uma carência de estudos publicados que avaliaram a eficácia da intervenção musical no pré-operatório para reduzir a ansiedade da criança e do acompanhante de forma simultânea, com exceção do estudo de Millett (2015) publicado recentemente nos Estados Unidos da América.

\subsection{Limitações do estudo e implicações para pesquisa e prática clínica de}

\section{enfermagem}

Dentre as limitações desse estudo, há que se destacar o fato do instrumento utilizado para mensurar o nível da ansiedade dos participantes ser um instrumento observacional e da 
equipe de pesquisa que o aplicou não ter sido cegada/mascarada para a condição experimental, ou seja, a equipe sabia quais crianças eram do grupo controle e quais do grupo experimental. Tal fato aponta para a possibilidade de viés de aferição ou de medição diferencial, que ocorre quando os participantes de um dos grupos investigados apresentam maior chance de ter detectado um desfecho clínico (NEWMAN et al, 2008; FLETCHER; FLETCHER, 2006). No caso dessa pesquisa, o fato das avaliadoras não terem sido cegadas pode ter influenciado a maneira como a manifestação comportamental de ansiedade foi observada e avaliada em relação a cada grupo.

Fletcher \& Fletcher (2006) apontam que, para minimizar o viés de aferição, é importante garantir que avaliadores e participantes desconheçam os grupos intervenção e controle; estabelecer critérios/regras bem definidas sobre o desfecho estudado; e despender igual esforço e curiosidade para identificar os desfechos em ambos os grupos estudados.

$\mathrm{Na}$ tentativa de reduzir esse viés, foram realizados treinamentos prévios com as auxiliares de pesquisa para alinhar e definir critérios em relação à aplicação da EAPY-m. Vale ressaltar também que, durante a coleta, as auxiliares foram acompanhadas a todo momento pela pesquisadora responsável, com quem discutiam possíveis divergências e dúvidas. Destaca-se, ainda, o comprometimento da pesquisadora em ter adotado, pelo menos conscientemente, uma postura imparcial em todo o processo da pesquisa. Dessa forma, verifica-se que dois dos três modos sugeridos por Fletcher \& Fletcher (2006) para reduzir o viés de aferição foram atendidos, já que, como dito anteriormente, não foi possível cegar a equipe envolvida na coleta de dados.

De fato, nem sempre é possível realizar o mascaramento de avaliadores em estudos de intervenções não-farmacológicas, principalmente se envolver o uso de instrumentos de medidas subjetivas como a a EAPY-m. Em revisão sistemática da Cochrane, apenas 11,5\% dos estudos que envolviam avaliação de medidas subjetivas de ansiedade referiram que os avaliadores foram cegados em relação à intervenção musical (BRADT; DILEO; SHIM, 2013). Um deles utilizou-se de um mascaramento com fones e CD's em branco para o grupo controle, o que não permitia que os avaliadores identificassem o grupo para o qual a criança havia sido alocada (GANIDAGLI et al, 2005). Outro, por sua vez, contou com uma equipe grande de pesquisa, inclusive com assistentes administrativos, o que viabilizou o mascaramento dos avaliadores (ALLEN et al, 2001).

O mascaramento dos participantes também é um grande desafio nos estudos sobre a intervenção musical, o que foi possível realizar com êxito nesta pesquisa. Dos vinte e seis 
estudos incluídos nessa mesma revisão da Cochrane, apenas três relataram mascaramento dos participantes por meio da estratégia do CD em branco (BRADT; DILEO; SHIM, 2013).

Particularmente, no contexto de pesquisas com crianças que utilizaram a música com intervenção, há poucos relatos de estratégias de mascaramento. Em uma pesquisa sobre o efeito terapêutico da música em crianças em pós-operatório de cirurgia cardíaca, os participantes do grupo controle foram submetidos a uma intervenção placebo, que consistia na "audição" de um CD branco - sem música alguma (HATEM; LIRA; MATTOS, 2006). Ocorreu, entretanto, que algumas crianças se recusaram a participar do estudo, pois acreditavam que o aparelho de CD player estava quebrado, já que não ouviram nenhuma música. Essa opção proposta parece ser inadequada, pois não considerou o grau cognitivo da criança para julgamento.

Em um estudo sobre o efeito da música na ansiedade pré-operatória de homens submetidos a cirurgias urogenitais, os pesquisadores utilizaram-se de uma alternativa muito interessante para cegar os participantes. No caso, todos os participantes ouviram música, inclusive os do grupo-controle, que também experienciaram a audição musical, mas isso somente após a coleta de dados propriamente dita (depois de decorridos 30 minutos sem intervenção alguma e da segunda aplicação do instrumento para avaliar a ansiedade). Dessa forma, esses homens não sabiam que pertenciam ao grupo-controle, que não foi submetido à intervenção musical para efeito de aferição dos dados, apesar de terem ouvido música em um segundo momento (ARSLAN; ÖZER; ÖZYURT, 2008).

Diante dessas leituras, decidiu-se adaptar a estratégia desses autores australianos para mascarar as crianças que participaram desta pesquisa. A experiência foi exitosa, pois as crianças não sabiam a que grupo pertenciam, porém exigiu tempo maior com o grupo-controle após a coleta de dados.

Vale ressaltar que, mesmo diante das dificuldades de mascaramento em ensaios com intervenção não-farmacológicas, essa pesquisa classifica-se como um estudo duplo-cego, pois não só os participantes foram cegados, como também a equipe estatística em relação aos dados que se referiam aos grupo controle e experimental.

Sobre a alocação, apesar dos participantes serem randomizadas por meio de uma lista gerada no computador, a dissimulação da alocação dos participantes - estratégias que impedem que os pesquisadores conheçam antecipadamente as futuras designações, depois de ser gerada a sequência aleatória dos participantes - não foi realizada por meio de envelopes opacos lacrados, conforme recomendações do CONSORT e outras bibliografias de metodologia de pesquisa clínica (CUMMINGS; GRADY; HULLEY, 2008; SCHULZ, 2010). 
A alocação dos participantes ocorreu mediante a disponibilidade e receptividade dos sujeitos elegíveis, sendo as crianças escolares priorizadas pela pesquisadora, uma vez que as cirurgias eram realizadas por ordem crescente de idade, ou seja, os escolares eram sempre os últimos a serem operados e a receberem sedativo.

Outra limitação consistiu no fato de o grupo controle não ter sido submetido a um cuidado padronizado/constante ao longo da pesquisa, o que aponta para um viés de confundimento, já que o grupo controle apresentou variações no padrão de cuidado. Às vezes havia brinquedos e desenhos para colorir na sala de espera, em outros dias havia televisão, e ainda em outros, nada era oferecido/disponibilizado às crianças. Sabe-se que ao promover a ambiência em unidades de pediatria com brinquedos, jogos, livros para colorir e televisão, a criança adapta-se melhor ao meio, e apresenta menor ansiedade e medo relacionados ao processo de hospitalização e de realização de procedimento médicos (CUMINO et al, 2013; WEBER, 2010; CARVALHO; BEGNIS, 2006). Dessa forma, nos dias em que não havia nenhum atrativo na sala de espera, havia a possibilidade da ansiedade das crianças do grupo controle ser maior do que das crianças que estiveram na condição da sala com ofertas de brinquedos ou televisão. Infelizmente não foi possível analisar esse viés, pois a pesquisadora não discriminou essas alterações por dia durante o período da coleta de dados.

O tamanho amostral limitado $(\mathrm{n}=52)$ também pode ter influenciado na análise estatística e na validade externa dos resultados, pois amostras aleatórias maiores viabilizam que diferenças nos resultados sejam detectadas estatisticamente, enquanto que, em amostras muito pequenas, as diferenças nem sempre são observadas (THOMPSON, 2010).

Exemplo disso são os resultados oriundos da análise das crianças com e sem ansiedade de ambos os grupos nos dois momentos de avaliação, que apesar de não ter sido significativa, observou-se que, no tempo 2, o p-valor foi 0,0850, valor próximo ao limite de significância de $5 \%$ e que pode ter sido limitado pelo tamanho da amostra. Somado à isso, apesar do intervalo de confiança para Odds Ratio conter o número 1, a sua amplitude não é grande, o que gera indícios de que, se a diferença fosse estatisticamente significante, pertencer ao grupo da audição musical diminuiria as chances da criança ser ansiosa no tempo 2 , uma vez que a Odds Ratio calculada foi de 0,35 .

De toda forma, não se pode esquecer que essa pesquisa consistiu em um estudo-piloto para fornecer estimativas de variância e correlação das variáveis-desfecho da população-alvo, diante da carência de estudos semelhantes a esse.

Ainda destaca-se a relevância dessa pesquisa, visto que nenhum estudo de caráter experimental como esse foi identificado até o momento no contexto brasileiro, com o objetivo 
de investigar o efeito da audição musical sobre a ansiedade pré-operatória de crianças préescolares e escolares.

Diante de tantas desistências de crianças do grupo experimental por conta do gênero musical selecionado e duração da intervenção, esse estudo aponta a necessidade de novas pesquisas que considerem ou até mesmo comparem a seleção de músicas sedativas às preferências das crianças, bem como de estudos que investiguem os efeitos da audição musical com duração inferior a 15 minutos.

As perdas de seguimento decorrentes das questões de rotina da clínica, onde foi realizada a pesquisa, apontam para a necessidade de ensaios com delineamentos híbridos, com vistas a identificar melhor as interações entre a intervenção musical e a implementação dessa na prática clínica.

Além disso, os questionamentos de alguns pais se participariam da pesquisa ouvindo músicas também apontam para a necessidade de se propor intervenções de enfermagem que visem reduzir os anseios e medos dos acompanhantes pediátricos, não somente por meio intervenções instrucionais, mas também das complementares e integrativas, como a música, e por que não de estudos que avaliem a efetividade da intervenção musical simultaneamente sobre a ansiedade de crianças e acompanhantes?

Apesar das limitações, esse estudo foi conduzido com rigor metodológico e relatado com base nas diretrizes do CONSORT, o que viabiliza a replicação do estudo e o uso dos resultados encontrados em futuras revisões sistemáticas.

Por fim, essa pesquisa pode contribuir na produção de evidências relativas à intervenção musical aplicada à criança em situação cirúrgica, porém como na maioria das investigações científicas, a questão de pesquisa não somente foi respondida como gerou novos questionamentos e aspectos a serem investigados em futuras pesquisas, a saber:

a) A audição de músicas de preferência de crianças submetidas a cirurgias eletivas, independentemente de apresentarem características sedativas ou não, aplicadas por um período inferior a 15 minutos, seria efetiva na redução da ansiedade pré-operatória?

b) Qual o impacto real de ensaios clínicos híbridos na implementação da intervenção musical na prática hospitalar?

c) Qual seria o efeito tanto na criança como no acompanhante se a audição musical fosse disponibilizada simultaneamente a ambos? 


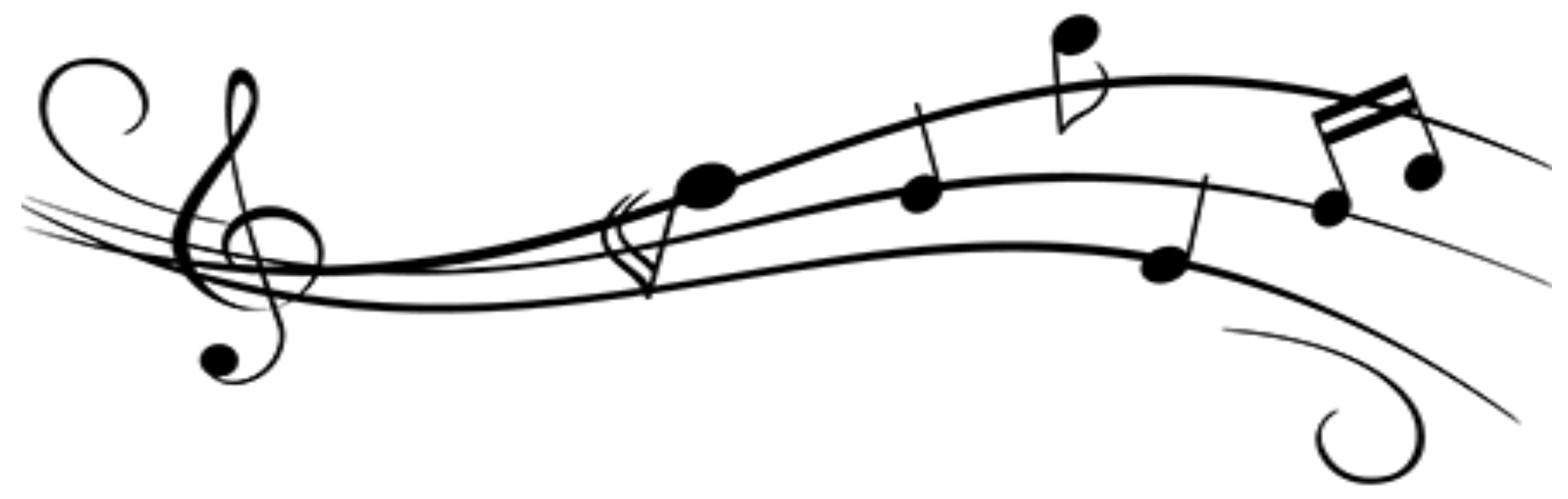

8. CONCLUSÃO 


\section{Conclusão}

A hipótese de que o efeito da audição musical na redução da ansiedade pré-operatória de crianças pré-escolares e escolares seja superior ao cuidado padrão oferecido em uma clínica pediátrica não foi comprovada, pois não se verificou diferença estatisticamente significante entre os grupos experimental e controle em relação às variáveis de ansiedade e sinais vitais.

Entretanto, houve redução estatisticamente significativa nos escores de ansiedade relacionada à interação do grupo submetido à audição musical com o tempo, sugerindo que 15 minutos é um tempo efetivo para reduzir a ansiedade em crianças no período pré-operatório.

Além do mais, apesar de não ter sido identificada diferença estatisticamente significativa na maioria dos sinais vitais avaliados, verificou-se que a audição musical contribuiu para reduzir a frequência respiratória de crianças na idade pré-escolar que ouviram músicas em comparação àquelas que apenas receberam os cuidados da clínica cirúrgica.

Também foi verificado que a maioria dos acompanhantes das crianças referiu sentir medo, nervosismo, ansiedade e preocupação em relação ao processo cirúrgico, o que aponta para a necessidade de incluir a família no contexto do cuidado da criança em situação cirúrgica, principalmente em relação a informações/orientações sobre o evento anestésico.

Por fim, vale destacar que esse estudo suscitou novas questões de pesquisa relacionadas ao tema da intervenção musical no contexto pediátrico, o que é muito pertinente na jornada interminável pelo saber, pois como disse a poeta polonesa Wislawa Szymborska: "Todo conhecimento que não leva a novas perguntas rapidamente morre: não consegue manter a temperatura necessária para a manutenção da vida”. 


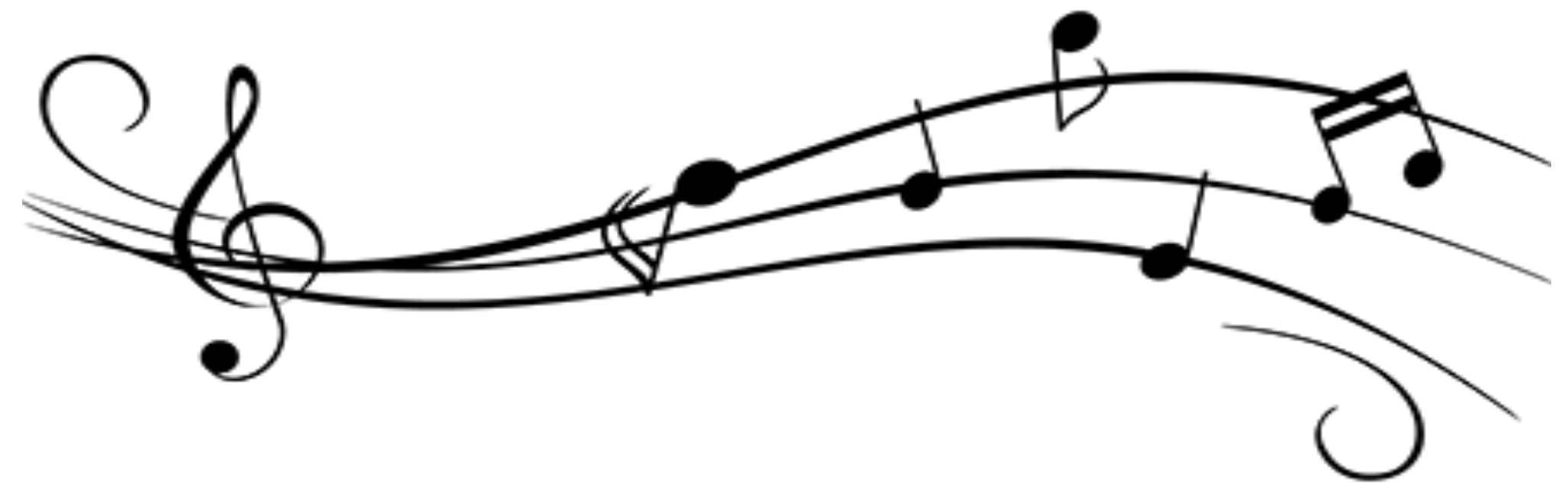

9. REFERÊNCIAS 
AHMED, M.T. et al. Preoperative anxiety in children: risk factors and non-pharmacological management. Middle East Journal of Anaesthesiology, Beirut, v. 21, n. 2, p. 153-164, jun. 2011.

ALLEN, K. et al. Normalization of hypertensive responses during ambulatory surgical stress by perioperative music. Psychosomatic Medicine, New York, v. 63, n. 3, p. 487-492, may./jun. 2001.

ALMEIDA, A. P. Canto gregoriano como redutor de ansiedade das mães de crianças hospitalizadas: estratégia para a enfermagem. 2010. 104 f. Dissertação (Mestrado em Enfermagem) - Escola de Enfermagem, Universidade de São Paulo, 2010.

ALMEIDA, A. P.; CASTRO, A. V. A Enfermagem e a Música: duas artes para refletir o cuidar na pediatria. Revista Nursing, São Paulo, v. 12, n. 142, p. 136-140, 2010.

ALVES, A. J. G. Estratégias de Enfermagem que contribuem para a diminuição da ansiedade da criança no pré-operatório de cirurgia programada. 2010. Trabalho de Conclusão de Curso (Licenciatura em Enfermagem) - Faculdade de Ciências da Saúde, Universidade Fernando Pessoa, Porto, 2010.

ARSLAN, S.; ÖZER, N.; ÖZYURT, F. Effect of music on preoperative anxiety in men undergoing urogenital surgery. Australian Journal of Advanced Nursing, Melbourne, v. 26, n. 2, p. 46-54, 2008.

BALEY, B. J.; JOHNSON, J. T. Otorrinolaringologia pediátrica: cirurgia de cabeça e pescoço. 4. ed. Tradução: Raymundo Martagão Gesteira. Rio de Janeiro: Revinter, 2009. v. 3. 388 p.

BERNET, A. C.; WILLENS, D. E.; BAUER, M. S. Effectiveness-implementation hybrid designs: implications for quality improvement science. Implementation Science, London, v. 8 (supl 1), p. 1-2; 2013.

BORTOLOTE, G. S.; BRÊTAS, J. R. S. O ambiente estimulador ao desenvolvimento da criança hospitalizada. Revista da Escola de Enfermagem da USP, São Paulo, v. 42, n. 3, p. 422-429, 2008.

BOUSSO, R. S.; SERAFIM, T. S.; MISKO, M. D. Histórias de vida de familiares de crianças com doenças graves: relação entre religião, doença e morte. Revista Latino-Americana de Enfermagem, São Paulo, v. 18, n. 2, p. 11-17, mar./abr. 2010.

BOUTRON, I. et al. Extending the CONSORT Statement to randomized trials of nonpharmacologic treatment: explanation and elaboration. Annals of Internal Medicine, Philadelphia, v. 148, n. 4, p. 295-309, feb. 2008.

BRADT, J.; DILEO, C.; SHIM, M. Music interventions for preoperative anxiety (Review). The Cochrane database of systematic reviews, Oxford, v. 6, n. 6, p. 1-81, jun. 2013.

BRASIL. Ministério da Saúde. Conselho Nacional de Saúde. Resolução no 196, de 10 de outubro de 1996. Aprova as diretrizes e normas regulamentadoras de pesquisas envolvendo seres humanos. Diário Oficial da União, Brasília, DF, 16 out. 1996. Seção 1, p. 2108221085. 
. Ministério da Saúde. Secretaria-Executiva. Núcleo Técnico da Política Nacional de Humanização. HumanizaSUS: Política Nacional de Humanização: a humanização como eixo norteador das práticas de atenção e gestão em todas as instâncias do SUS. Brasília: Ministério da Saúde, 2004. 20 p. (Série B. Textos Básicos de Saúde).

. Ministério da Saúde. Secretaria de Atenção à Saúde. Núcleo Técnico da Política Nacional de Humanização. Ambiência. 2. ed. Brasília: Ministério da Saúde, 2010. 32 p. (Série B. Textos Básicos de Saúde).

. Ministério da Saúde. Conselho Nacional de Saúde. Resolução no 466, de 12 de dezembro de 2012. Aprova as diretrizes e normas regulamentadoras de pesquisas envolvendo seres humanos. Diário Oficial da União, Brasília, DF, 13 jun. 2013. Seção 1, p. 59-62.

. Ministério da Saúde. Política Nacional de Humanização. 1. ed. Brasília: Ministério de Saúde, 2013.

Presidência da República. Casa Civil. Subchefia para Assuntos Jurídicos. $\overline{\text { Mensagem n }}^{\circ}$ 832, de 29 de outubro de 2008. Decide vetar o PL n ${ }^{\circ}$ 25/2005 (PL n ${ }^{\circ}$ 4827/01 na Câmara dos Deputados), que dispõe sobre a regulamentação do exercício da profissão de Musicoterapeuta. Diário Oficial da União, Brasília, DF, 30 out. 2008. Seção 1, p. 11.

BRÉSCIA, V. L. P. Educação musical: bases psicológicas e ação preventiva. 2. ed. Campinas, SP: Editora Átomo, 2011. 145p.

BROERING, C. V.; CREPALDI, M. A. Percepções das mães sobre a preparação précirúrgica de seus filhos segundo dois modelos. Psicologia Argumento, Curitiba, v. 29, n. 66, p. 327-341, jul./set. 2011a.

BROERING, C. V.; CREPALDI, M. A. Preparação psicológica para a cirurgia em pediatria: importância, técnicas e limitações. Paidéia, Ribeirão Preto, v. 18, n. 39, p. 61-79, 2008.

BROERING, C. V.; CREPALDI, M. A. Preparação psicológica e o estresse de crianças submetidas a cirurgias. Psicologia em Estudo, Maringá, v. 16, n. 1, p. 15-23, jan./mar. $2011 b$.

BUSSOTTI, EA; TRAJANO, C; VENDRAMIM, P. A música e a criança hospitalizada. In: LEÃO, E. R. (Org.). Cuidar de pessoas e música: uma visão multiprofissional. São Caetano do Sul, SP: Yendis Editora, 2009. p. 109-126.

CAIRES, S.; ESTEVES, C. H.; ALMEIDA, I. Palhaços de hospital como estratégia de amenização da experiência de hospitalização infantil. Psico-USF, Bragança Paulista, v. 19, n. 3, p. 377-386, set./dez. 2014.

CARVALHO, A. M.; BEGNIS, J. G. Brincar em unidades de atendimento pediátrico: aplicações e perspectivas. Psicologia em Estudo, Maringá, v. 11, n. 1, p. 109-117, jan./abr. 2006.

CASTRO, R. C. F. Registros de ensaios clínicos e as consequências para as publicações científicas. Medicina, Ribeirão Preto, v. 42, n. 1, p. 31-35, 2009.

COLLET, N.; OLIVEIRA, R.; VIERA, C. A criança e a hospitalização. In: Manual de Enfermagem em pediatria. 2. ed. Goiânia: AB, 2010a. p. 49-107 . 
COLLET, N.; OLIVEIRA, R.; VIERA, C. Patologias Cirúrgicas mais frequentes na criança. In: . Manual de Enfermagem em pediatria. 2. ed. Goiânia: AB, 2010b. p.507-524.

CONSELHO FEDERAL DE PSICOLOGIA. Define e regulamenta o uso, a elaboração e a comercialização de testes psicológicos e revoga a Resolução CFP n ${ }^{0}$ 025/2001. Resolução $n$. 002, de 24 de março de 2003a.

CONSELHO FEDERAL DE PSICOLOGIA. Altera a Resolução CFP $n^{0}$ 002/2003, que define e regulamenta o uso, a elaboração e a comercialização de testes psicológicos. Resolução n. 005, de 08 de março de 2012.

CONSELHO FEDERAL DE PSICOLOGIA. Teste psicológico: Inventário de Ansiedade Traço-Estado, formas C-I e C-II/DATE-C. Parecer CFP, de 28 de junho de 2003b.

CONSELHO REGIONAL DE ENFERMAGEM DE SÃO PAULO. Musicoterapia. Parecer n. 025, de 14 de junho de 2010.

CULLUM, N. et al. Introdução à enfermagem baseada em evidências. In:

Enfermagem baseada em evidências: uma introdução. Tradução de Ana Thorell. Porto Alegre: Artmed, 2010. p. 23-31.

CUMINO, D. O. et al. Impacto do tipo de informação pré-anestésica sobre a ansiedade dos pais e das crianças. Revista Brasileira de Anestesiologia, Rio de Janeiro, v. 63, n. 6, p. 473 $482,2013$.

CUMMINGS, S. R.; GRADY, D.; HULlEY, S. B. Delineando um ensaio clínico randomizado cego. In: HULLEY, S. B. et al. Delineando a pesquisa clínica: uma abordagem epidemiológica. 3. ed. Tradução: Michael Schmidt Duncan. Porto Alegre Artmed, 2008. p. 165-180.

CURRAN, G. M. et al. Effectiveness-implementation hybrid designs: combining elements of clinical effectiveness and implementation research to enhance public health impact. Medical Care, Philadelphia, v. 50, n. 3, p. 217-226, mar. 2012.

CUZZOCREA, F. et al. Psychologists in preoperative programmes for children undergoing surgery. Journal of Child Health Care: for professionals working with children in the hospital and community, London, dec. 2014.

DAVIS, W.; HADLEY, S. A History of Music Therapy. In: WHEELER, B. L (Ed.). Music Therapy Handbook. New York: The Guilford Press, 2015. p. 17-28.

DILEO, C. Introduction to Music Therapy and Medicine: definitions, theoretical orientations and levels of practice. In: Music Therapy \& Medicine: theoretical and clinical applications. Silver Spring: The American Music Therapy Association, 1999. p. 4-10.

DOANE, D. P.; SEWARD, L. E. Distribuições amostrais e estimação. In: Estatística aplicada à administração e economia. 4. ed. Nova Iorque: McGraw-Hill, 2014. p. 290-335.

DOBBRO, ERL. A música como terapia complementar no cuidado de mulheres com fibromialgia. 1998. 153 f. Dissertação (Mestrado) - Escola de Enfermagem, Universidade de São Paulo, São Paulo, 1998. 
DOCHTERMAN, J. McC.; BULECHEK, G. M. (Org.). Classificação das intervenções de enfermagem (NIC). Tradução: Regina Machado Garcez. 4. ed. Porto Alegre: Artmed, 2008, p. 516-517.

ENGWALL, M.; DUPPILS, G. S. Music as a nursing intervention for postoperative pain: a systematic review. Journal of Perianesthesia Nursing, Philadelphia, v. 24, n. 6, p. 370-383, dec. 2009.

FERREIRA, C. C. M; REMEDI, P. P.; LIMA, R. A. G. L. A música como recurso no cuidado à criança hospitalizada: uma intervenção possível? Revista Brasileira de Enfermagem, Brasília, v. 59, n. 5, p. 689-693, set./out. 2006.

FLEMMING, K. Perguntas passíveis de respostas. In: CULLUM, N. et al (Org.). Enfermagem baseada em evidências: uma introdução. Tradução de Ana Thorell. Porto Alegre: Artmed, 2010. p. 42-48.

FLETCHER, R. H.; FLETCHER, S. W. Epidemiologia Clínica: Elementos Essenciais. 4. ed. Porto Alegre: Artmed, 2006. 288p.

FONTELLES, M. J., et al. Metodologia da pesquisa: Diretrizes para o cálculo do tamanho da amostra. Revista Paraense de Medicina, Paraná, v. 21, n. 2, p. 57-64, abr./jun. 2010.

FRANZOI, M. A. H.; PAULA, E. S.; MARTINS, G. Intervenção musical aplicada à criança e ao adolescente em situação cirúrgica: revisão sistemática. Revista de Enfermagem UFPE On Line [Internet], Pernambuco, v. 7, n. (esp), p. 5645-5655, set. 2013.

GAIVA, M. A. M. Pesquisa envolvendo crianças: aspectos éticos. Revista Bioética, Brasília, v. 17, n. 1, p. 135-146, 2009.

GANIDAGLI, S. et al. The effect of music on preoperative sedation and the bispectral index. Anesthesia and Analgesia, Baltimore, v. 101, n. 1, p. 103-106, jul. 2005.

GAO, X. L. et al. Effect of interesting games on relief of preoperative anxiety in preschool children. International Journal of Nursing Sciences, v. 1, n. 1, p. 89-92, mar. 2014.

GHETTI, C. M. Music therapy and music-based interventions for surgery, medical procedures and examinations. Journal Medical Music Therapy, v. 7, p. 1-10, 2014.

GILLEN, E.; BILEY, F.; ALLEN, D. Effects of music listening on adult patients preprocedural state anxiety in hospital. Internacional Journal of Evidence-Based Healthcare, Sydney, v.6, n. 1, p. 24-49, mar./2008.

GOLAN, G. et al. Clowns for the prevention of preoperative anxiety in children: a randomized controlled trial. Paediatric Anaesthesia, Paris, v. 19, n. 3, p. 262-266, mar. 2009.

GOMES, G. C. et al. O apoio social ao familiar cuidador durante a internação hospitalar da criança. Revista Enfermagem UERJ, Rio de Janeiro, v. 19, n. 1, p. 64-69, jan./mar. 2011.

GARANHANI, M. L.; VALLE, E. R. M. O significado da experiência cirúrgica para a criança. Ciência, Cuidado e Saúde (online), Maringá, v. 11, p. 259-266, 2012. 
GUARATINI, A. A. et al. Estudo Transversal de Ansiedade Pré-Operatória em Crianças: Utilização da Escala de Yale Modificada. Revista Brasileira de Anestesiologia, Rio de Janeiro, v. 56, n. 6, p. 591-601, nov./dez. 2006.

HATEM, T. P.; LIRA, P. I. C.; MATTOS, S. S. Efeito terapêutico da música em crianças no pós-operatório de cirurgia cardíaca. Jornal de Pediatria, Porto Alegre, v. 82, n. 3, p. 186192, 2006.

HOCKENBERRY, M. J.; WILSON, D. Wong: Fundamentos de Enfermagem Pediátrica. Tradução: Maria Inês Corrêa Nascimento et al. 8. ed. Rio de Janeiro: Elsevier, 2011. 1280 p.

HOSSEINPOUR, M.; MEMARZADEH, M. Use of a preoperative playroom to prepare children for surgery. European Journal of Pediatric Surgery, Paris, v. 20, n. 6, p. 408-411, nov. 2010.

HUFF, L. et al. Atraumatic care: EMLA cream and application of heat to facilitate peripheral venous cannulation in children. Issues in Comprehensive Pediatric Nursing, New York, v. 32 , n. 2, p. 65-76, 2009.

JAHROMI, S. A. H. et al. Comparison of the effects of intranasal midazolam versus different doses of intranasal ketamine on reducing preoperative pediatric anxiety: a prospective randomized clinical trial. Journal of Anesthesia, Japan, v. 26, n. 6, p. 878-882. 2012.

JENKINS, B. N. et al. Development of a short version of the Modified Yale Preoperative Anxiety Scale. Anesthesia and Analgesia, Baltimore, v. 119, n. 3, p. 643-650, sep. 2014.

JESUS, L. E. et al. Formação e demanda do cirurgião pediátrico no Brasil. Revista do Colégio Brasileiro de Cirurgiões, Rio de Janeiro, v. 36, n. 4, p. 356-361, 2009.

JIANG, J. et al. The effects of sedative and stimulative music on stress reduction depend on music preference. The Arts in Psychotherapy, v. 40, n. 2, p. 201-205, apr. 2013.

JOANNA BRIGGS INSTITUTE (JBI). The Joanna Briggs Institute Best Practice Information Sheet: Music as an intervention in hospitals. Nursing and Health Science, Melbourne, v. 13, p. 99-102, mar. 2011.

JUSTUS, R. et al. Preparing children and families for surgery: Mount Sinai's multidisciplinary perspective. Pediatric Nursing, New Jersey, v. 32, n. 1, p. 35-43, jan./feb. 2006.

KAIN, Z. N. et al. Measurement too for preoperative anxiety in young children: The Yale Preoperative Anxiety Scale. Child Neuropsychology, London, v. 1, n. 3, p. 203-210, 1995.

KAIN, Z. N. et al. The Yale Preoperative Anxiety Scale: How does it compare with a "gold standard"? Anesthesia and Analgesia, Baltimore, v. 85, n. 4, p. 783-788, oct. 1997.

KAIN, Z. N. et al. Sensory stimuli and anxiety in children undergoing surgery: a randomized, controlled trial. Anesthesia and Analgesia, Baltimore, v. 92, n. 4, p. 897-903, apr. 2001.

KAIN, Z. N. et al. Interactive music therapy as a treatment for preoperative anxiety in children: a randomized controlled trial. Anesthesia and Analgesia, Baltimore, v. 98, n. 5, p. 1260-1266, may. 2004. 
KAIN, Z. N. et al. Family-centered preparation for surgery improves perioperative outcomes in children: a randomized controlled trial. Anesthesiology, Philadelphia, v. 106, n. 1, p. 6574, jan. 2007.

KARINO, M. E.; FELLI, V. E. A. Enfermagem baseada em evidências: avanços e inovações em revisões sistemáticas. Ciência, Cuidado e Saúde, Maringá, v. 1, (suplem.), p. 11-15, 2012.

KLASSEN, J. A. et al. Music for pain and anxiety in children undergoing medical procedures: a systematic review of randomized controlled trials. Ambulatory Pediatrics, New York, v. 8, n. 2, p. 117-128, mar./apr. 2008.

KUSTER, D. K.; BISOGNO, S. B. C. A percepção do enfermeiro diante da morte dos pacientes. Disciplinarum Scientia, Santa Maria, v. 11, n. 1, p. 9-24, 2010.

LACERDA, R. A. et al. Práticas baseadas em evidências publicadas no Brasil: identificação e análise de suas vertentes e abordagens metodológicas. Revista da Escola de Enfermagem da USP, São Paulo, v. 45, n. 3, p. 777-786, 2011.

LAMY, Z. C.; GOMES, R.; CARVALHO, M. A percepção de pais sobre a internação de seus filhos em unidade de terapia intensiva neonatal. Jornal de Pediatria, Porto Alegre, v. 73, n. 5, p. 293-298, 1997.

LEÃO, E. R. Por uma compreensão e inserção da música no cuidar. In: Cuidar de pessoas e música: uma visão multiprofissional. São Caetano do Sul, SP: Yendis Editora, 2009. p. 347-368.

LEÃO, E. R.; BUSSOTTI, E. A.; AQUINO, C. R. Uma canção no cuidar de si e do outro. In: LEÃO, E. R. (Org.). Cuidar de pessoas e música: uma visão multiprofissional. São Caetano do Sul, SP: Yendis Editora, 2009. p. 321-346.

LEÃO, E. R. et al. Música e Enfermagem: um recurso integrativo. In: SALLES, L. F.; SILVA, M. J. P. (Org.) Enfermagem e as Práticas Complementares em Saúde. São Caetano do Sul, SP: Yendis Editora, 2011. p. 155-174

LEÃO, E. R.; SILVA, M. J. A música como intervenção de enfermagem no controle da dor. In: CHAVES, I. D.; LEÃO, E. R. (Org.). Dor $-5^{\circ}$ sinal vital: reflexões e intervenções de enfermagem. 2. ed. revisada e ampliada. São Paulo: Martinari, 2007. p. 581-606.

LEVIN, R.; CHANG, A. Tactics for teaching evidenced-based practice: determining the level of evidence of a study. Worldviews on Evidence-Based Nursing, v. 11, n. 1, p. 75-78, 2014.

LI, H. C. W. Evaluating the effectiveness of preoperative interventions: the appropriateness of using the children's emotional manifestation scale. Journal of Clinical Nursing, Oxford, v. 16, n. 10, p. 1919-1926, oct. 2007.

MAGALHÃES, F. M.; GUSMAM, D. P. P.; GRECCA, K. R. R. Preparo psicológico em cirurgia cardíaca pediátrica. Revista Brasileira de Terapias Cognitivas, Rio de Janeiro, v. 6, n. 2, p. 144-166, 2010.

MAKIC, M. B. F. et al. Continuing to challenge practice to be evidence based. Critical Care Nurse, California, v. 35, n. 2, p. 39-50, apr. 2015. 
MANCINI, P. C. et al. Medidas de biossegurança em audiologia. Revista CEFAC, São Paulo, v. 10, n. 4, p. 603-610, out./dez. 2008.

MARINELO, G. S.; JARDIM, D. P. Estratégias lúdicas na assistência ao paciente pediátrico: aplicabilidade ao ambiente cirúrgico. Revista SOBECC, São Paulo, v. 18, n. 2, p. 57-66, abr./jun. 2013.

MARTINS, J.; SOUSA, L. M.; OLIVEIRA, A. S. Recomendações do enunciado CONSORT para o relato de estudos clínicos controlados e randomizados. Medicina (Ribeirão Preto), Ribeirão Preto, v. 42, n. 1, p. 9-21, 2009.

MED, B. Teoria da Música. 4. ed. rev. e ampl. Brasília, DF: Musimed, 1996. 420p.

MELNYK, B. M.; FINEOUT-OVERHOLT, E. Creating and sustaining a culture for evidence-based practice. In: Evidence-based practice in nursing \& healthcare: a guide to best practice. 2. ed. Philadelphia: Lippincot Williams \& Wilkins, 2011. p. 239-275.

MILLETT, C. R. The effect of music therapy interation on children and parental preoperative anxiety in parents of children undergoing day surgery. 2015. $172 \mathrm{f}$. Thesis (Master in Music Therapy) - College of Fine Arts, University of Kentucky, Kentuchy, 2015.

MIOT, H. A. Tamanho da amostra em estudos clínicos e experimentais. Jornal Vascular Brasileiro, v. 10, n. 4, p. 275-278, 2011.

MORO, E. T.; MÓDOLO, N. S. P. Ansiedade, a criança e os pais. Revista Brasileira de Anestesiologia, Rio de Janeiro, v. 54, n. 5, p. 728-738, set./out. 2004.

MURAKAMI, R.; CAMPOS, C. J. G. Importância da relação interpessoal do enfermeiro com a família de crianças hospitalizadas. Revista Brasileira de Enfermagem, Brasília, v. 64, n. 2, p. 254-260, mar./abr. 2011.

NARDOZZA JÚNIOR, A.; REIS, R. B.; CAMPOS, R. S. M (Ed.). MANU: Manual de Urologia. São Paulo: PlanMark, 2010. 242p.

NAVIDI, W. Distribuições normalmente usadas. In: Probabilidade e Estatística para Ciências Exatas. Nova Iorque: McGraw-Hill, 2012. p. 122-178.

NAYLOR, K. T. et al. The Effectiveness of Music in Pediatric Healthcare: A Systematic Review of Randomized Controlled Trials. Evidence-Based Complementary and Alternative Medicine, New, York, v. 2011, p. 1-18, 2011.

NEWMAN, T. B. et al. Delineando estudos transversais e de caso-controle. In: HULLEY, S. B. et al. Delineando a pesquisa clínica: uma abordagem epidemiológica. 3. ed. Tradução: Michael Schmidt Duncan. Porto Alegre Artmed, 2008. p. 127-144.

NIGHTINGALE, F. Notes on nursing: what it is, and what it is not. California: Neeland Media LLC, 2012.

NIGHTINGALE, F. Notes on nursing: what it is, and what it is not. Radford: Wilder Publications, 2015. 
NILSSON, U. The Anxiety-and Pain-Reducing Effects of Music Interventions: A Systematic Review. AORN Journal, New York, v. 87, n. 4, p. 780-807, apr. 2008.

NÓBREGA, E. D.; SOUSA, M. N. A. Música na assistência de enfermagem: resultados baseados em evidências. InterScientia, João Pessoa, v. 1, n. 3, p. 103-114, set./dez. 2013.

PECCIN, M. S. Registro de ensaios clínicos: Quando e por que fazer? Brazilian Journal of Physical Therapy, São Carlos, v. 11, n. 6, p. 419-507, nov./dez. 2007.

PEDROLO, E. et al. A prática baseada em evidências como ferramenta para prática profissional do enfermeiro. Cogitare Enfermagem, Paraná, v. 14, n. 4, p. 760-763, out./dez. 2009.

PIAGET, J. Seis estudos de psicologia. Tradução: Maria Alice Magalhães D'Amorim e Paulo Sérgio Lima Silva. 25. ed. Rio de Janeiro: Forense Universitária, 2014. 143p.

PITTMAN, S.; KRIDLI, S. Music intervention and preoperative anxiety: an integrative review. International Nursing Review, Oxford, v. 58, n. 2, p. 157-163, jun. 2011.

QUIRINO, D. D.; COLLET, N.; NEVES, A. F. G. B. Hospitalização infantil: concepções de enfermagem acerca da mãe acompanhante. Revista Gaúcha de Enfermagem, Porto Alegre, v. 31, n. 2, p. 300-306, jun. 2010.

RIBEIRO, J. P.; GOMES, G. C.; THOFEHRN, M. B. Ambiência como estratégia de humanização da assistência na unidade de pediatria: revisão sistemática. Revista da Escola de Enfermagem da USP, São Paulo, v. 48, n. 3, p. 530-539, 2014.

ROBERTS, J.; DICENSO, A. Identificação do melhor tipo de estudo para ajustar-se à questão. Parte 1: Pesquisa quantitativa. In: CULLUM, N. et al (Org.). Enfermagem baseada em evidências: uma introdução. Tradução de Ana Thorell. Porto Alegre: Artmed, 2010. p. $75-81$.

ROMÃO, R. L. P. Afecções congênitas geniturinárias. In: TANNURI, U (Coord.). Doenças Cirúrgicas da Criança e do Adolescente. 1. ed. Barueri, SP: Manole, 2010. p. 413-423. (Coleção Pediatria. Instituto da Criança. Hospital das Clínicas; 13).

ROSÁRIO, C. A.; ESCH, C. F. "Que negócio é esse de operar?" - A abordagem gestáltica e o acompanhamento psicológico a crianças em processo cirúrgico. IGT na Rede, Rio de Janeiro, v. 11, n. 21, p. 345-361, 2014.

SABATÉS, A. L. Reações da criança ou do adolescente e de sua família relacionadas à doença e à hospitalização. In: ALMEIDA, F. A.; SABATÉS, A. L. (Org.). Enfermagem Pediátrica: a criança, o adolescente e sua família no hospital. São Paulo: ABEn-SP, Manole, 2008. p. 49-56. (Série Enfermagem).

SAMPAIO, C. E. P. et al. Nível de ansiedade dos acompanhantes de crianças em cirurgia ambulatorial: contribuições da consulta de enfermagem. Revista Enfermagem UERJ, Rio de Janeiro, v. 22, n. 2, p. 233-238, mar./abr. 2014.

SAMPAIO, C. E. P. et al. Sentimento dos acompanhantes de crianças submetidas a procedimentos cirúrgicos: vivências no perioperatório. Revista Mineira de Enfermagem, Belo Horizonte, v. 13, n. 4, p. 558-564, out./dez. 2009. 
SANTOS, T. S. P. Intervenções de enfermagem para reduzir a ansiedade pré-operatória em crianças em idade escolar: um revisão integrativa. Revista de Enfermagem Referência, Coimbra, v. 4, n. 3, p. 149-155, nov/.dez. 2014.

SCHULZ, K. F. Investigação da alocação dissimulada e cega nos ensaios controlados randomizados: por que o incômodo? In: In: CULLUM, N. et al (Org.). Enfermagem baseada em evidências: uma introdução. Tradução de Ana Thorell. Porto Alegre: Artmed, 2010. p. 157-162.

SIGAUD, C. H. S. et al. Aspectos éticos e estratégias para a participação voluntária da criança em pesquisa. Revista da Escola de Enfermagem da USP, São Paulo, v. 43, n. 2 (esp.), p. 1342-1346, dez. 2009.

SILVA, J. P.; GARANHANI, M. L. O significado do cuidado perioperatório para a criança cirúrgica. Revista Eletrônica de Enfermagem, Goiânia, v. 13, n. 2, p. 259-268, abr.jun. 2011.

SILVA, L. C.; FERREIRA, E. A. B. F.; CARDOZO, E. E. A música e a musicoterapia no contexto hospitalar: uma revisão integrativa de literatura. In: Encontro Nacional de Pesquisa em Musicoterapia, 12., 2012, Olinda. Anais do XII ENPEMT - Encontro Nacional de Pesquisa em Musicoterapia, Olinda: Associação de Musicoterapia do Nordeste, 2012. p. 7589.

SPRUCE, L. Back to basics: implementing evidence-based practice. AORN Journal, New York, v. 101, n. 1, p. 106-112, jan. 2015.

STOUFFER, J. W.; SHIRK, B. J.; POLOMANO, R. C. Practice Guidelines for Music Interventions with Hospitalized Pediatric Patients. Journal of Pediatric Nursing, Philadelphia, n. 22, n. 6, p. 448-456, dec. 2007.

TAETS, G. G. C. T.; BARCELLOS, L. R. M. Música no cotidiano de cuidar: um recurso terapêutico para enfermagem. Revista de Pesquisa: cuidado é fundamental online, Rio de Janeiro, v. 2, n. 3, p. 1009-1016, jul./set. 2010.

TANNURI, U. Defeitos da parede abdominale da região inguinoescrotal. In:

Doenças Cirúrgicas da Criança e do Adolescente. 1. ed. Barueri, SP: Manole, 2010. p. 261 274. (Coleção Pediatria. Instituto da Criança. Hospital das Clínicas; 13).

TEIXEIRA, V. M.; BRAZ, M. Estudo sobre o respeito ao princípio da autonomia em crianças e/ou adolescentes sob tratamento oncológico experimental, através do processo de obtenção do consentimento livre e esclarecido. Revista Brasileira de Cancerologia, Rio de Janeiro, v. 56, n. 1, p. 51-59, 2010.

THOMPSON, C. Se fosse possível fornecer uma amostra: avaliação da amostra nos trabalhos de pesquisa quantitativa e qualitativa. In: In: CULLUM, N. et al (Org.). Enfermagem baseada em evidências: uma introdução. Tradução de Ana Thorell. Porto Alegre: Artmed, 2010. p. 88-98.

TORCHI, T. S.; BARBOSA, M. A. M. A música como recurso no cuidar em Enfermagem. Ensaios e Ciência, Valinhos, v. 10, n. 3, p. 125-138, dez. 2006. 
URIZZI, F.; CORRÊA, A. K. Vivências de familiares em terapia intensiva: o outro lado da internação. Revista Latino-Americana de Enfermagem, São Paulo, v. 15, n. 4, p. 598-604, jul/ago. 2007.

VARGAS, T. V. P.; MAIA, E. M.; DANTAS, R. A. S. Sentimentos de pacientes no préoperatório de cirurgia cardíaca. Revista Latino-Americana de Enfermagem, São Paulo, v. 14, n. 3, p. 383-388, maio/jun. 2006.

WAZLAWICK, P.; CAMARGO, D.; MAHEIRIE, K. Significados e sentidos da música: uma breve composição a partir da psicologia histórico-cultural. Psicologia em Estudo, Maringá, v. 12, n. 1, p. 105-113, jan./abr. 2007.

WEBER, F. S. A influência da atividade lúdica sobre a ansiedade da criança durante o período pré-operatório no centro cirúrgico ambulatorial. Jornal de Pediatria, Porto Alegre, v. 86, n. 3, p. 209-214, 2010.

WRIGHT, K. D.; STEWART, S. H.; FINLEY, G. A. When are parents helpful? A randomized clinical trial of the efficacy of parental presence for pediatric anesthesia. Canadian Journal of Anaesthesia, Toronto, v. 57, n. 8, p. 751-758, ago. 2010.

YU, H.; LIU, Y.; MA, X. Effects of music on anxiety and pain in children with cerebral palsy receiving acupuncture: a randomized controlled trial. International Journal of Nursing Studies, New York, v. 46, n. 11, p. 1423-1430, 2009. 
APÊNDICE A

FORMULÁRIO DADOS DEMOGRÁFICOS

\section{1- IDENTIFICAÇÃO}

INICIAIS DO NOME:

NÚMERO DO PACIENTE:

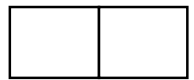

DATA DE NASCIMENTO:

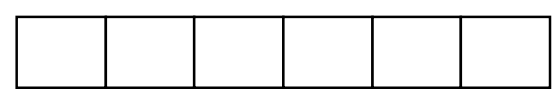

IDADE:

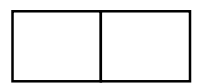

PRÉ-ESCOLAR:

ESCOLAR:

2 - DADOS DA CIRURGIA

TIPO DE CIRURGIA

POSTECTOMIA:

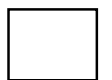

ORQUIDOPEXIA:

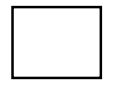

CORREÇÃO DE HIDROCELE:

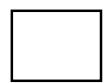

HERNIOPLASTIA:

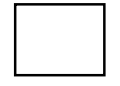

OUTRA:

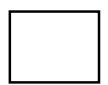

DATA DA CIRURGIA:

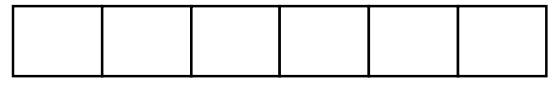

TURNO DA CIRURGIA:

$\mathrm{M} \quad \mathrm{T}$


APÊNDICE B

\section{FORMULÁRIO DOS DADOS VITAIS}

\section{1 - IDENTIFICAÇÃO}

INICIAIS DO NOME:

SEXO: $\mathrm{M} \square \mathrm{F} \square$

NÚMERO DO PACIENTE:

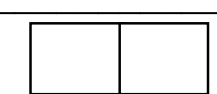

PRIMEIRO EVENTO CIRÚRGICO DA CRIANÇA: SIM $\square$ NÃO

\section{2 - PARÂMETROS VITAIS}

FREQUÊNCIA CARDÍACA (FC):
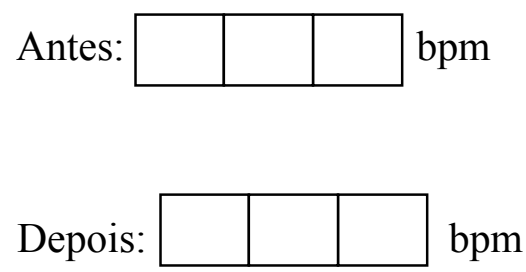

PRESSÃO ARTERIAL (PA):

Antes:

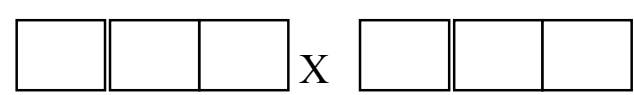

$\mathrm{mmHg}$

Depois:
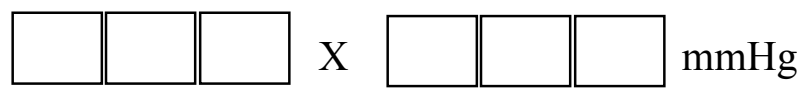

FREQUÊNCIA RESPIRATÓRIA (FR):

Antes:
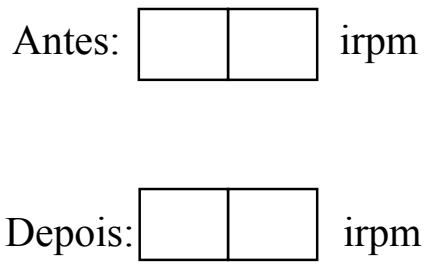

SATURAÇÃO DE OXIGÊNIO $\left(\mathrm{SatO}_{2}\right)$ :

Antes:

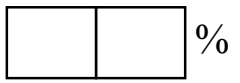

Depois:

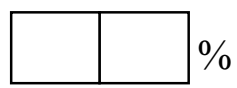


APÊNDICE C

PERGUNTA PARA ENTREVISTA COM OS PAIS

INICIAIS DO NOME DA CRIANÇA:

NÚMERO DO PACIENTE (CRIANÇA):

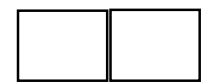

1) O que você pensa sobre a cirurgia que seu/sua filho(a) irá fazer? Você tem medo? Está ansioso (a)? 


\section{APÊNDICE D \\ Termo de Consentimento Livre e Esclarecido - Responsável Legal}

Seu (sua) filho (a) está sendo convidado (a) a participar da pesquisa "A audição musical aplicada à criança submetida à cirurgia: uma intervenção de enfermagem para alívio da ansiedade". O projeto está sendo desenvolvido pela pesquisadora Enfa. Mariana André Honorato Franzoi, sob a orientação da Profa. Dra. Gisele Martins, da Faculdade de Ciências da Saúde da Universidade de Brasília (UnB).

O objetivo principal do estudo consiste em investigar o efeito de ouvir música sobre os níveis de ansiedade pré-operatória de crianças a serem submetidas a cirurgias previamente agendadas.

Caso você concorde e autorize a participação do seu (sua) filho (a) nessa pesquisa, ele (a) poderá ser selecionado para fazer parte ou do grupo-controle (crianças que serão submetidas aos cuidados padronizados e de rotina do hospital e poderão ouvir música após a observação e avaliação final da pesquisadora) ou do grupo-estudo (crianças que irão ouvir músicas entre as observações e avaliações da pesquisadora).

Se seu (sua) filho (a) for selecionado para o grupo-controle, em um primeiro momento, a pesquisadora responsável irá verificar e registrar os dados vitais (pulso, respiração, pressão arterial, oxigenação) através de um aparelho de pressão arterial digital de braço e de um aparelho chamado oxímetro pediátrico, antes da cirurgia (período préoperatório imediato) e após 15 minutos decorridos da primeira coleta desses dados. Após isso, será disponibilizado um aparelho MP3 Player para que ele (a) possa ouvir música por alguns minutos. Se por caso ele (a) for selecionado para o grupo-estudo, a pesquisadora também irá aferir e registrar os mesmos dados vitais, antes e imediatamente após a criança ouvir músicas pré-selecionadas e disponibilizadas através de um aparelho MP3 Player, durante um período de 15 minutos. Além disso, independentemente do grupo em que seu (sua) filho (a) for fazer parte (a), a pesquisadora irá observar e registrar as manifestações de ansiedade que seu (sua) filho (a) poderá apresentar.

Os riscos relacionados com a participação do seu (sua) filho (a) neste estudo não trazem prejuízos legais, pois os procedimentos adotados nesta pesquisa obedecem aos Critérios da Ética em Pesquisa com Seres Humanos conforme Resolução nº . 466/2012 do Conselho Nacional de Saúde.

Quanto aos benefícios relacionados com a participação do seu (sua) filho (a) no estudo, é importante ressaltar que não haverá despesas pessoais ou benefícios diretos.

Os resultados dessa pesquisa irão contribuir para esclarecer e confirmar a efetividade ou não acerca do uso da música como um recurso a ser utilizado na assistência de enfermagem pediátrica, especialmente para crianças em situação cirúrgica. Para isso, os resultados serão divulgados aqui no Setor da Clínica Cirúrgica Pediátrica e na Universidade de Brasília, podendo também serem publicados em revistas e eventos científicos. É importante ressaltar, que iremos assegurar sigilo total sobre a participação de seu (sua) filho (a), ou seja, em nenhum momento os dados serão divulgados de forma a possibilitar a identificação da criança. Informamos também que os dados e materiais utilizados na pesquisa ficarão sobre a guarda da pesquisadora.

Vale lembrar que você não é obrigado (a) a autorizar a participação do seu (sua) filho (a) e que isso não acarretará nenhum prejuízo ao tratamento de seu filho (a), além disso, mesmo que você autorize a participação dele (a), a qualquer momento, você poderá retirar a permissão de participação de seu (sua) filho (a) na pesquisa.

Você receberá uma cópia deste termo e a outra cópia ficará com a pesquisadora responsável. Caso tenha qualquer dúvida, estamos à disposição para esclarecê-la através do telefone (61) 8402 5032, disponível durante horário comercial (8h às 18h), telefone de contato 
da Enfa. Mariana, pesquisadora responsável pela pesquisa a ser realizada pelo Programa de Pós-Graduação de Enfermagem da Universidade de Brasília.

Ressaltamos que este projeto foi aprovado pelo Comitê de Ética em Pesquisa da $\mathrm{SES} / \mathrm{DF}$, e, portanto, quaisquer outras dúvidas ou reclamações relacionadas aos direitos do seu (sua) filho (a) como sujeito de pesquisa e à ética deste estudo, você poderá entrar em contato com este Comitê através do telefone: (61) 3325 4955; endereço: SMHN Quadra 3, Conjunto A, Bloco 1 - Edifício FEPECS - Asa Norte. CEP: 70710-907. Brasília (DF). Site: www.fepecs.edu.br/index.php/comite-de-etica-em-pesquisa

Agradecemos sua atenção!

Diante da leitura deste Termo, entendo os objetivos, riscos e benefícios decorrentes da participação do meu (minha) fillho (a) nesta pesquisa e autorizo a participação dele(a).

Brasília, de de

Nome da criança

Nome/Assinatura do responsável

Assinatura da pesquisadora Enfa. Mariana André Honorato Franzoi Enfermeira, Mestranda em Enfermagem Pesquisadora Responsável Faculdade de Ciências da Saúde (UnB) Departamento de Enfermagem Telefone: (61) 84025032

E-mail: mari.franzoi88@gmail.com
Assinatura da orientadora Profa. Dra. Gisele Martins Professora Doutora Adjunta III Faculdade de Ciências da Saúde (UnB) Departamento de Enfermagem Pesquisadora em Enfermagem Urológica 


\section{APÊNDICE E \\ Termo de Assentimento Livre e Esclarecido - Criança Pré-Escolar}

Oi!

Eu quero the convidar para participar de uma pesquisa para saber se a música ajuda as crianças a ficarem mais calmas antes da cirurgia.

Se o seu pai e/ou mãe autorizarem sua participação e você também aceitar a participar, você irá ouvir algumas músicas que eu já gravei no MP3 Player durante algum tempinho antes da sua cirurgia.

Ah, eu também vou "olhar" duas vezes sua pressão e sua respiração, tá bom?

Se você não quiser participar não precisa; você não é obrigado(a)! E se você quiser desistir de participar da pesquisa depois de ter aceito o convite, você também pode!

Você não vai ganhar nenhum prêmio ou presente se participar, nem vai ser tratado mal se não quiser participar também!

Qualquer pergunta que você quiser fazer para mim, eu estou aqui para lhe responder, tá bom?

E aí, você aceita? Se sim, você tem que assinar/desenhar dois documentos desse aqui; um ficará com você e outro comigo, tá?

Desenhe você nesse quadradinho:

Assinatura da pesquisadora Mariana André Honorato Franzoi Mestranda em Enfermagem Enfermeira e Pesquisadora Responsável Faculdade de Ciências da Saúde (UnB) Departamento de Enfermagem Telefone: (61) 84025032 


\section{APÊNDICE F \\ Termo de Assentimento Livre e Esclarecido - Criança Escolar}

Oi!

Eu quero the convidar para participar de uma pesquisa para saber se a música ajuda as crianças a ficarem mais calmas antes da cirurgia.

Se o seu pai e/ou mãe autorizarem sua participação e você também aceitar a participar, você irá ouvir algumas músicas que eu já gravei no MP3 Player durante alguns minutos antes da sua cirurgia.

Ah, eu também vou "olhar" duas vezes sua pressão e sua respiração, tá bom?

Se você não quiser participar não precisa; você não é obrigado(a)! E se você quiser desistir de participar da pesquisa depois de ter aceito este convite, você também pode!

Você não vai ganhar nenhum prêmio ou presente se participar, nem vai ser tratado mal se não participar também!

Qualquer pergunta que você quiser fazer para mim, eu estou aqui para lhe responder, tá bom?

E aí, você aceita? Se sim, você tem que assinar dois documentos desse aqui, um ficará com você e outro comigo, tá?

Desenhe você neste quadradinho:

Ou escreva seu nome nesta linha:

Assinatura da criança

Assinatura da pesquisadora

Mariana André Honorato Franzoi Mestranda em Enfermagem Enfermeira e Pesquisadora Responsável Faculdade de Ciências da Saúde (UnB) Departamento de Enfermagem Telefone: (61) 84025032 


\section{APÊNDICE G \\ Termo de Consentimento Livre e Esclarecido - Pais}

Você está sendo convidado(a) a participar da pesquisa "A audição musical aplicada à criança submetida à cirurgia: uma intervenção de enfermagem para alívio da ansiedade". O projeto está sendo desenvolvido pela pesquisadora Enfa. Mariana André Honorato Franzoi, sob a orientação da Profa. Dra. Gisele Martins, da Faculdade de Ciências da Saúde da Universidade de Brasília (UnB).

O objetivo principal do estudo consiste em investigar o efeito de ouvir música sobre os níveis de ansiedade pré-operatória de crianças a serem submetidas a cirurgias geniturinárias previamente agendadas. Dentre um dos objetivos secundários, pretendemos descrever a percepção da família quanto ao entendimento do processo cirúrgico que a criança será submetida.

Caso você concorde em participar, iremos realizar uma breve entrevista (uma pergunta) para saber e entender um pouco sobre a sua percepção em relação à cirurgia que seu/sua filho(a) será submetido(a). A entrevista será gravada através um mini-gravador digital para que possamos analisar posteriormente.

Os riscos relacionados com a sua participação neste estudo não trazem prejuízos legais, pois os procedimentos adotados nesta pesquisa obedecem aos Critérios da Ética em Pesquisa com Seres Humanos conforme Resolução $n^{\circ}$. 466/2012 do Conselho Nacional de Saúde.

Quanto aos benefícios relacionados a sua participação no estudo, é importante ressaltar que não haverá despesas pessoais ou benefícios diretos.

É importante ressaltar, que iremos assegurar sigilo total sobre sua participação, ou seja, em nenhum momento os dados serão divulgados de forma a possibilitar a sua identificação. Informamos também que os dados e materiais utilizados na pesquisa ficarão sobre a guarda da pesquisadora.

Os resultados dessa entrevista irão contribuir para esclarecer a percepção da família sobre o processo cirúrgico de crianças no período pré-operatório (antes da cirurgia). Para isso, os resultados serão divulgados aqui no Setor da Clínica Cirúrgica Pediátrica e na Universidade de Brasília, podendo também serem publicados em revistas e eventros científicos.

Vale lembrar que você não é obrigado(a) a participar e que isso não acarretará nenhum prejuízo ao tratamento de seu filho(a), além disso, mesmo que você concorde em participar, a qualquer momento, você poderá desistir da pesquisa.

Você receberá uma cópia deste termo e a outra cópia ficará com a pesquisadora responsável. Caso tenha qualquer dúvida, estamos à disposição para esclarecê-la através do telefone (61) 8402 5032, disponível durante horário comercial ( $8 \mathrm{~h}$ às $18 \mathrm{~h}$ ), telefone de contato da Enfa Mariana, pesquisadora responsável pela pesquisa a ser realizada pelo Programa de Pós-Garaduação de Enfermagem da Universidade de Brasília.

Ressaltamos que este projeto foi aprovado pelo Comitê de Ética em Pesquisa da SES/DF, e, portanto, quaisquer outras dúvidas ou reclamações relacionados aos seus direitos como sujeito de pesquisa e à ética deste estudo, você poderá entrar em contato com este Comitê através do telefone: (61) 3325 4955; endereço: SMHN Quadra 3, Conjunto A, Bloco 1 - Edifício FEPECS - Asa Norte. CEP: 70710-907. Brasília (DF).

Site: www.fepecs.edu.br/index.php/comite-de-etica-em-pesquisa

Agradecemos sua atenção! 
Diante da leitura deste Termo, entendo os objetivos, riscos e benefícios decorrentes da minha participação nesta pesquisa

Brasília, de de

\section{Nome/Assinatura do participante}

Assinatura da pesquisadora

Enfa. Mariana André Honorato Franzoi

Enfermeira, Mestranda em Enfermagem

Pesquisadora Responsável

Faculdade de Ciências da Saúde (UnB)

Departamento de Enfermagem

Telefone: (61) 84025032

E-mail: mari.franzoi88@gmail.com
Assinatura da orientadora

Profa. Dra. Gisele Martins

Professora Doutora Adjunta III

Faculdade de Ciências da Saúde (UnB)

Departamento de Enfermagem

Pesquisadora em Enfermagem Urológica 


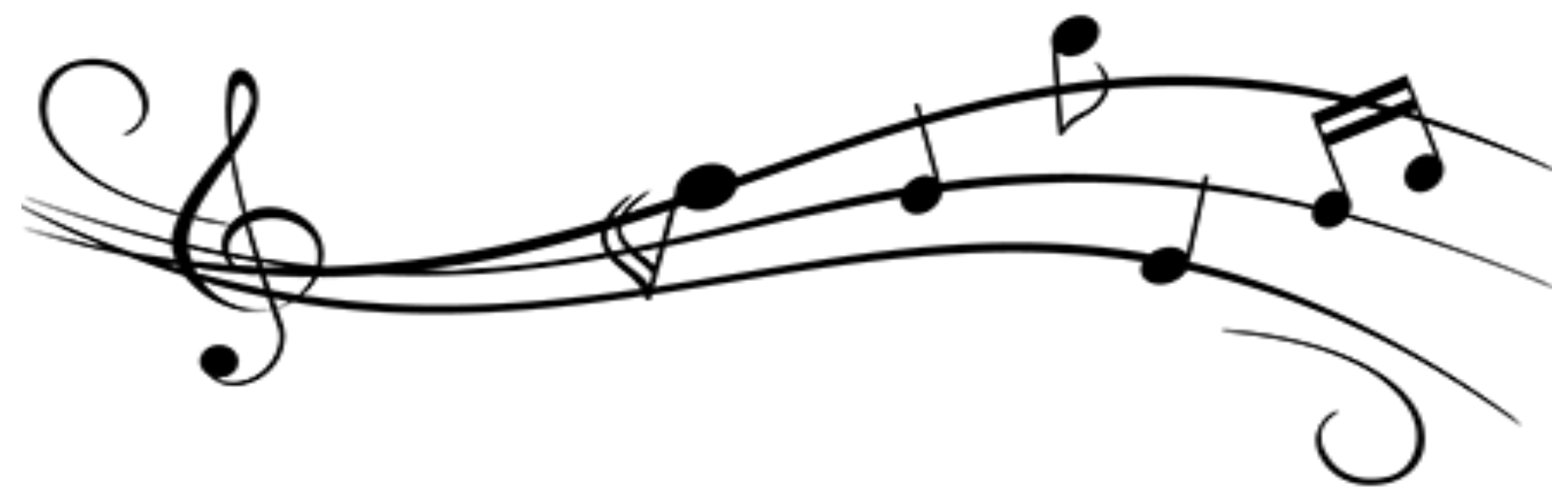

11. ANEXOS 
ANEXO A

INICIAIS DO NOME:

SEXO: M

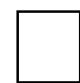

$\square$

\section{Escala de Ansiedade Pré-operatória de Yale Modificada — EAPY-m}

\section{Atividades}

1 Olha ao redor, curiosa, brinca com os brinquedos, lê (ou outro comportamento apropriado para a idade); movimenta-se na sala pré-anestésica/sala de tratamento para pegar os brinquedos ou ir até os familiares; pode se movimentar em direção ao equipamento da sala cirúrgica;

2 Não explora ou brinca, pode olhar para baixo, remexe as mãos, ou chupa o polegar (lençol); pode se sentar perto dos familiares enquanto brinca, ou a brincadeira tem qualidade definitivamente maníaca;

3 Desloca-se de maneira desconcentrada do brinquedo aos familiares, movimentos não-advindos de atividades; movimentação ou brincadeira frenética/agitada; contorção, movimenta-se na mesa; pode empurrar a máscara ou agarrar os familiares;

4 Ativamente tenta escapar, empurra com os pés e braços, pode movimentar o corpo todo; na sala de espera, corre em volta de maneira desconcentrada, não olha os brinquedos, não quer se separar dos familiares, agarra-se desesperadamente.

\section{Vocalização}

1 Lê (não-vocalização adequada para a atividade), pergunta, faz comentários, balbucia, ri, responde prontamente a perguntas, mas em geral fica em silêncio; criança muito nova para falar em situações sociais ou muito absorta na brincadeira para responder;

2 Responde aos adultos mas sussurra, “conversa de bebê," somente balança a cabeça;

3 Quieta, nenhum som ou resposta para os adultos;

4 Chorosa, gemendo, grunhindo, chorando em silêncio;

5 Está chorando, ou pode gritar "não";

6 Choro, grito alto e sustentado (audível através da máscara).

\section{Expressividade emocional}

1 Visivelmente feliz, sorridente ou concentrada na brincadeira;

2 Neutra, sem expressão visível na face;

3 De preocupada (triste) a assustada, triste, preocupada ou com olhos lacrimejantes;

4 Angustiada, chorando, extremamente descontrolada, pode estar de olhos bem abertos.

\section{Estado de despertar aparente}

1 Alerta, às vezes olha ao redor, percebe ou acompanha o que o anestesiologista faz (pode estar relaxado);

2 Retraída, senta-se calma e em silêncio, pode chupar o polegar ou o seu rosto ficar parecido com o de adulto;

3 Vigilante, olha rapidamente ao redor, poderá se espantar com ruídos, olhos bem abertos, corpo tenso;

4 Choraminga em pânico, pode chorar ou repelir os outros, vira o corpo.

\section{Interação com os familiares}

1 Brinca absorta, senta-se inativa ou envolvida em comportamento apropriado para a idade e não necessita dos familiares; pode interagir com os familiares, se os mesmos iniciarem a interação;

2 Procura contato com os familiares (aproxima-se deles e conversa com os familiares que até então estiveram em silêncio), busca e aceita conforto, pode recostar-se nos familiares;

3 Olha para os familiares em silêncio, aparentemente observa as ações, não busca contato nem conforto, aceita-o se for oferecido ou agarra-se aos familiares;

4 Mantém os familiares a uma certa distância ou poderá se retirar ativamente da presença dos pais, poderá empurrar os familiares ou se agarrar desesperadamente a eles e não deixá-los irem embora.

\section{Pontuação final}




\section{ANEXO B \\ Aprovação do projeto de pesquisa pelo Comitê de Ética em Pesquisa da FEPECS.}

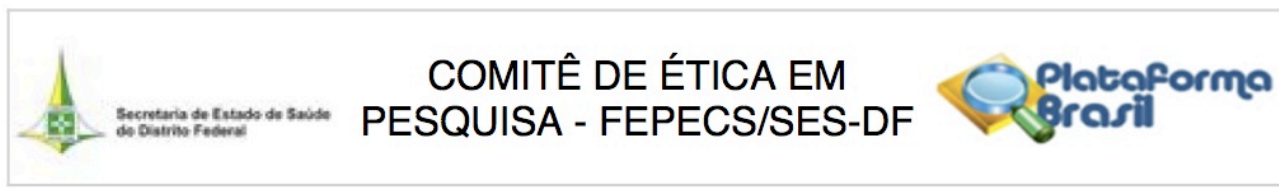

\section{PARECER CONSUBSTANCIADO DO CEP}

\section{DADOS DO PROJETO DE PESQUISA}

Título da Pesquisa: Audição musical aplicada à criança submetida à cirurgia geniturinária: uma intervenção de enfermagem para alívio da ansiedade

Pesquisador: Mariana André Honorato Franzoi

Área Temática:

Versão: 1

CAAE: 07045613.3 .0000 .5553

Instituição Proponente: DISTRITO FEDERAL SECRETARIA DE SAUDE

Patrocinador Principal: Financiamento Próprio

\section{DADOS DO PARECER}

Número do Parecer: 525.251

Data da Relatoria: $27 / 01 / 2014$

\section{Apresentação do Projeto:}

Trata-se de pesquisa que consiste ensaio clínico controlado randomizado para investigar o efeito terapêutico da audição musical sobre a ansiedade pré-operatória em crianças pré-escolares e escolares do sexo masculino submetidas a cirurgias eletivas do trato geniturinário na clínica cirúrgica pediátrica no Hospital Materno Infantil de Brasília.

\section{Objetivo da Pesquisa:}

Objetivo Primário:

Avaliar o efeito da audição musical sobre os níveis de ansiedade pré-operatória de crianças submetidas a cirurgias geniturinárias eletivas.

\section{Objetivo Secundário:}

Comparar os níveis de ansiedade entre o grupo experimental (audição musical) e o grupo controle (cuidado habitual) por meio da aplicação de instrumento validado para aferição de ansiedade; - Comparar os dados vitais (frequência cardíaca, frequência respiratória, pressão arterial e saturação de oxigênio) entre o grupo experimental e o grupo controle; - Verificar as possíveis

Endereço: SMHN 2 Qd 501 BLOCO A - FEPECS Bairro: ASA NORTE

UF: DF Município: BRASILIA

CEP: $70.710-904$

Telefone: (61)3325-4955 Fax: (33)3325-4955 E-mail: comitedeetica.secretaria@gmail.com 


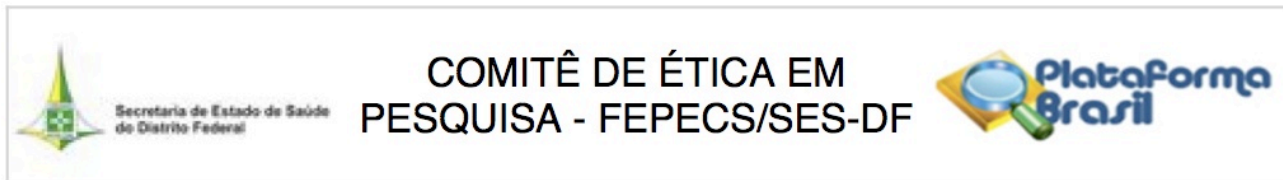

Continuação do Parecer: 525.251

relações entre a idade dos participantes e nível de ansiedade, tanto no grupo controle como no grupo experimental. - Descrever a percepção da família quanto ao entendimento do processo cirúrgico ao qual a criança será submetida.

\section{Avaliação dos Riscos e Benefícios:}

Qualquer pesquisa que envolva seres humanos deve observar os princípios da BENEFICÊNCIA, DA NÃO MALEFICÊNCIA, DA AUTONOMIA e da JUSTIÇA.

A análise dos riscos inerentes a qualquer pesquisa deve considerar a possibilidade de danos não somente na esfera física, como perda de janela terapêutica, sequelas, cicatrizes ou a própria morte, como também aquelas da estatura moral, psíquica, intelectual, cultural, espiritual em qualquer dos momentos da pesquisa.(CONSELHO NACIONAL DE SAÚDE, Resolução $n^{\circ}$ 466, 12 de dezembro de 2012, Diário Oficial da União)

Estas dimensões são apreciadas nos Conselhos de Ética em Pesquisa, que são colegiados com múnus público e que defendem os interesses dos sujeitos de pesquisas, sua integridade e dignidade contribuindo para o controle dos padrões éticos das pesquisas.

Assim, os riscos associados à pesquisa confrontados com os que os sujeitos normalmente estão expostos;as medidas tomadas para mitigar os riscos previsíveis; os prováveis benefícios da pesquisa; a razoabilidade entre os riscos e benefícios; verificar se a descrição e informação dos riscos, desconfortos ou benefícios antecipados serão recebidos pelos sujeitos; os intervalos dos relatórios a serem apresentados, pelo pesquisador ao CEP, necessários ao acompanhamento da pesquisa são verificados pelas Comissões de Ética em Pesquisa.

As pesquisas isentas de risco são aquelas em que se não são realizadas intervenções, invasão da intimidade ou modificações nas variáveis fisiológicas ou psicológicas dos sujeitos.

O presente projeto, por conseguinte, não é isento de risco, contudo, por suas características o risco é mínimo guardando uma RELAÇÃO RISCO X BENEFÍCIO ADEQUADA.

\section{Comentários e Considerações sobre a Pesquisa:}

Projeto bem estruturado com risco mínimo ao paciente.

Endereço: SMHN 2 Qd 501 BLOCO A - FEPECS

Bairro: ASA NORTE

UF: DF Município: BRASILIA

CEP: $70.710-904$

Telefone: (61)3325-4955 Fax: (33)3325-4955 E-mail: comitedeetica.secretaria@gmail.com 


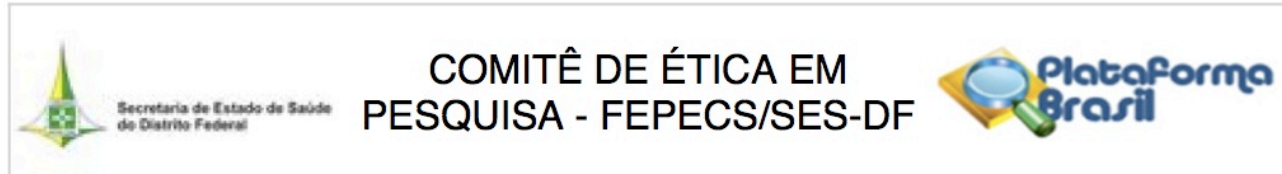

Continuação do Parecer: 525.251

Considerações sobre os Termos de apresentação obrigatória:

Folha de Rosto; Projeto de Pesquisa em Português; Critérios de Inclusão e Exclusão; Termo de

Consentimento Livre e Esclarecido; Orçamento do Projeto; Curricullum vitae dos pesquisadores; Termos de Concordância. FORAM APRESENTADOS

Recomendações:

Manter este CEP atualizado com andamento da pesquisa.

Conclusões ou Pendências e Lista de Inadequações:

Diante do exposto manifesto APROVAÇÃO.

Situação do Parecer:

Aprovado

Necessita Apreciação da CONEP:

Não

Considerações Finais a critério do CEP:

BRASILIA, 10 de Fevereiro de 2014

Assinador por:

luiz fernando galvão salinas

(Coordenador)

Endereço: SMHN 2 Qd 501 BLOCO A - FEPECS

Bairro: ASA NORTE

UF: DF Município: BRASILIA

CEP: $70.710-904$

Telefone: (61)3325-4955 Fax: (33)3325-4955 E-mail: comitedeetica.secretaria@gmail.com 


\section{ANEXO C \\ Aprovação do último parecer consubstanciado referente à última emenda realizada no projeto de pesquisa - alteração de título e população.}

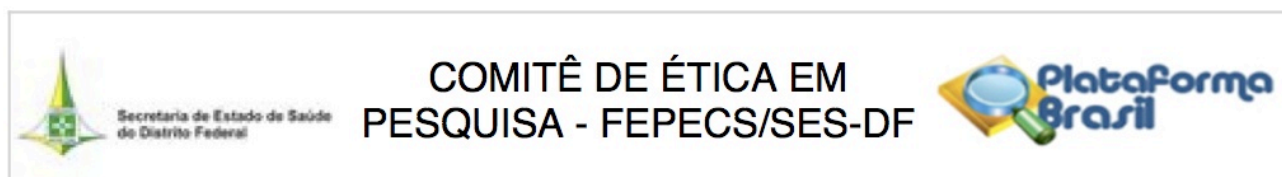

\section{PARECER CONSUBSTANCIADO DO CEP}

\section{DADOS DO PROJETO DE PESQUISA}

Título da Pesquisa: A audição musical aplicada à criança submetida à cirurgia: uma intervenção de enfermagem para alívio da ansiedade

Pesquisador: Mariana André Honorato Franzoi

Área Temática:

Versão: 6

CAAE: 07045613.3 .0000 .5553

Instituição Proponente: DISTRITO FEDERAL SECRETARIA DE SAUDE

Patrocinador Principal: Financiamento Próprio

\section{DADOS DO PARECER}

Número do Parecer: 954.343

Data da Relatoria: 23/02/2015

\section{Apresentação do Projeto:}

Emenda de Alteração do Título da Pesquisa de "A audição musical como intervenção de

enfermagem para alívio da ansiedade em crianças submetidas a cirurgias geniturinárias" para "A audição musical aplicada à criança submetida à cirurgia: uma intervenção de enfermagem para alívio da ansiedade".

\section{Objetivo da Pesquisa:}

Objetivo Primário:

- Investigar o efeito da audição musical sobre os níveis de ansiedade pré-operatória de crianças submetidas a cirurgias eletivas.

Objetivo Secundário:

- Comparar os níveis de ansiedade entre o grupo experimental (audição musical) e o grupo controle (cuidado habitual) por meio da aplicação de instrumento validado para aferição de ansiedade;

- Comparar os dados vitais (frequência cardíaca, frequência respiratória, pressão arterial e saturação de oxigênio) entre o grupo experimental e o grupo controle;- Verificar as possíveis relações entre a idade dos participantes e nível de ansiedade, tanto no grupo controle como no grupo experimental.

Endereço: SMHN 2 Qd 501 BLOCO A - FEPECS

Bairro: ASA NORTE

UF: DF Município: BRASILIA

Telefone: (61)3325-4955 Fax: (33)3325-4955

CEP: $70.710-904$ 


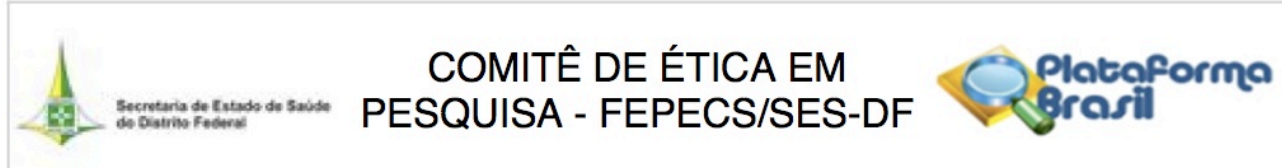

Continuação do Parecer: 954.343

- Descrever a percepção da família quanto ao entendimento do processo cirúrgico

ao qual a criança será submetida.

Avaliação dos Riscos e Benefícios:

Sem alteração ao projeto inicial.

Comentários e Considerações sobre a Pesquisa:

Estudo analítico, de caráter experimental, randomizado, prospectivo e comparativo, com análise quantitativa dos dados.

Considerações sobre os Termos de apresentação obrigatória:

Adequadamente apresentados.

Recomendações:

Conclusões ou Pendências e Lista de Inadequações:

Sem pendências.

Situação do Parecer:

Aprovado

Necessita Apreciação da CONEP:

Não

Considerações Finais a critério do CEP:

BRASILIA, 13 de Fevereiro de 2015

Assinado por:

Helio Bergo

(Coordenador)

Endereço: SMHN 2 Qd 501 BLOCO A - FEPECS

Bairro: ASA NORTE

UF: DF Município: BRASILIA

CEP: $\quad 70.710-904$

Telefone: (61)3325-4955

Fax: (33)3325-4955

E-mail: comitedeetica.secretaria@gmail.com

Página 02 de 02 


\section{ANEXO D \\ Registro do estudo na plataforma REBEC e ICTRP}

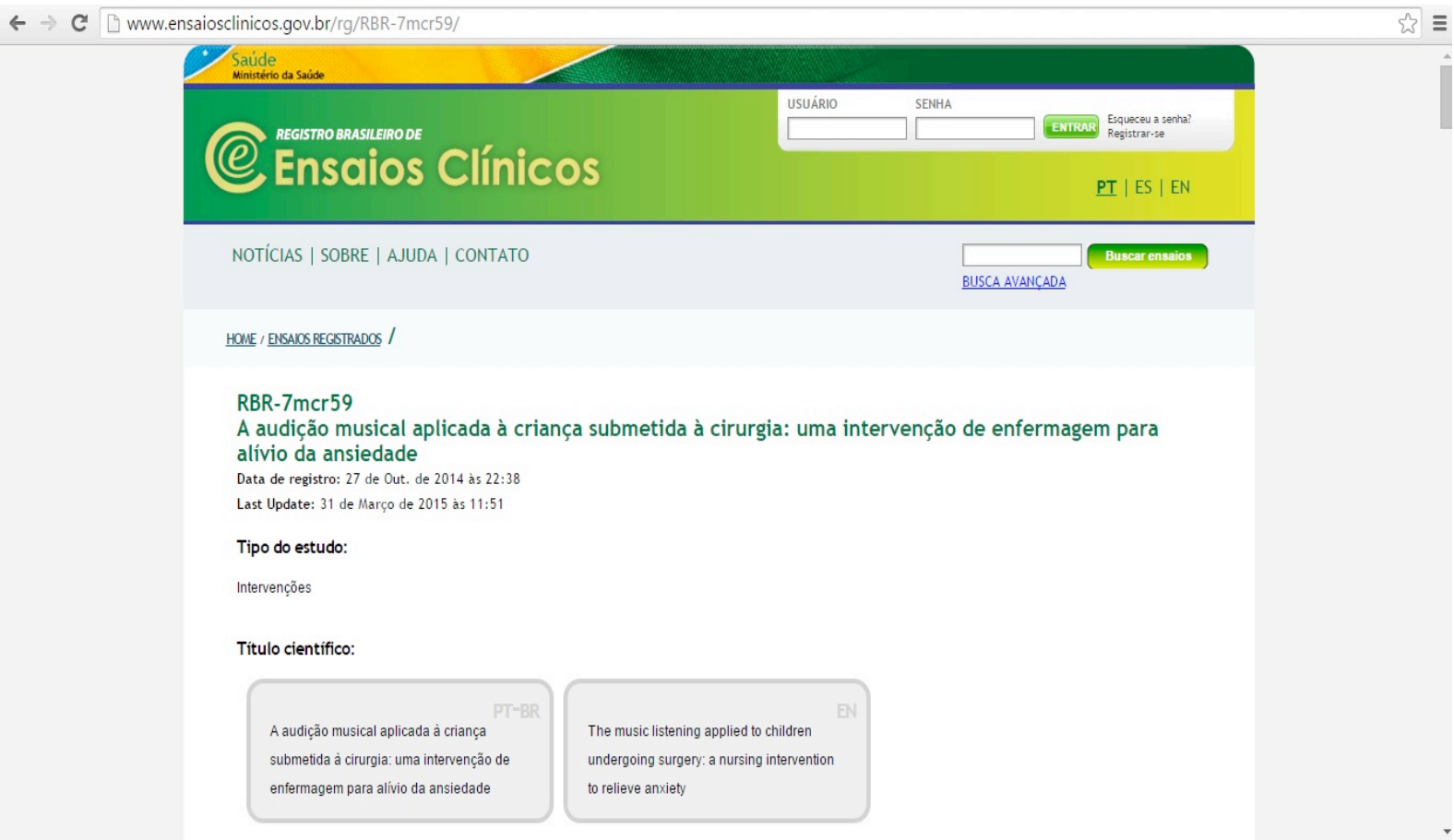

International Clinical Trials

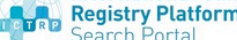

Home Advanced Search List By $\quad$ Search Tips UTN । ICTRP website

\section{Main}

Note: This

Register:

Last refreshed on:

REBE

18 August 2015

Date of registration:

Primary sponsor: $\quad$ Distrito Federal Secretaria de Saude - Brasilia, DF, Brazil

Public title: $\quad$ The effect of music on the anxiety of children before surgery: a nursing intervention

Scientific title:

Date of first enrolment:

Target sample size:

Recruitment status:

URL.

Study type:

Study design:

http://wwww.ensaiosclinicos. gov. br/rg/RBR-7mcr59

Intervention

Phase:

Brazil

Contacts 
ANEXO E

Autorização para fotografar a Sala Dia da Cirurgia Pediátrica

GOVERNO DO DISTRITO FEDERAL

Secretária de Estado de Saúde

Coordenação Geral de Saúde da Asa sul

Hospital Materno Infantil de Brasília

Ao

NEPS/HMIB e CIPE/HMIB

ASSUNTO: Autorização de fotografias da Sala Dia da Cirurgia pediátrica

Informamos que pesquisadora Mariana André Honorato Franzoi está autorizada a fazer fotografias da Sala Dia localizada na Unidade de Cirurgia Pediátrica do HMIB. A pesquisadora combinará com a equipe o melhor horário e dia para fazer as fotos apenas do ambiente físico para retratar em seu trabalho sobre 0 feito da música no pré e pós operatório.

Atenciosamente,

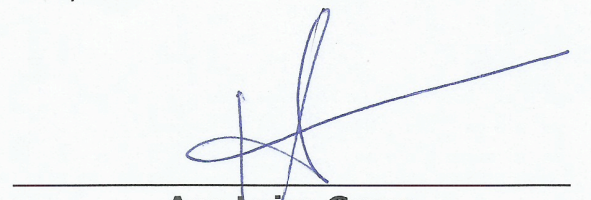

Ana Luiza Greca

Assessora de Imprensa

HMIB/CGSAS 